$8 F$

487

.3856

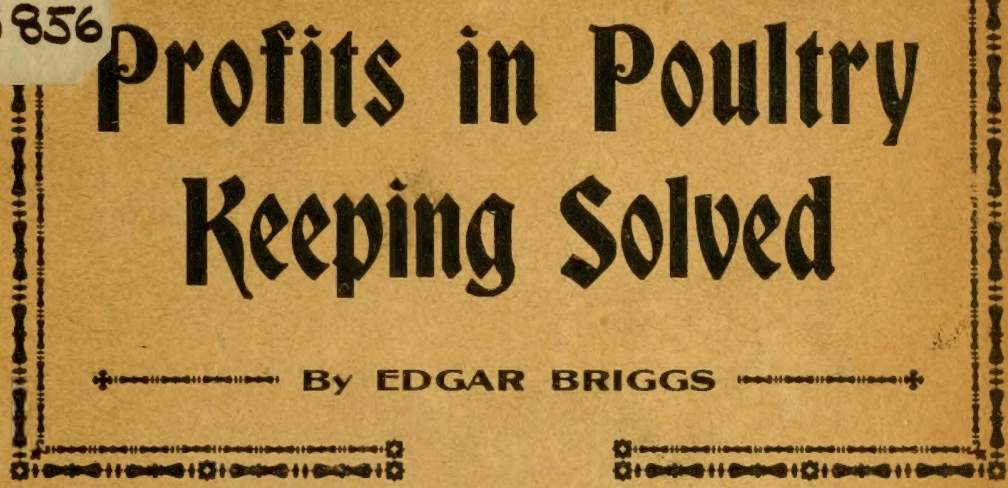

THE BRIGGS’ SYSTEM

FOURTH EDITION

Including Also "Secrets in Poultry Culture"

HOSTERMAN PUBLISHING COMPANY PUBLISHERS. 

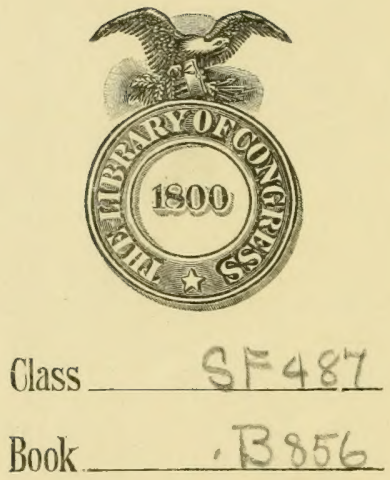

Copyrightit No

COPYRIGHT DEPOST: 





\title{
PROFITS IN POULTRY KEEPING SOLVED
}

\section{THE BRIGGS' SYSTEM AND SECRETS OF SUCCESSFUL POULTRY RAISING}

\author{
An Economical, Labor Saving, Profit Assuring \\ System of Poultry Raising
}

BY

\section{EDGAR BRIGGS}

\section{Edited and Revised by HENRY TRAFFORD,} EDITOR POULTRY SUCCESS

FOURTH EDITION

1910

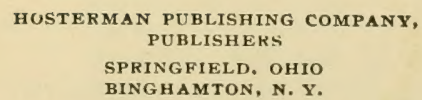

SPRINGFIELD, OHIO

BINGHAMTON, N. Y. 


\section{(๑ீ) ILLUSTRATIONS ๑ீ6)}

PAGE

Portrait of Author, Edgar Briggs...................... 4

Home of Author and Experimental Plant ................. 6

General View Briggs' Poultry Plant ..... . . . . . . . . . . . . 8

Sectional View Briggs' Poultry Plant .................. 9

'The Briggs' Model Laying House. . . . . . . . . . . . . . . . 12

Frame of Briggs' Model Laying and Brooder House . . . . . . . . . . . 14

Section of Nest Boxes ................................ 18

Feed Hopper, End and General View . . . . . . . . . . . . . . . . . 19

Diagram of End of Laying House . . . . . . . . . . . . . . . 20

Section of Briggs' Poultry Farm, Arrangement, Etc. ........... 23

Typical White Wyandotte Cock ........................ 24

Series of Bins for Spouting Oats and Grain .............. 27

Prize Winning Barred Plymouth Rock Cock . . . . . . . . . . . . . . 30

Pair Ideal Rose Comb Rhode Island Reds . . . . . . . . . . . . . . . 32

Prize Winning White Plymouth Kock Hen . . . . . . . . . . . . . 34

Prize Winning White Wyandotte Hein .................... 36

Pen of Single Comb White Leghorns . . . . . . . . . . . . . 37

Prize Winning White Orpington Cock ... . . . . . . . . . . 39

Brooder Hover Complete . . . . . . .................... 44

One Half of Brooder from Center to Back................ 45

Brooder complete except Hover ...................... 46

Trio of Prize Winning White Leghorns ................ 46

Colony House Showing Portion of Brooder ... . . . . . . . . . 47

A Flock of Handsome Pekin Ducks ...................... 51

Typical s. C. White Leghorn Cock ..................... 53

A Pair of Winning Silver Laced Wyandottes.............. 56

A Turkey produced by the Briggs' System................ . 59

A Prize Winning Black Minorca Hen................... 64

Typical Heads of Male and Female White Wyandottes .......... 71

A Famous Pen of White Wyandottes .......................... 77

A High Class S. C. White Leghorn Cock .................... 79

A Barred Plymouth Rock Male, fine Shape and Barring.... . . . . 81

A Barred Plymouth Rock Hen of Fine Type............... 83

A Famous Pen of S. C. White Leghorns ................ . 85

A Popular Member of the Wyandotte Family ............... 87

A Pen of Prize Winning Columbian Wyandottes............... 88

A Trio of Noted S. C. White Leghorns................... 90

A Well Bred S. C. White Leghorn Cock .................... 92

Copyright 1910 by

HOSTERMAN PUBLISHING CO.

First Edition Copyright 1906.

Second Edition Copyright 1907.

Third Edition Copyright 1908. 


\section{๑ீ(6) CONTENTS (ூீ)}

CHAP'TER II-How to Erect and Run a Poultry Plant for Profit 10

CHAP'TER III-Location of a Plant................. 11

CHAPTER IV - Laying Out a Plant ......................... 12

CHAPTER V-Specifications for the Model Laying House ........ 13

CHAPTER VI-Directions for Constructing the Model Laying House 15

CHAPTER VII - Making of Hoppers .................. 21

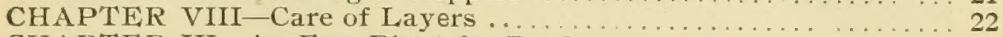

CHAPTER IX-An Egg Plant for Profit $\ldots \ldots \ldots \ldots \ldots \ldots \ldots . \ldots \ldots$

CHAPTER X-Processed Feeds and How to Produce Them ....... 28

CHAPTER XI-Summer Care . . . . . . . . . . . . . . . . 31

CHAPTER XII-A Free Range Plant with Little Labor........... 33

C'HAPTER XIII-Caring for Yarded Plant ................. 35

CHAPTER XIV-How to Build an Ideal Incubator House........ 37

CHAPTER XV--How to Run an Incubator.................. 38

CHAP'TER XVI-Chicks Raised Nature's Way . . . . . . . . . . . . . 40

CHAPTER XVII-A Perfect Brooder. . . . . . . . . . . . . . . . . . 44

CHAPTER XVIII-Raising Broilers-Bowel Trouble, It's Cause

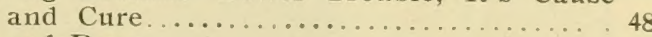

CHAPTER XIX-Cold and Roup ............................ 50

CHAPTER XX-Caring for a Plant where Wheat or Screenings Cannot be Bought...................... 51

CHAPTER XXI-When and How to Start in Poultry Business... . 52

CHAP'TER XXII - A* Leghorn Plant for Profit............. 54

CHAPTER XXIII-A White Wyandotte Plant for Profit........... 57

CHAP'TER XXIV-A Combination Plant for Profit, Fruit, Poultry and Bees.

CHAPTER XXV-Loss of Breeders During Heavy Laying Season 60

CH.APTER XXVI-Molting ................... 62

CHAPTER XXVII-Feeding and Selection of Large Breeds

Important

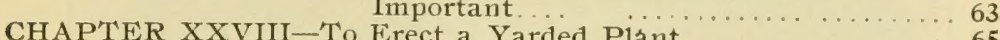

CHAPTER XXIX-Fireless Brooders, Trick of the Trade......... 65

CHAPTER XXX-Duck Culture...................... 68

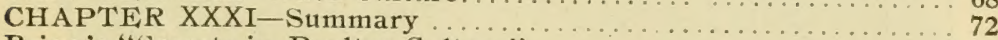

Brigg's "Secrets in Poultry Culture" ......................... 75

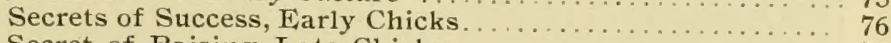

Secret of Raising Late. Chicks. . . . . . . . . . . . . . . 76

، “

“ “ Feeding Unthrashed Grain in Winter. . . . . . . . . . 79

“ “ “ Getting Eggs Every Month.............. . . . 80

“ " Curing White Diarrhoea ................ 81

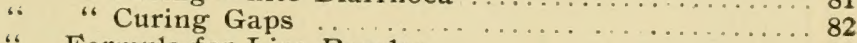

“ Formula for Lice Powder..................... ${ }_{82}$

“ for Making Liquid Lice Killer................ 83

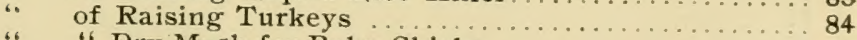

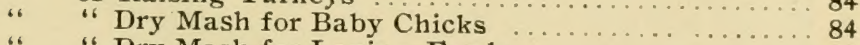

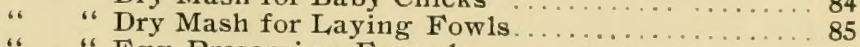

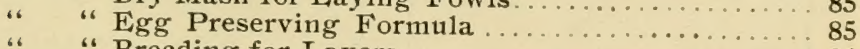

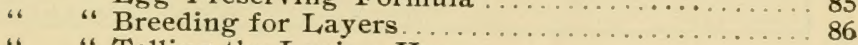

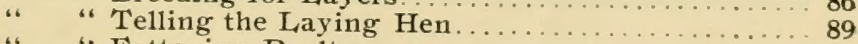

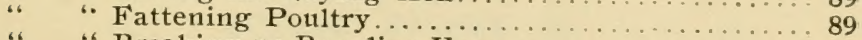

" " $\quad$ Breaking up Brooding Hens . . . . . . . . . . . . . . . 89

" " Molting Fowls Early . . . . . . . . . . . . . . . . . . 90

" " Preparing White Birds for Exhibition ... . . . . . . 91

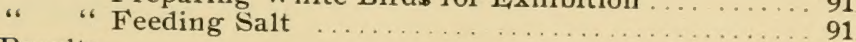

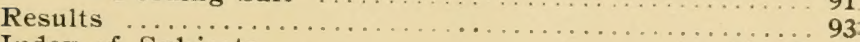

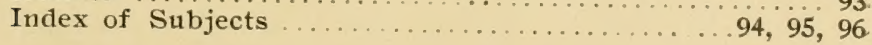




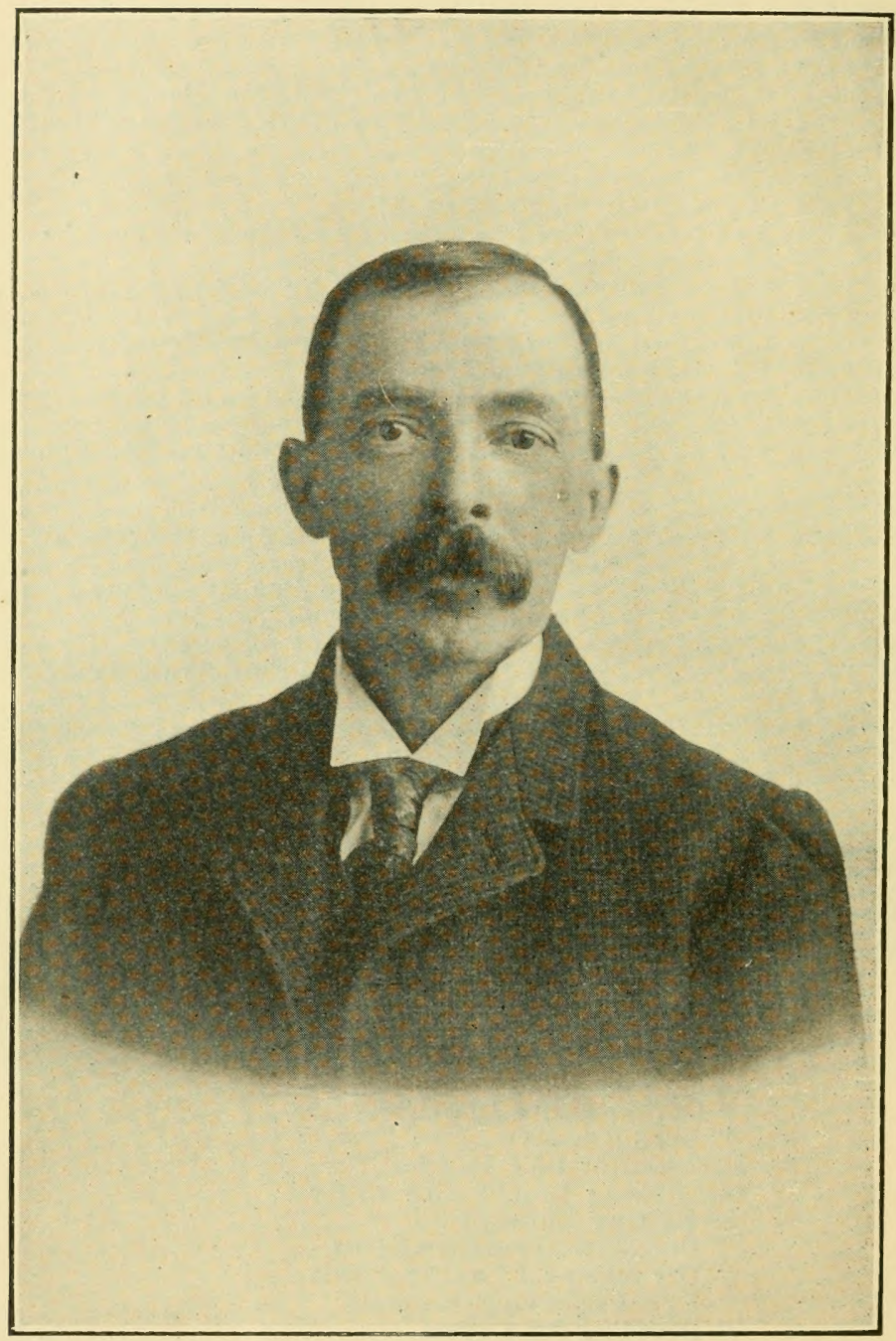

\section{EDGAR BRIGGS}

Author of "Profits in Poultry Keeping Solved" and "Secrets in Poultry Culture" 


\section{INTRODUCTORY}

In the way of introduction to those who have never heard of me or of my new methods, it is perhaps advisable that I should say something about myself. I was born a poultryman; my father before me bred fancy stock all his life and from a small boy I gathered eggs, took charge of the poultry, exhibited them at the county fairs and had birds of my own. I have bred fancy stock all my life and tried the winter broiler business with fatal results, as hundreds of others have done. This led me to experimenting and also studying nature's methods to see if there was not some way in which they could be raised on a large scalc without such great loss. The result is. after fifteen years of careful experimenting, I have solved the problem and am now able to put any poultry plant on a paying basis, regardless of location or other obstacles. Plants that went out of business on account of using the ordinary niethods have started up under my new methods and have had wonderful success The first edition of my book which was put on the market five years ago has all been sold, as well as the second edition of 3,000 copies in 1907; and the third edition of 5,000 copies in 1908 , and this fourth edition is now required.

My great feed, for such it is, at I 5 cents or less per bushel, will make any plant pay. After experimenting with processed oats, my main feed for 15 years, I consider I now have as near a perfect feeding system as can be obtained for either a yarded or free-range plant. Follow my methods and my instructions as laid down in this book, and success is certain. Read every line carefully. You cannot go wrong. A fortune awaits everyone who builds one of my free-range or yarded plants, as they are bound to pay a handsome profit under my system of care and feeding.

Very truly yours,

EDGAR BRIGGS,

Author.

Dated September Ist, Igog. 


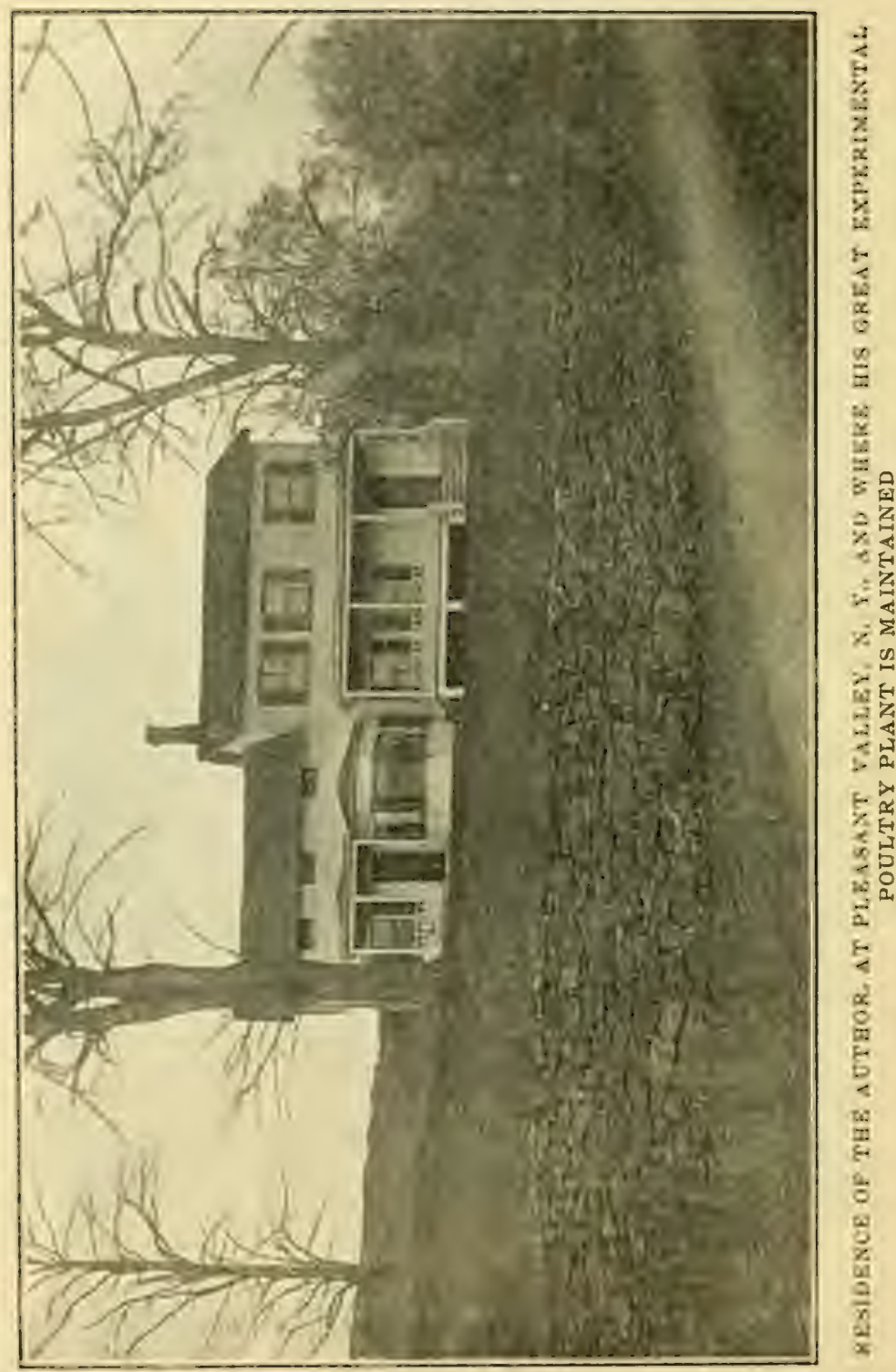




\section{CHAPTER I}

\section{Briggs' Poultry Plant}

The first edition of my book appeared in April, I906; and a second edition of 3,000 copies in 1907 , a third edition of 5,000 copies in 1908 . I am now offering a fourth edition, as my main object is to get out a new edition every year so as to give the benefit of all my latest experiments. I bought two years ago a 60-acre farm specially adapted to building one of my free-range plants upon, where I can entertain my friends and where they will aways be welcome and made at home. I am now carrying on my plant 2,000 layers of the very choicest White Wyandottes and Single-Comb White Leghorns by my famous free-range system. No time nor expense will be spared in making this one of the greatest paying plants in this country. This will also be to some extent an experimental farm, as my aim will be, if possible, to improve on my system. All my young stock will be raised on the free-range system as laid down in this book. For this I have two four-acre fields, side by side, which are inclosed by a wire netting fence, as described elsewhere, one field is used for White Wyandottes and one for Single-Comb White Leghorns. I expect to raise each season 2,000 of each breed. Four choice matings of each variety will be kept to produce prize winners and to produce males for breeders and for my customers, as my great aim is to produce the best hatching eggs in this country from the best stock at the lowest prices. Those who have bought my book, will get the benefit of all my experiments as well as the benefit of exceptional quality in stock and eggs.

In front of my dwelling I have a five-acre field with a fine stream of water running through it, one of the most natural locations to be found hereabout. I carry one thousand White Wyandotte layers of high quality in this field such as are seldom seen in such numbers together. I have another six-acre field on another part of my farm, where I carry one thousand Single-Comb White Leghorn layers, no finer nor greater layers can be found in this country. A large feed house is built on a side hill, and underneath it will be a large cellar divided up, one part for incubators, one part for an egg room, and one-half for processing oats. Labor is a small item on my plant, as all my feeding, etc., is done with the aid of a gentle horse. My first work after getting possession of this farm, April I, 1908, was to build laying houses 


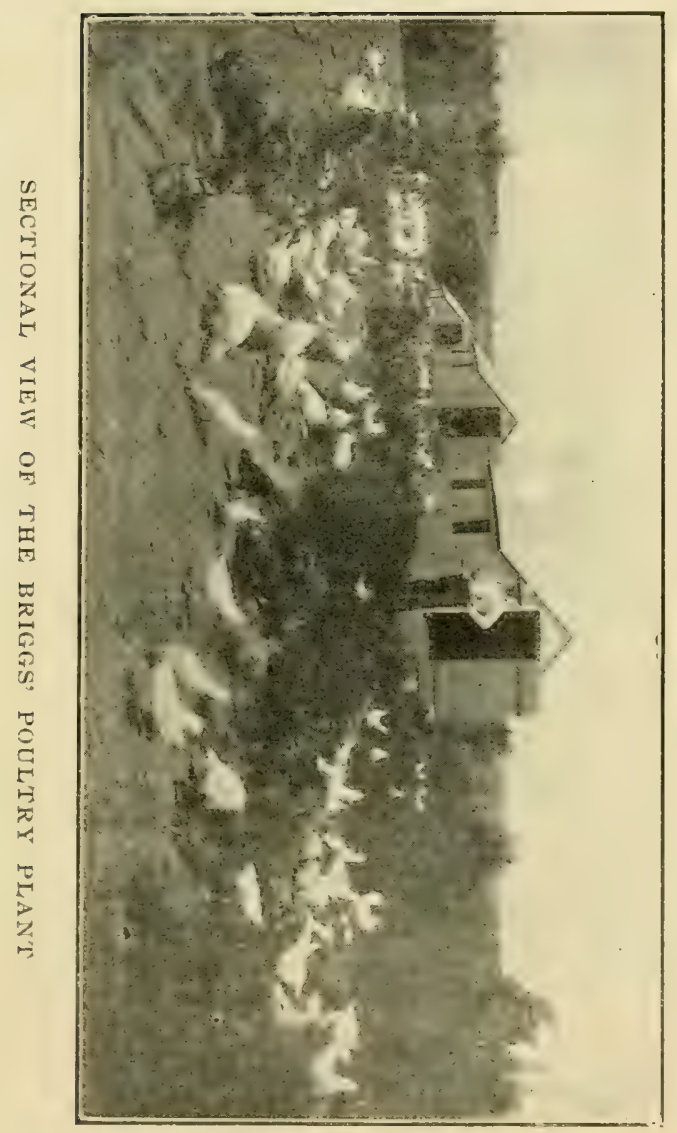




\section{CHAPTER II}

\section{How to Erect and Run a Poultry Plant for Profit}

I will now tell you how to erect and run a poultry plant on an entirely new system for saving labor and money making. A plant for the farmer, as much as the business man; a plant that can be run by an amateur, so that without experience it can be made to pay a profit from the start. It is conceded by men who know, that ninety-five out of every one hundred who start make a failure in the poultry business. The reason for this is because they go entirely opposite to nature in caring for them. A hen in her wild state roosts in trees and feeds on seeds of various kinds, worms and insects of every description, and when you shut her up in a yard you make a prisoner of her. Under these conditions she is fed on mashes of various kinds until she is sick and out of condition and the natural resilt or consequence is she does not lay more than $1 / 2$ the eggs she is capable of doing, in some cases not an egg. Hens kept under such conditions in many cases die of roup or cholera or other malignant diseases.

Another very important thing we can learn from the hen in her wild state is that she always lays her brood of eggs during the spring time, hatches and raises her chicks when the ground gives up a crop of worms and various other insects, and by the time the chicks are fit to wean, dry weather of summer comes on and worms and insects become scarce and the result is the hen lays no more eggs during the year.

Now, in order to keep hens laying the year round, we must produce spring time conditions the year round. And there is nothing that can take the place of insects equal to green cut bone but this is very hard to obtain in most places, and especially on a large scale, therefore, as a rule, we must use beef scraps in place of it. 


\section{CHAPTER III}

\section{Location}

First of all we must have a suitable location. This is a very important thing if you are going in the poultry business for profit. If you do not own a farm and wish to buy one, by all means spend some time and get one suitable for the business. I advise not less than fifty to seventy-five acres. One with a nice, big orchard on it is most desirable. By all means get a place with one or more streams of water running through it, and if these streams are fed by springs so much the better. Under no circumstances buy a place for the poultry business unless it is well watered, for this is where a great amount of labor saving comes in, moreover, the poultry will do much better-this is nature.

Get a place, if possible, sloping to the south, with gravelly or sandy soil. Sixty acres will carry five thousand layers nicely and leave room enough to raise six thousand youngsters if it is laid out right, besides furnish pasture for your horses and cows, leaving room for garden and various other things you will want on a farm. An ideal poultry farm should be inclosed with a five-foot fence of wire netting and two barb wires over this. It should also have a base board of rough hemlock sunk two inches or more below the surface of the ground. This makes a plant practically proof against all kinds of animals, and there is nothing that has more enemies than chickens. This is all the fence you will need on your plant, as a rule, unless you go into fancy breeding or wish to divide your cockerels and pullets, in this case you should fence in the fields. Your hens must have free range if you want results and you should remember the profit lies in eggs. Therefore, an egg plant is what you must have to make money. A plant of this kind laid out right and handled properly can be run by the labor of one man most of the time, as under my system labor is reduced to the minimum. High cost of labor has put more poultry plants out of business than any other one thing. 


\section{CHAPTER IV}

\section{Liying Out a Plant}

Build the laying houses on both sides of tha stream of water far enough away to keep them on high ground. Put your houses 60 to 75 feet apart according to your ground, allowing from 60 to 75 Leghorns to a house; or fifty Wyandottes, Rocks or the larger breeds. Colonize your flocks in this manner, then you will have no further trouble, as nearly every hen will go in her own house.

To flock or colonize them, put your hens in the house and keep them shut up for three days, letting them out on the third day one hour before dark. Your hens get acquainted in the three day's they are shut up together and will ever after that rum together and return to their own house to lay and roost. After trying houses of various kinds and styles, I have never found one that suits me so well as the one illustrated below and will later describe. I consider it the most perfect house built at the present time-and also the cheapest of construction.

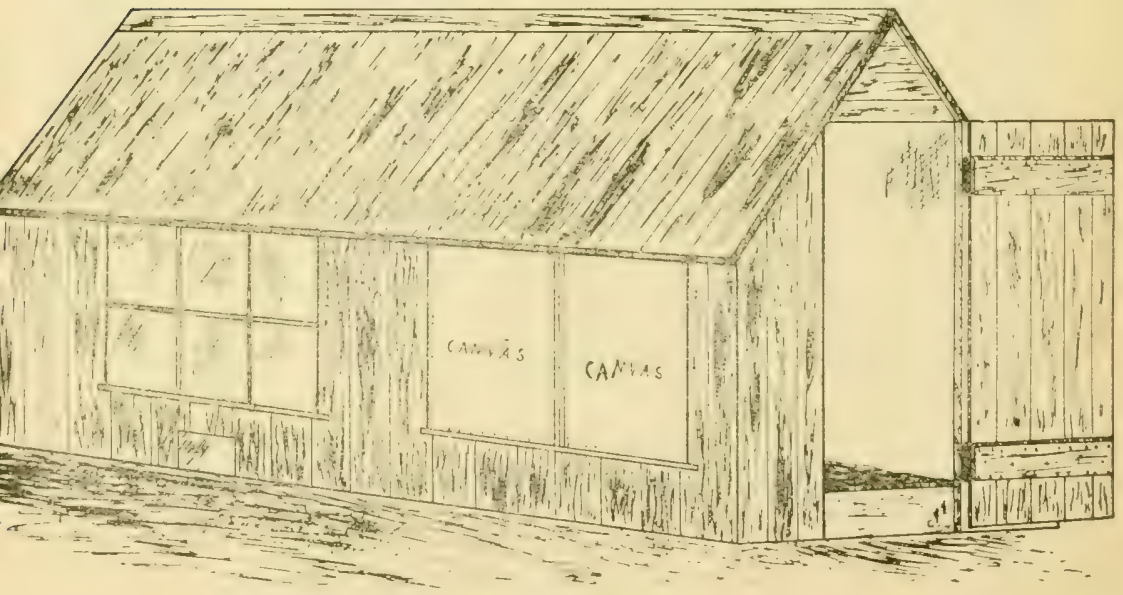

THE BRIGGS MODEL LAYING HOUSE 


\section{CHAPTER V}

\section{Specifications for the Model Laying House}

Following is a list of the lumber that is required to build a house, such as is referred to in the preceding chapter:

Three chestnut planks, 2 by 8 by 20 feet long. grooved.

Thirty-three boards, I by 8 by i6 feet long, tongued and

Thirty-three boards, I by 8 by I 4 feet long, tongued and grooved.

Twelve hemlock, 2 by 4 by 20 feet long.

Five 2 by 3 , ten feet long, for roosts.

Three windows, one 8 by lo glass, six panes each and 2 canvas covered frames.

This house is ten feet wide, twenty feet long, four feet high at eaves, with double pitched roof made of tongued and grooved boards, so that roofing of any kind is not required. A roof of this kind will never leak, to any amount, if put up with lumber well dried out.

Cypress is the best of all lumber for these houses, as it will stand the weather far better than any other kind, and will last for many years without decaying. White pine is the next best, and the only other kind of lumber that can be successfully used where no lining paper or roofing paper is used. Second quality lumber will answer every purpose if you use judgment in cutting it and putting it on, but you must have your lumber good and dry, so it will not shrink apart.

Use the best lumber on north side and ends of house. A view of the frame illustrated elsewhere will aid you very much in building your first house. 


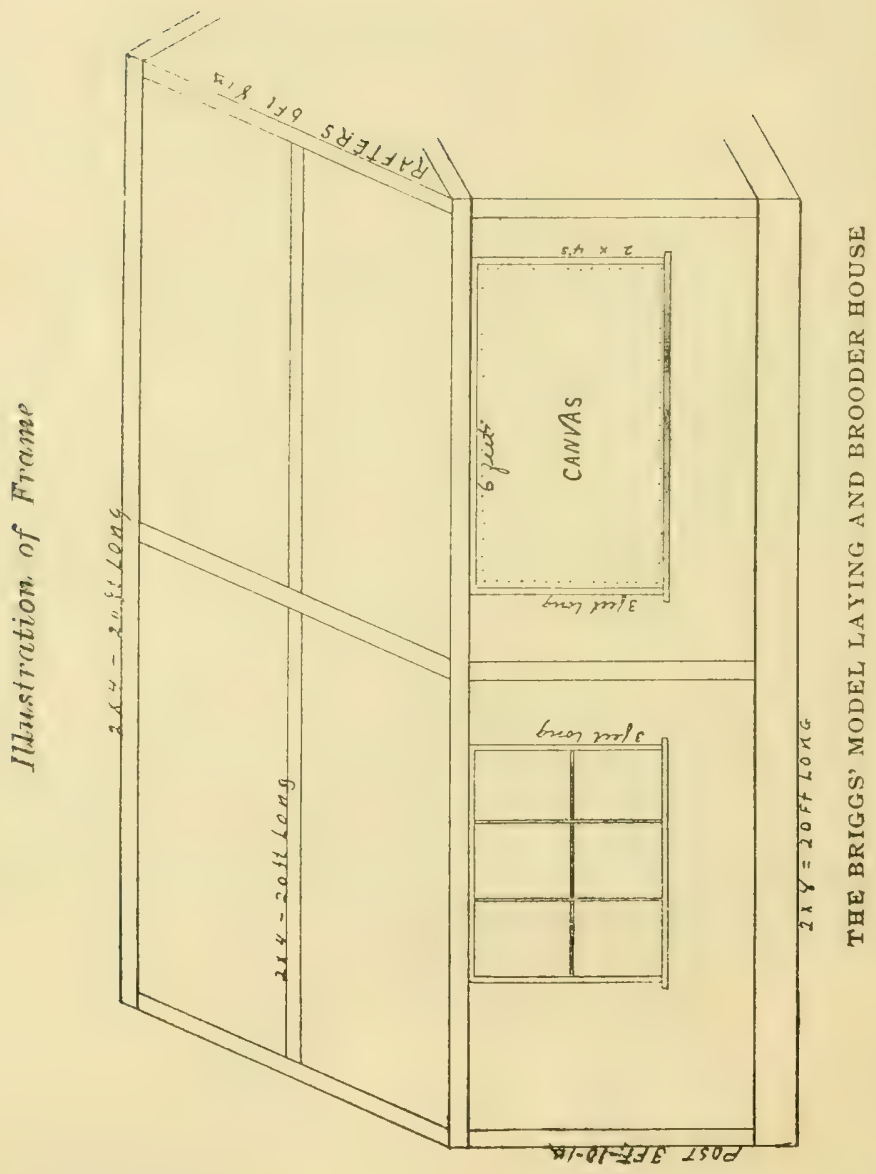




\section{CHAPTER VI}

\section{Directions for Constructing the Model Laying House}

I will now try to tell you very plainly how to construct these houses, so that anyone that can use a saw and hammer ought to be able to build them.

First square up your planks twenty feet long, then take your third plank and make two planks ten feet long each. Now spike your twenty-foot plank on your ten-foot plank, using twenty-penny nails, and you have a box twenty feet long and ten feet four inches wide, outside measure.

Saw six pieces of 2 by 4 , four feet long, then saw out each one of these 2 by 8 . These make your corner posts and also your center posts. Spike these firmly on your plank box, one in each corner, and one in the center of house, letting the 2 by 8 piece come on your plank. Nail from inside and let flat side come toward ends. This will make your outside even. Then saw four pieces 3 feet 4 inches long to double your corners with. These nail from plank up on each end. This will make them all even on ends and sides. Now take a 2 by 4 , just 20 feet long, nailing one on each side flatways on top of your uprights, even with ends and outside. Now take a 2 by 4 ten feet four inches long, saw two inches out of each end, drop this in center of house on your plank, which drops bottom two inches below level of plank; spike firmly both ways. This keeps your house from spreading and is also a division. Take a 2 by 4 nine feet eight inches long, spike this at end of house, opposite end from door, between your 2 by 4 even with top of plate. This piece stays and keeps your end from spreading and is also used to nail your end boards to. Now take two more 2 by 4 , saw ten feet three inches long, nail one in center of house to upright under plate, nail the other at end where your door goes in same way, using a twenty-penny nail-just one in each end-as both of these come out after your roof is on. These are used to keep house from spreading and are also used in putting roof on, as we lay a 20-foot plank on them to stand on in nailing the roof on. Now saw two sets of rafters, each rafter 6 feet 8 inches long. Heel must fit on plate and have your top come together nicely.

Make a pattern and keep it for future sawing, as you may have trouble fitting the first pair.

Nail each set together on ground, then spike firmly on to your plates even with outside in each case. After this, put 
in a ridge, a 2 by 4 , 19 feet 8 inches long. Spike this in peak between your sets of rafters, letting tlat side come even with south side of house and upper edge even with peak. Spike firmly through end of ralters, using three spikes in each end. Then fit a pair of rafters in center of house, raising youi ridge in center a little above a level. Then put in two cross-p.eces, three feet from peak on each side. Spike firmly through end rafters and center rafter, as your roof boards nail on these. Now put in your door studding in center of end. Then make your door about thirty inches wide, according to the width of your boards, and about six feet high. Put in a 2 by 4 on each side, setting bottom on plank and sawing on top to fit under rafter. Now put a short piece on top and you have your frame complete, except a 2 by 4 from door frame to corner of house, to nail your end boards to.

Now you are ready for the siding. Take, if you use white pine, 1 by 8 , 16 foot boards. Take 16 boards, sawing each in four feet lengths. This gives you 64 boards, four feet long. Begin at a corner, nailing one inch from top of plate, as your roof boards come over these and just pass it. See that you get your joints perfectly tight.

After putting on both sides put on your ends, up and down same as siding. For roof boards saw 14 foot boards one-half inch from center. This makes_one-half of the boards just one inch longer than the other. Now plane off that groove in first board. Let this project two inches over end of house. Put on the south side first, using your shortest boards nailing them about three-eights of an inch from the peak, as the boards on north side nail over these, and in this case you use no ridge board.

Your roof boards should be very dry, and if put firmly together, you will have no leaky roofs.

Next, saw out openings for your windows, and curtain frames. One opening for each.

Just back of the center of the south side, cut opening for a glass window, nail a 2 by 4 lengthwise for window in slide on. Put your other opening in towards front from center about two boards from center of house and under plate, just the same as the window opening was placed and fit a irame covered with muslin instead of sash in this opening. See illustration.

Saw a hole for letting out fowls in front part of house under the two openings and put in a slide which may be slid sideways with your feet.

Now place your roosts. First, nail a strip up and down seven feet from back end. Put a 2 by 4 block on plank to 
keep this strip out so window will slide in between. Now nail a seven foot strip from end of house to your short strip sixteen inches below top of plate. Do this on both sides and on these boards lay your roosts 2 by 3 ten feet long. About 5 of these gives sixty hens plenty of room. You can notch your board one inch to lay them in. Do not nail them.

Put in your feed hoppers and nests, and your house is practically complete.

\section{$\mathcal{N E S T S}$}

I will tell you in this connection how to make one of the handiest and best nests I know of, one of my own invention, very simple in construction, one anyone can make, who can use a saw and hammer. Take a tongued and grooved board (yellow pine is the cheapest), 7 I-2 inclies wide I6 ft. long, sawed in two making two 8 foot lengths. Take 3 of these 8 foot lengths, cleat them together with 4 cleats about 21 inches long leaving I inch at back for nest to rest on a long cleat nailed to side of house when nest is put up. Nail another board on top of this in front which forms the front of you: nests. Now saw 9 pieces 13 inches long and put one every foot. Nail these inside of board which forms your front by nailing through this board into each strip. At end of these 9 pieces nail a 4 inch strip entire length 8 feet, and you have 8 nests complete. In order to put a steep cover on your nests so no hens can roost upon the nest, you saw 6 boards same length as the bottom of your nests about $22 \mathrm{I}^{-2}$ inches long, and saw on a slant from back side or from side of house to your front board so the nest is about I board high in front and 3 boards high in back. For a cover lay your first board even with outer edge of nest. The next board is nailed firmly to the 3 partitions also your next which will come to the siding just under plate; now hinge your first board to second, then all you have to do to get your eggs is to raise your hinged board which gives access to all eight nests. The hens enter the nests at either end, on side nearest to wall of your house. I nail these nests against back side of house about 18 inches from floor. Leghorn hens easily jump in them. For larger breeds it is best to nail a short board at each end, 4 inches lower than opening. I find this set of 8 nests sufficient for 75 layers. 


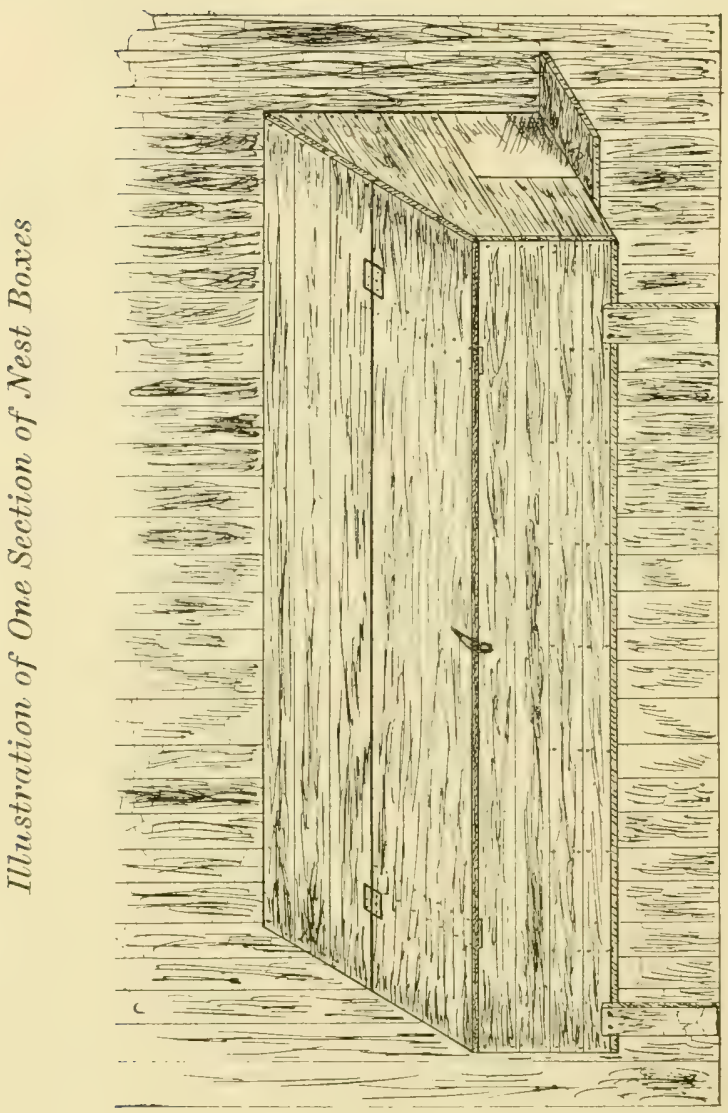




\section{Illustration of Feed Hopper}
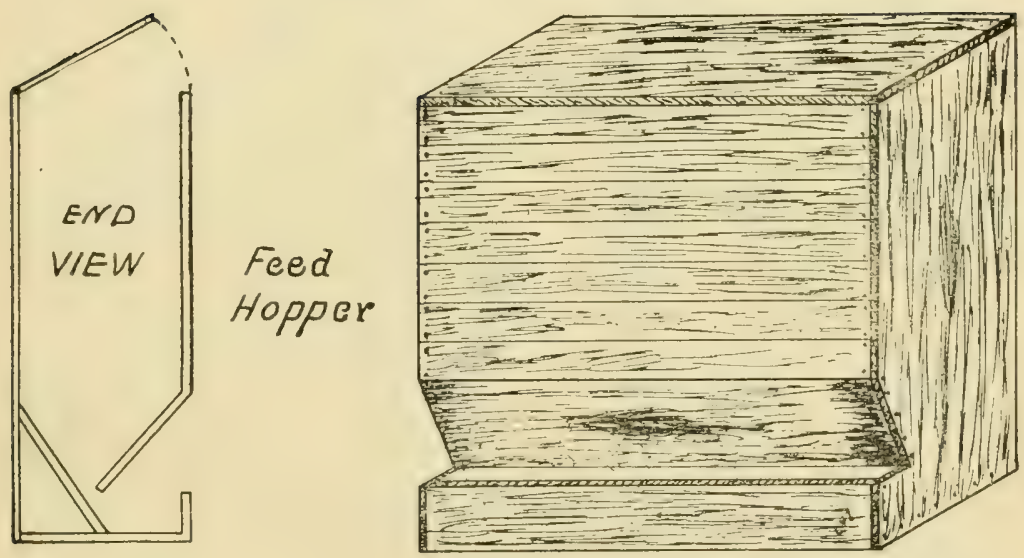
Diagram of End of House

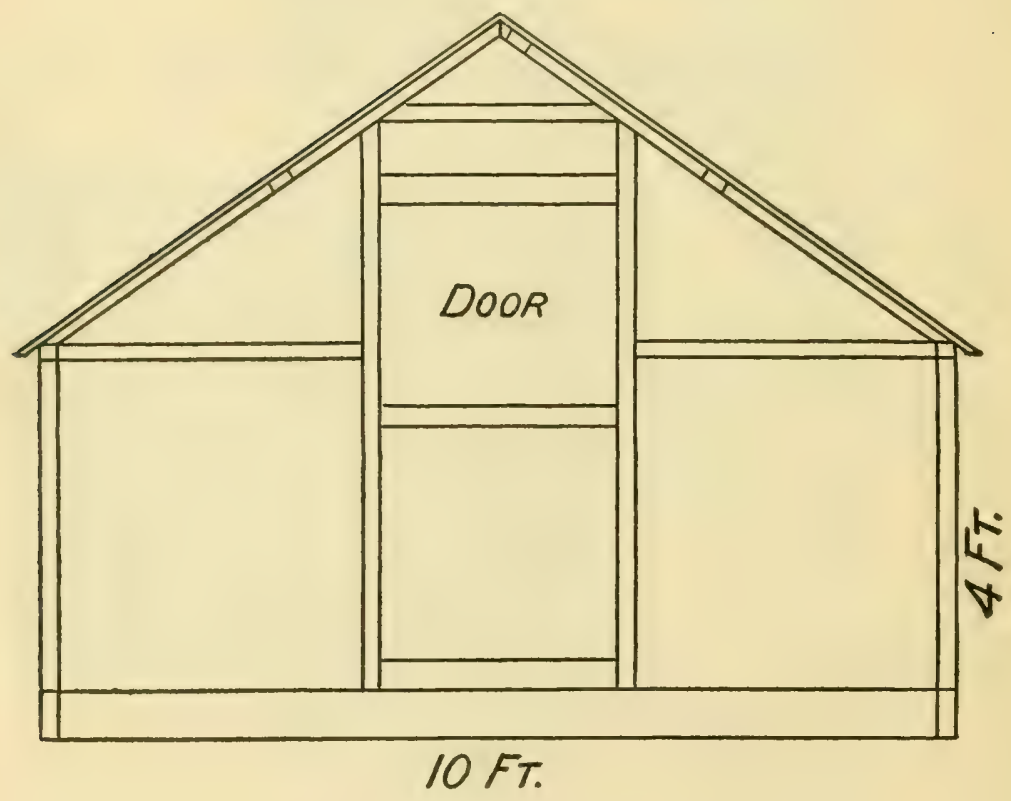




\section{CHAPTER VII}

\section{Making of Hopper's}

Your feed hopper should be made large enough to take a bag of feed of one hundred pounds, sufficient to last a flock of sixty layers, near two weeks. To make this, take a common hemlock board, twelve inches wide, for bottom and ends, saw a piece two feet long for bottom, two pieces three feet long for ends. Nail these together. Now use tongued and grooved boards for back and front. To put in your back, fit your first board inside of ends, letting it come on bottom in center of hopper and top edge of board even with back of hopper, putting rest of back boards even with outside. Better put rest of boards on outside. Now for your front put first board, one inch from bottom and one inch from your other board, letting top of board come even with outside front of feeder, then board up on outside. This lets your feed come out in front. Now put a four-inch strip across front at bottom. This keeps your hens from throwing out the grain.

You can also make a three-department box for oyster shells, grit and charcoal, which should be kept before them at all times-grit to grind their feed, oyster shells for lime in making shells, etc., and charcoal for a regulator.

Another hopper which can be made at small expense and is grand for feeding beef scraps is as follows: Get a box at grocery store, say I 5 inches long, 5 inches wide, and Io or I2 inches high; now board this box up tight; only leave a 3 -inch opening across entire front of box at top. Fill this box with beef scraps; hang on a nail by boring a hole near the top and your hens can eat until it is empty and no bother about clogging. Other sizes of boxes will work just the same. You can use one double this size for other feed. Your hens put their heads in this 3-inch opening and eat. Hang box close to the ground. These boxes will cost you nothing at grocery stores where you trade. 


\section{CHAPTER VIII}

\section{Care of Layers}

I will now tell you how to care for three thousand layers with but little labor, so you should clear $\$ 3,000$ a year from them.

If you have built your plant on a stream of water you will have no watering to do.

Keep your feed boxes filled at all times.

Never let them get empty.

Your main feed is to be the best quality of wheat screenings.

Your large hopper will take a one-hundred-pound bag of feed which should last a full week, often two weeks.

lou should make a round every week and fill all your hoppers-one with wheat screenings, one with beef scraps, ind your three-department hopper with grit, oyster shells and charcoal.

If your plant is built on a stream and inclosed with a good wire-netting fence, all the work you have to do during the week is to gather your eggs every night and at the same time give each flock of fowls two quarts of cracked corn in litter.

Remember, your fowls should have wheat feed before them all thc time, so they can safely have a light feed of grain every night.

A horse and wagon should be used for making the rounds at all times. A good gentle horse that can be left standing and is afraid of nothing is what you want.

From November until April you will have to make two trips a day to your houses. As cold weather comes on your windows and curtain fronts will have to be closed nights and should be opened again in the morning when the sun shines and warms things up.

On this same trip you should give your hens all the processed oats they will eat-about four quarts to each colony of birds.

In case of heavy snow storms your hens can eat snow and they will lay just as many eggs as though they got to the brook to drink-and even more.

You should keep the end of your house, where your nests, hoppers, etc., are, well bedded during the winter, and throw your grain in so as to give them all the exercise possible. 


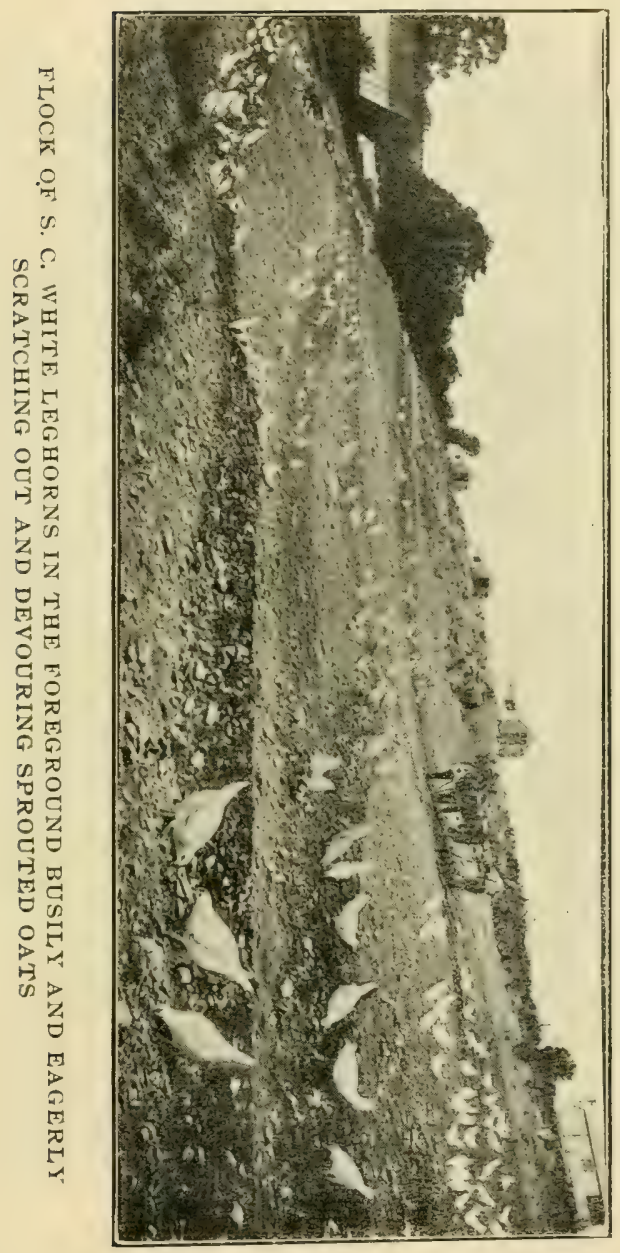

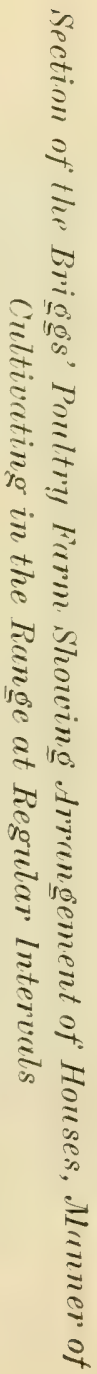




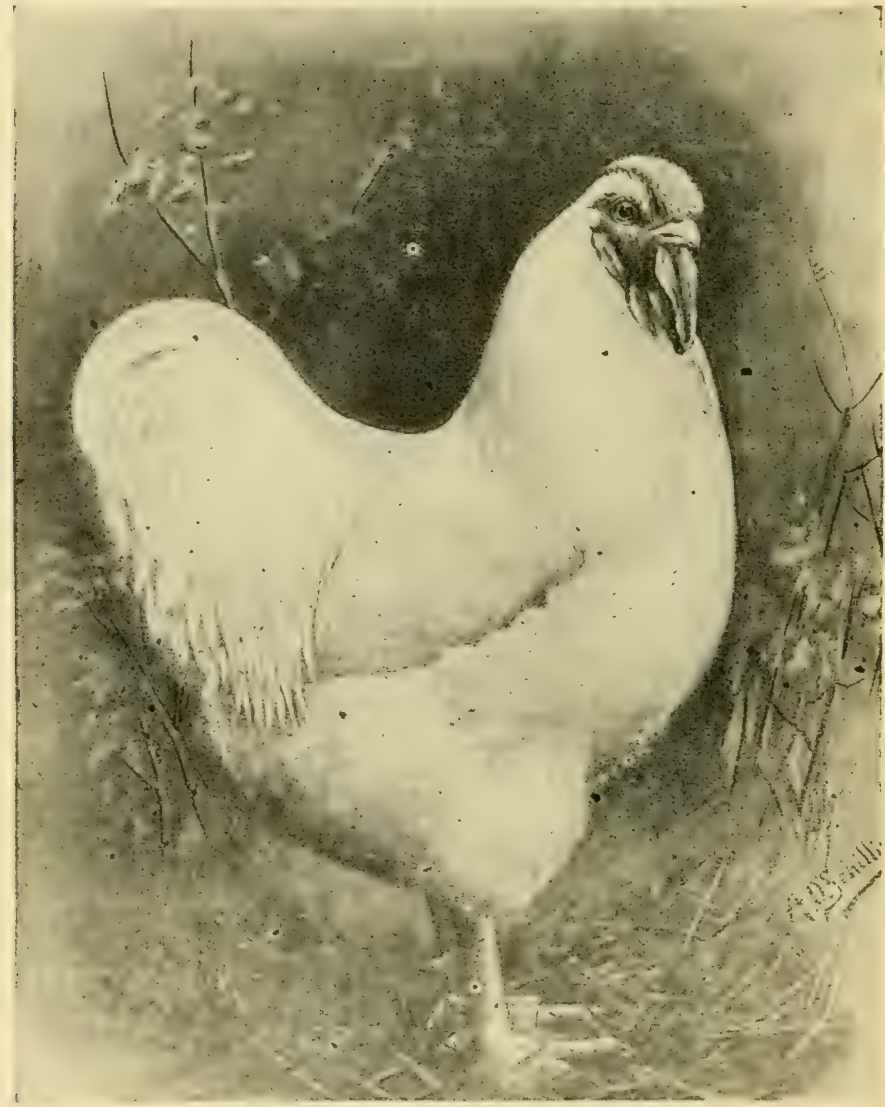

TYPICAL WHITE WYANDOTTE OCK 


\section{CHAPTER IX}

\section{An EgG Plant for Profit}

To run a large poultry plant for the greatest possible profit, will require correspondingly more labor, but will pay the most profit, labor considered, of anything I know of at the present timie. I have experimented to my entire satisfaction, and find that fowls, to be kept in perfectly healthy condition, should have free access to feed at all times, and they will lay fully one-third to one-half more eggs a year,- - eggs that will hatch, for they will be produced in nature's way.

I have found nothing better than good quality wheat screenings same to be kept before them at all times so you must keep a hopper of wheat screenings always before them; also one of beef scraps, grit, oyster shells and charcoal. If possible in order to get your greatest profit, you should have a freerange plant such as I have described and I prefer Leghorns. Of all the Leghorn family there is none that will produce more eggs, larger and finer ones than the Single-Comb White Leghorn.

I am positive an average of 200 eggs a hen can be produced under this system of feeding and caring for them.

One good man can care for five thousand layers during the summer, providing some one looks after marketing of the eggs. But in winter care, say from November I to April I, it will keep two men busy. My aim is to tell you how to produce eggs the year around in the greatest possible number.

I will begin with the winter care, say November I, when your stock should all be properly housed in the colony houses I have already told you how to build. We will assume you have Leghorn plant of three to five thousand layers. WVe usually have much cold weather during November in this part of the state. Of course, you will have to vary this part of the system according to your own weather conditions. The first thing in the morning, as soon after daylight as convenient, start out with a load of processed oats, and give each flock of sixty layers about four quarts each. If the morning is warm, open your windows. If cold, leave your windows closed until your next trip, after breakfast, about 8 to 9 a. m.

If the morning is cold and freeezing, you should take a load of warm water and give each flock enough for the day. The finest thing I know of to water a large plant of this kind is a I I-2 gallon butter crock. Get the low kind, for they are easily kept clean and require but little labor in filling. Even if your hens have free access to a stream of water they 
should be watered in their houses during the winter if you want a large egg yield. In the morning, when a hen comes off the roost, she is apt to be dry, especially if she is laying, and it is very essential at this time that she should have warm water to drink for cold water chills her and makes her dull and all humped up and the result is your egg yield stops.

About one p. m. give each flock all they will eat again of processed oats. Feed this very liberally, as you will find that they will always be hungry for it. You cannot overfeed them on it. This is one of the greatest egg prolucing feeds I know of, and there is nothing which makes eggs so fertile.

Hens will eat processed oats when they will look at nothing else. It can be produced for fifteen cents a bushel at the highest. I will tell you in my next chapter how to process the oats in the most convenient time-saving way.

This one thing alone is worth hundreds of dollars to anyone who owns a large plant, as I will prove to you further on.

For your last round, just before sundown, give each flock two quarts of cracked corn in their litter, to induce more exercise. Gather your eggs and close up your windows if cold. If weather is very warm leave your window and muslin curtain open or partly open in scratching part. You must use judgment in these things.

A plant cared for this way during the winter should give you fifty to sixty per cent egg yield right through, providing your pullets are of a laying age and your old hens have passed through their molt.

You will see that I feed four times as much processid oats as I do any other kind of feed. Oats to a hen are what oats are to a horse. It gives them vigor and puts life in them, such as no other feed will do.

If you follow these instructions to the letter, and use judgment in keeping your houses from getting too warm during the day, you will never fail to bring in a load of eggs cvery day in the year.

Always empty your water jars at night on the last trip, so your hens will always be dry in the morning when you come around with the load of warm water. This is very important.

About II a. $m$. give each flock of 60 layers about one quart of green cut bone and at the same time, if weather is very cold, gather your eggs, for if you are saving them for hatching, care must be taken that they do not get chilled. If green bone cannot be easily obtained then keep beef scraps before them. 


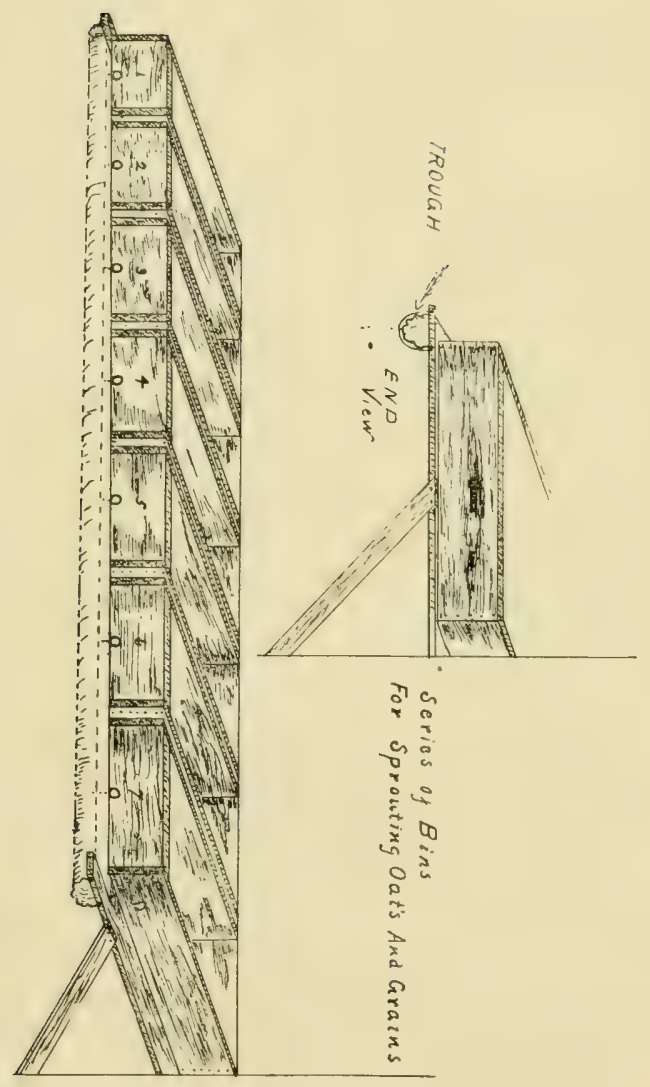

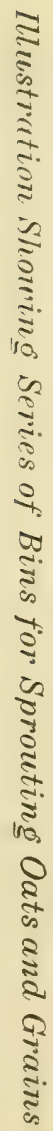




\section{CHAPTER X}

\section{Processed Feeds and How to Produce Them}

The most wonderful feed known at the present time is sprouted oats. They are positively one of the greatest egg producers ever discovered and something that will make eggs hatch any time of the year. IVhat would a horse be worth without oats? But very little. They are the same to a hen. The main objection to oats for fowls is their very tough hull, which is very hard to digest, and for this reason alone many people will not feed them to hens. I have experimented very extensively with oats and have fed them for weeks boiled, with no results in eggs. They make a very good fattening feed when boiled, but of no value for eggs-simply put the hens out of laying condition. But when processed, hens eat them in preference to anything else. In fact, they will eat them when they will touch nothing else, while on the other hand, they are the last thing to be eaten by the hens in their natural dry state.

To process them, take a pail of good, ordinary oats, same as you feed your horses, cover them with water and let them soak five hours in summer and ten hours in winter, then turn them in a larger pail, one that will hold double the amount. First bore a one-half inch hole in your pail before turning them in, so it will not hold water; leave them in this pail until they sprout thoroughly and begin to germinate heat, which will be in three or four days if in a moderately warm place. Always keep them covered with an old bag and stir and sprinkle with water once daily. After they become a mass of roots turn into a box holding about five pails. The oats should not be over three or four inches thick in the box. This must also have a couple of one-half inch holes in bottom so water will quickly drain off after wetting them each day.

They will grow very rapidly when they begin to sprout, and are at their best for feeding when sprouts are one inch to nne and one-half inches long. One bushel will make four to five bushels if oats are good and grow as they should. Always keep oats covered with a heavy bag or old blankets to keep them warm, for they will grow much faster, and the sprouts will remain white and very crisp. By feeding when sprouts are only one-half to one inch long you not only get the full nutrive value of your oats, but they also take the place of green feed, and there is nothing I know of which will start hens laying so quickly and will bring so many eggs during the 
year. On another page is shown a series of bins which will be founc very useful and handy for processing oats and other grains. I am here simply giving the principle or reason of preparing the feed.

For growing young chicks there is nothing as good as sprouted oats. Give your little chicks all they will eat twice a day after they are a week old. They are at their best for little chicks when sprouts are one-half inch long.

If possible always grow them in a cellar, but in warm weather they can be grown under open sheds, under trees or north side of buildings. They grow at their best in a temperature of 60 degrees.

For a large plant where you must grow them in large quantities you will find a series of bins the best plan. A large butter tub may be used if desired. Fill tub threefourths full of grain and fill up with water and let them soak ten hours. If you soak two or three tubs at a time you can dump them all in one barrel, and leave them in this barrel until they sprout and begin to heat. They should be thoroughly wet every day so long as they remain in the barrel, and as soon as they develop heat they must be dumped in boxes that have holes in bottom, say 3 to 5 inches thick, and wet and turned daily until ready for feeding. If they get too hot in boxes cool down with cold water and spread out thinner. To have them at their best you should start a lot every day and keep them fed up as fast as they get fit. You will soon learn just how many to start every day. A little salt distributed through them evenly when fed will greatly increase your egg yield and keep your hens in the pink of condition - a teaspoonful of salt to a common pailful. As an experiment I kept two pens of Leghorns six months on processed oats, with beef scraps before them with no other feed and they laid well all that time and went through the earliest molt of any hens on the plant, although I do not advise following this plan. If one has no cellar to grow their oats in, nor a warm place in winter they can be grown then in an open shed or barn by piling up a foot or more of horse manure, setting your box on it and bank your box on all sides with horse manure. Put on a board cover and throw over this a blanket and you can easily grow them in this way during the coldest winter weather. You can grow them much quicker in winter time by wetting them with warm water, but in summer time they should be wet with cold water.

Processed oats make a great feed for ducks. Remember there is nothing that will grow chicks so fast as processed 
oats, and nothing so cheap. When they grow at their best they can be grown for fifteen cents per bushel or less. This feeding system alone is worth hundreds of dollars to any one with a big plant; and for small yarded plants it solves the green feed question entirely and will make any plant pay a profit. Leghorn pullets can be grown and be put to laying at four months of age on this feed. I have also done this with White Rocks and White Wyandottes. Never soak oats over five hours in summer or in a warm cellar in winter where a heater is run, for if you do you destroy the sprouting qualities of the oats.

Barley is the next best grain for processing, and will give nearly as good results. Wheat and buckwheat can also be processed in same manner with grand results.

To prove that processed oats is a discovery that I made I5 years ago and is the greatest discovery for poultrymen known you will fiud it has been copied by various poultrymen as their own discovery, but not until the first edition of my book was put on the market was it seen in the poultry journals or advertised by others.

It is not too much to claim for my system of processing grains, as do others who are successfully following my methods, that it is the silo of the poultry world.

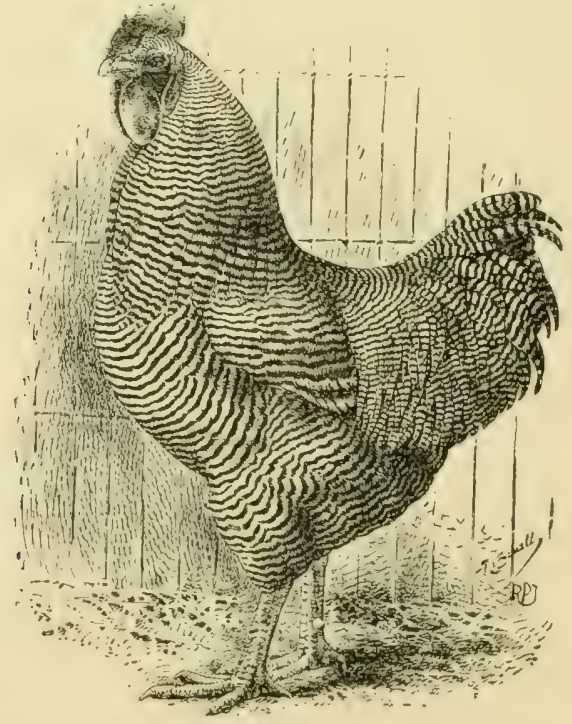

PRIZE COMMING BARRED PLYMOUTH ROCK COCK 


\section{CHAPTER XI}

\section{Summer Care}

For the summer care of flocks, beginning about April I, or as soon as the ground can be worked, take a strip of land along the ends of your house, which end is most convenient, and plow a good-sized strip. If you have ten or twenty houses in a row, plow the whole length of them all, if you can. Now sow this strip liberally with oats, and if you can harrow this every morning so much the better, and sow lightly of oats, three times a weak until the coming November. Do this all summer long, using a spring tooth harrow, and your hens will work in this ground for the sprouted grain conr tinually. As this grain keeps sprouting and coming up all the time you will have springtime for these hens from spring until November. If you follow this up the result in eggs will surprise you. The hen keeps right on laying all through the summer and fall, not even stopping when she is molting. I claim under these conditions a two hundred to two hundred and fifty egg hen can be a common thing. Flocks treated this wav should average two hundred or more eggs each, for you see the hens feast on an abundanc of worms and insects as well, and they will not consume more than half the quantity of beef scraps and other feeds when treated this way.

In changing from winter to summer care, if your plant is laid out on a stream of water, as have advised, you will have no watering to do, and just as soon as you get to plowing your ground you will not need to give as much beef scraps and give only one feeding a day of processed oats, as your hens will get all the oats they can eat, started in their natural way in the ground. The worms and insects they now get will take the place of green cut bone, so that all the work you have to do during the summer is to cultivate this ground and keep sowing onts and at night hitch up your horse and give each flock of fowls about two quarts of cracked corn and gather your eggs. If you follow up this system strictly the hens will "keep at it" all during the molting season. You must make your rounds every week during the summer and fill all your hoppers, one with beef scraps, and one with wheat screenings; also grit, oyster shells and charcoal. These tssentials must be kept before them winter and summer. Never let the hoppers get empty. When freezing weather comes in the fall you must change your plans at once if you 
want the egg yield to continue. Remember this is how the profit comes in. Under no circumstances let your hens fall off on eggs. Start on your winter rations as I have outlined in a previous chapter, just as soon as severe weather of November comes on.

During the summer your windows are to be left open day and night; also your door, providing your plant is enclosed with a wire netting fence such as I have described in opening chapter of this book.

You must remember another thing. If you let your fowls get knocked out in any way, through carelessness, it will take three or four weeks to get them back again, and in the meantime you have lost a month's laying of eggs. So great care and judgment must be used. Sickness will scarcely be known if my instructions are faithfully followed. Your hens should always be in the pink of condition, and your eggs from January to September should run 90 per cent fertile and give wonderful hatches. I think you will agree with me that this is caring for fowls the nearest to nature's way and under the best system known at the present time.

During dry weather of summer always give one feeding a day of processed oats with a little salt on, do not neglect the salt at any time of the year as it is very important for 2 large egg yield.

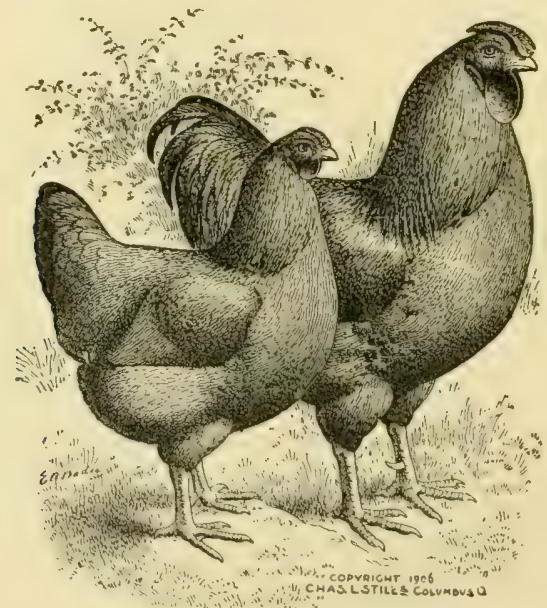

PAIR IDEAL ROSE-COMB RHODE ISLAND REDS 


\section{CHAPTER XII}

\section{A Free Range Plant With Least Labor}

In this chapter, I will describe how to care for a free range plant with the smallest amount of labor and one helper.

First, make a feed hopper, such as I have described that will hold a bag of feed. You should have three of these. Fill one with wheat screenings, one with oats and one with cracked corn. Also a small hopper for beef scraps and a three-department hopper with grit, oyster shells and charcoal. If your plant is built on a stream of water and inclosed with a wire-netting fence, as I have already described, all the work you have to do is to gather your eggs every night and send your man around once a week and fill all your hoppers. He should also spray carbolic acid and kerosene, half and half, well mixed, on the roosts once during the winter, and once a month during the summer. In September he should clean the houses out thoroughly and coat the floors over with new sand. Your hens will go to the creek to drink, and in winter, if ground is covered with snow, they will eat snow and will lay even more eggs. The hole to let them out of the house should never be closed, day or night, winter or summer. In the winter time your windows would have to be kept closed. Your hens will pay you a fine profit under this system with practically no labor. You will not get a big egg yield during the winter, but you can depend on a profit of one dollar or more from each hen on this no-labor system. You will be surprised at the results. For a business man in the city, who owns a small place in the country and wishes to make some money at home, there is nothing I know of that will pay him so large a profit on the money invested as a poultry plant run in this marner. Of course, he would have to buy his breeders each season and the best way to do this is to sell off half of the stock during the early fall and replace them with pullets which can always be bought at one dollar each during September and October. Better birds for less money can be bought during these two months than at any other time of the year. One reason I specially advise Single-Comb White J eghorns in preference to any other breed, is because one can always buy all they want for one dollar each of good laying stock.

I advise changing the breeding stock at end of second year's laying, as two years is all a hen can be relied upon to 
pay a good profit and they should never be kept after this unless they are extro good ones that you may want to use as breeders.

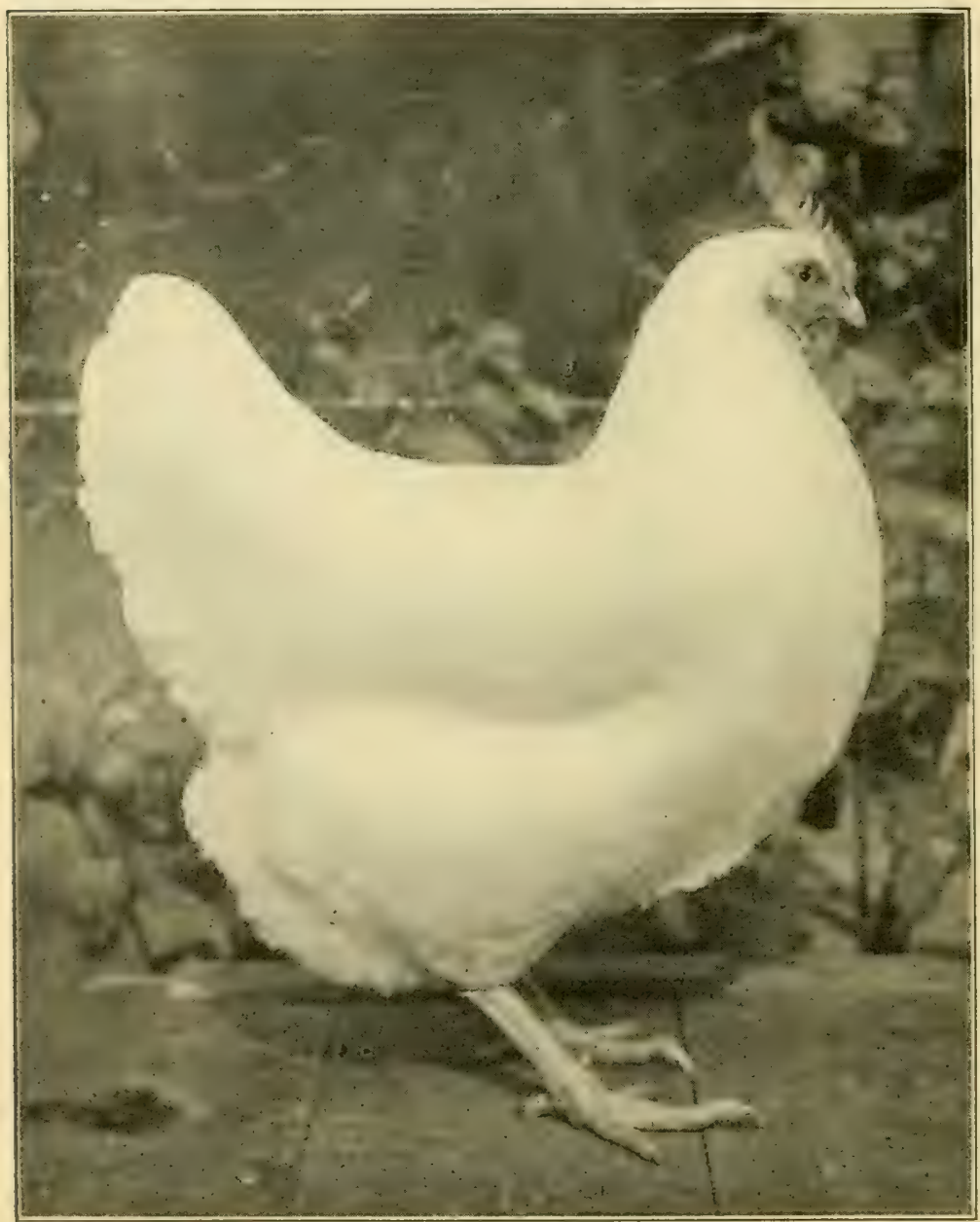

PRI\%E WINNING ITHITE PLYMOUTH ROCK HEN-WINNER OF MANY FIRST PRIZES 


\section{CHAPTER XIII}

\section{Caring for a Yorded Plant}

To handle a yarded plant for the greatest possible profit and for those who are so unfortunate as to own one, for such plants seldom pay unless it is used for breeding fancy stock, I have sxperimented for many months on yarded plants and 1 find that hens even over crowded in small runs will produce more than double the eggs fed on the hopper system than they will fed the ordinary way. Just keep good quality wheat screenings and beef scraps before tlıem at all times and give a !beral feeding of processed oats in the morning-all they will eat and at 3 p. m., another feeding of processed oats, all they will eat. Remember you cannot over-feed on the processed oats, as they are light and quickly digested. At night in winter give a light feeding of cracked corn in litter and you will be surprised at the results. Your fowls will always be in the pink of condition and practically no sickness among them. Roup, colds and cholera will scarcely be known, even on the same plants that have always previously been over run with these various diseases where hot mashes were daily fed.

Another valuable secret for a yarded plant, if your hens have long, narrow yards, say 1o by 60 or more feet long; is how to keep green feed in their yards all summer. Spade up haif of the yard, sow it to oats early in the spring and put in cross boards eight inches high, cover it over with one inch mesh wire netting, stretching it tight ans stapling it firmly to the boards. As soon as the oats get a good start your hens will eat them through the wire netting and the oats will grow just as fast as your hens can eat them off. In this way they will be supplied with green feed all summer long. I am satisfied a yarded plant can be made to pay run in this manner. Cut your hot and cold mashes entirely out. If possible, feed green cut bone once a day. About II a. m. I find the best time for this. If you are in a position to get plenty of green cut bone, feed a yarded plant as follows: Keep a hopper of wheat screenings, also one of beef saraps, always before them, as well as grit, oyster shells and charcoal. Give a feeding of processed oats, in the morning and at II a. m. a light feeding of green cut bone; $2 \mathrm{p}$. $\mathrm{m}$. another feeding of processed oats, at night a light feeding of cracked corn in litter to induce exercise, and your fowls will keep in the pink of condition, lay well all winter long, and colds and roup will hardly be klown if they are properly housed. They should be 
given warm water mornings in very cold weather, as they are dways dry in the morning, and should not be allowed to have ice water. After they drink all they want of warm water in the morning. the rest of the day they will drink but little at a time ind cold water will not hurt them. If your houses have dropping boards you should clean the drofpings off at least twice a week the year around. In the houses I have described for a free-range plant your droppings go right on the ground, and it is not at all necessary to clean them out oftener than twice a year. So you can see the amount of labor sáved.

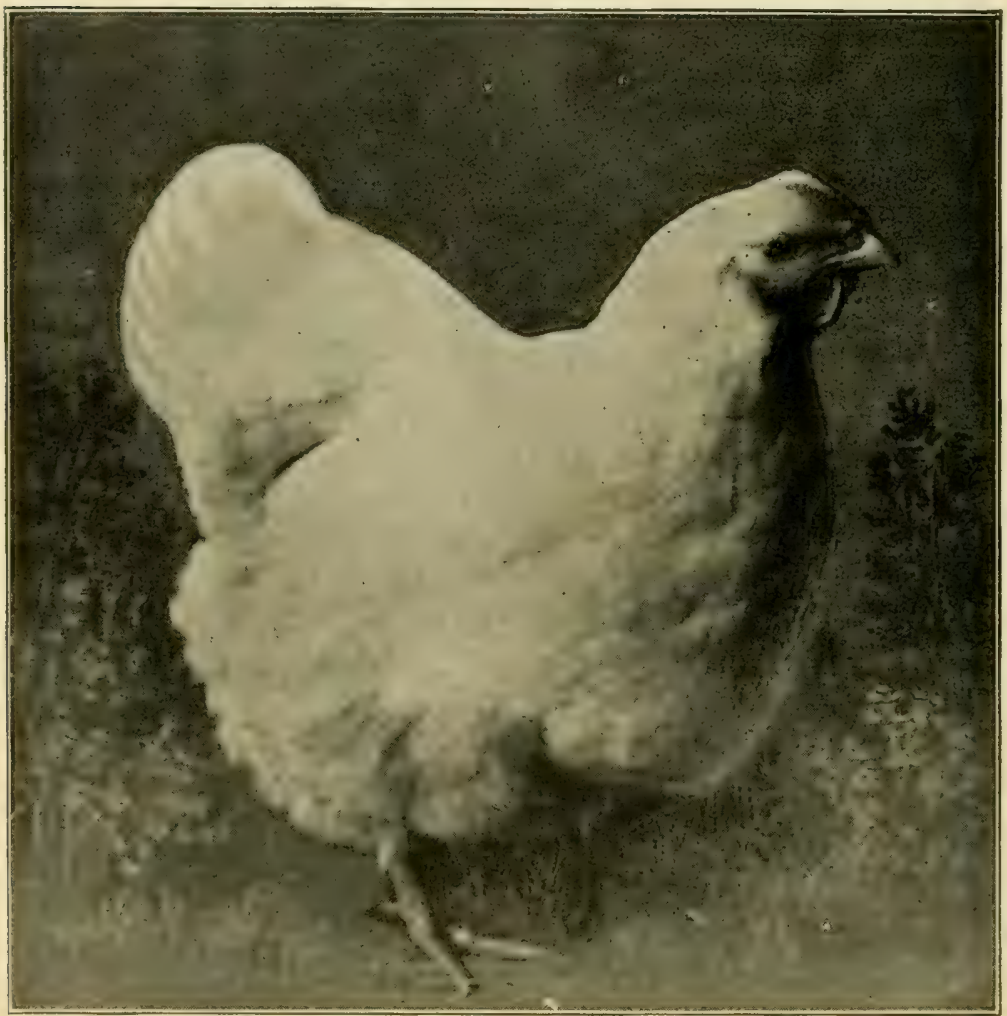

RIZE WINNING WHITE WYANDOTTE HEN -WINNER OF MANY FIRST PRIZES 


\section{CHAFTER XIV}

\section{How to Build an Ideal Incubator House}

I have told you in my former chapters how to produce eggs in the gieatest possible numbers, eggs that will give you the largest hatches. You will not want to know how to hatch them. First, I will tell you how to build what I consider the most perfect incubator house or cellar. Select a side hill if you have one near by; for a perfect incubator house should be part under and part above ground. Iou can determine the size of house needed by the number of machines you want to use and the number of chicks you wish to hatch. But it is always safer to build much larger than your present needs, then you will not have to rebuild or enlarge when your business grows.

First, lay up a wall of stone five feet high on all four sides, patting in windows at the top of your wall; a four-pane window $8 \mathrm{ly}$ Io glass will answer the purpose nicaly. Hinge at bottom so they w.ll open inside.

Put windows in c $\mathrm{n}$ each side and at south end. A window every ten feet is alcut right. Now put a window in each end for ventilation. Put these windows near peak, a six light window, 8 by 10 glass, and in summer these can be left open foi ventilation. 'I his makes an ideal incubator house.

Throw up dirt on top of wall on all sides, except south and and put in a double door here wide enough to carry out any incubator, set up.

The air in such a house as this alwavs smells free from lamp smoke. If you fail to get good hatches in such a house you will know that it is not the fault of the house.

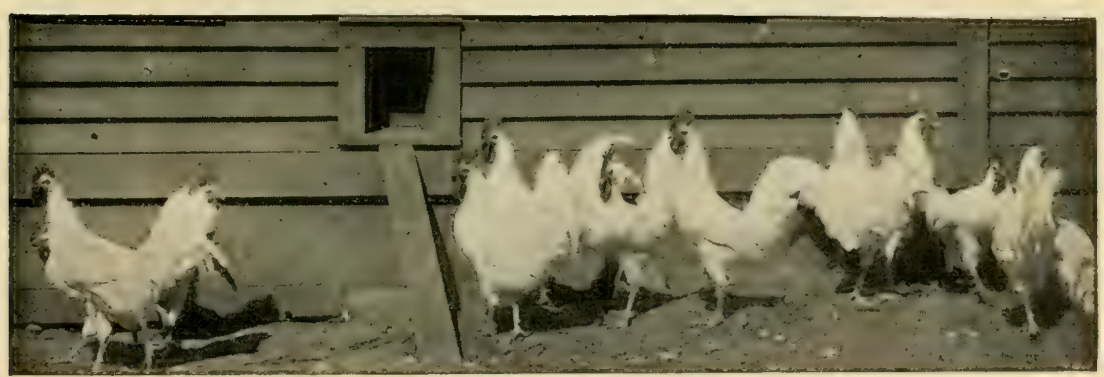

PEN OF SINGLE COMB WHITE LEGHORN - AMONG THE GREATEST OF EGC PROUUCERS 


\section{CHAPTER XV}

\section{How to Kiun an Incubator}

First, after setting up your machine and starting your lamp, you must let up or release your regulator. Keep unscrewing it until temperature goes up to IO2 I-2 degrees. Remember the temperature cannot raise when your disk over the lamp is raised. When you get temperature to I02 I-2 and your disk raised one-eighth of an inch, or so it just clears, then your machine is ready for the eggs.

Better run your machine twenty-four hours after you get your temperature right before putting in the eggs. As soon 2s you put your eggs in your temperature will disappear; give your machine twenty-four hours to get back to 102 I-2 degrees. Regulate ventilation according to directions sent with the machine you use.

Change trays from side to side in the morning and from end to end at night in a two tray machine, and turn the eggs at end of first day. After this turn twice a day until eighteenth day. Turn last time at end of eighteenth day, but continue to change your tray from side to side and end to end until you see the first pip. Handle your eggs very carefully from the eighteenth day on, using care not to jar them in changing trays. Remember animal heat begins to take place after the seventh day and the temperature will begin to work up and you should give the regulating nut part of a turn every time the temperature crawls up to I03, so as to keep it down as near IO2 I-2 as possible, if you are operating your machine in a room which registers above 65 degrees; if not over 40 to 45 degrees, then keep your machine at ro3 and do not air your eggs.

In a room of 50 to 70 degrees begin airing your eggs on the fifth day and air each night, depending on temperature of room.

A good airing for an hour or two on seventeenth day will much improve the hatch in warm weather.

Give plenty of air during hot weather.

Good, fresh eggs hatch much better than those kept two or three weeks.

If you are hatching white eggs test them on the fifth day, and take out all clear eggs and dead germs

If you are incubating brown-shelled eggs test them at the end of the serenth day, at which time you can test them nicely. 
All eggs should be tested again at the end of fifteenth day. Remove all dead eggs and if they do not show a good, fairsized air cell you must give more ventilation, for a good hatch cannot be had without a good-sized air cell.

After you see the first pip do not open your machine again under any circumstances until the hatch is practically through, say the morning of the twenty-first day for Leghorns and at the end of twenty-first day for all large breeds.

Leave chicks in incubator fully twenty-four leurs after all are out.

I have been experimenting for the past 20 years with in(ubators and have tried nearly all the leading makes running them side by side with eggs laid by same flocks of fowls and have given the moisture machines as well as the nonmoisture machines every chance by running them through several hatches during an entire season and the results in every case were in favor of the moisture machines, and I shall not use any other kind in the future. In some cases I have hatched every fertile egg with moisture machines. My average hatches from 400 eggs set was 300 to 340 chicks and in many cases not a cripple or deformed one among them.

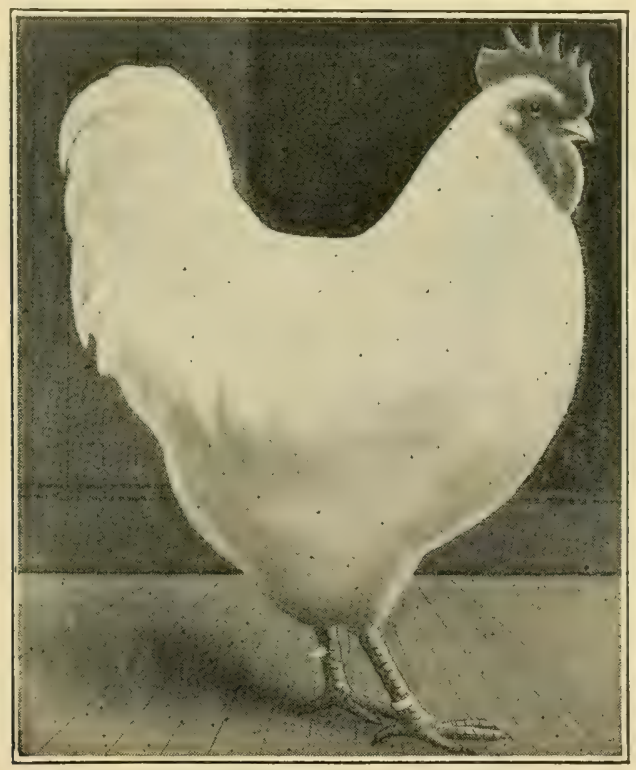

PRIZE WINNING WHITE ORPINGTON COCK 


\section{CHAPTER XVI}

\section{Chicks Ruised Nature's Way}

Now comes the most difficult part of all, the business of raising the chicks. Here is where nearly all fail except those using my System and Secrets.

First of all to raise chicks successfully and raise the greatest number you must have a projer place to raise them in. 'To raise chickens in February and March you must of necessity have a house and for this purpose there is no cheaper or better house than the colony house I will here describe which should be built exactly like my laying house only I-5 smaller. Use 16 foot plank, making the houses 8 feet wide and 16 feet long outside measure, four feet high at eaves same as the laying houses. For the roof saw a 16 foot board into three pieces and saw rafters 5 feet $I$ inch long. Build it the same as the laying house dividing it in center with 2 Io inch boards, and you will have an ideal house for raisiner chicks in. Put windows and curtain opening the same size as you use in the laying houses, one in each side in center of each department. For the curtain opening make a frame out of a furring strip $I$ inch by 2 inches and covar with muslin no glass to be 11sed. Have windows so they will slide open towards the door also put a slide under each window for letting chicks out. In these houses place two of my indoor brooders such as I will give you plain instructions for building in the next chapter. You can place any number of these houses in a row from 5 to ro putting them about 30 feet apart. Try to fill one row of houses with chicks as near the same age as possible. All should be hatched within 2 or 3 weeks of each other. You can put I 50 to 200 chicks in each house.

To raise chicks on a larse scale, say from three to six thousand, you must keep some one among them all the time, if you do not want them all carried away by hawks and crows and various other animals, as there is nothing that has so many enemies as youne chicks. Hawks, crows, rats, weasels cats, skunks, wood chucks in rare cases, raccoons and foxes are the worst.

Select a nice, large orchard if possible fกr roising chicks if you have one; if not you must arrenge for artifizi?l shade. About sivty feet in front of the row of houses put a one and one-half fort fence of cne inch mesh wire netting; then another row of houses about eight feet from this fence; then \&nother fence, same as the other. 
It makes no difference how many brooders you have in line, twenty could be handled all right if they were all filled with chicks at nearly the same time.

If the field is nearly level they will equalize themselves all right in the brooders.

You can safely put seventy-five to Ioo chicks in each brooder and should have no trouble in raising 70 to 90 per cent of them to maturity if you follow my instructions.

For first feed I grind fine eggshells and feed these for first three days. You must see to it that they are never out of feed again as long as you own them. Here is one of the great secrets of success, for if your chicks always have free access to feed, they will never overeat and die of indigestion. As soon as you put them out give them fine grit and fine charcoal, also water that is lukewarm, and the eggshells, and as I have said before, the next day set dry mash before them.

On the third day also set beef scraps before them and see that they are never without it. Begin feeding them processed oats on the seventh day. 'They will quickly take to it and tat off all the roots and sprouts, leaving nothing but the hulls. Feed them all the processed oats they will eat from then on, say twice a day. Do not be afraid, for they cannot overeat of it.

From the seventb day on, your chicks must have always i.efore them water, chick feed, grit, charcoal and beef scraps; and do not forget the oats. I generally set a panful in the pen first thing in the morning and again at noon, dumping out the hulls every time. It is a pleasure to raise chickens this way as sickness and disease is scarceiy known.

After three weeks add a good quality of wheat screenings to the rations, which must also be kept before them from then on as long as you own them. I know of nothing that can in any way compare with it for growing young chicks, and nothing so cheap as screenings and processed oats. If you cannot get good screenings use wheat.

Good, clean, fresh water is very important-in fact, thousands of chickens are lost every year through dirty water and filthy drinking dishes, as disease starts in the drinking tountains in many cases.

If your fountains are not kept clean, and if you are not particular and wash out your fountains every time you fill them, slime collects on the inside, and this is rank poison to the chickens.

The best fountain you can get is the two-piece earthen fountain, which keeps the water cool and clean. I would not use any other kind under any circumstances. If you can 
yard your little chicks on a stream of water, so much the better, : m much labor is thus saved.

Keep your brooder at 95 degrees first five days, then it should be lowered to 90 degrees, after two weeks to 85 degrees, and after three weeks to 80 degrees gradually reducing the temperature and harden them off, depending on the season of the year and the weather. Here is where common sense and judgment counts. Give your chicks heat just as long as they need it if you wish to attain the most rapid growth, and rugged birds of extra good size, such birds, as a rule, are never sick.

I will give you the secret of success in raising chicks and getting them beyond the danger period, especially Leghorns, that are from twenty to forty days old. Nature's way is the secret.

In front of my colony houses used for brooders, say six feet I plow a good, big strip the entire length of them all. I do th:s the day the chickens begin to hatch, and sow this strip lightly with oats. By the time the chicks come out of their brooders the oats are nicely sprouted. I let the chicks cut of the colony brooders the seventh day about ro a. $m$., if the weather is nice. The next day I run the harrow over the ground and sow more oats. Every day after this I harrow this ground, sowing more oats every day. The result-the chicks keep at work from morning until night and never get time to become sick.

I consider this, the only good or perfect way to raise chicks, at least about the only successful way. Pullets raised this way should lay at four or five months of age.

As soon as the chicks reach a weight of two pounds each or near this weight, the cockerels should be marketed-except those you desire to retain for breeders-these should be separated from the pullets in order to mature them in best shape.

Bear in mind the most critical time of a chick's life is between twenty and forty days old. During this period they must not be neglected, as they begin to grow rapidly at this age, and if stunted they never recover.

You should sow more liberally of oats at this time, and do not neglect the harrowing; it takes but a short time each day and is very essential that it should be done with regularity.

Continue to give your chicks all the processed oats they will take at this time.

In order to economize and save labor, as soon as the chicks are large enough to leave the brooder you can move 
your pullets to the laying houses; that is, pullets that you want to keep for your own laying and breeding stock to take the place of your yearlings.

A convenient way to replace a flock of old hens with pullets is to just put up a lean-to on the back end of your laying houses-say 6 by 6 feet square would answer every purpose. This can be put up with a single pitch roof and a wire netting front. Put some low ruosts in this lean-to and shut in about sixty of your finest, largest pullets for three days, then you can let them run with the hens.

Feed pullets in their own department in an open trough, continuing same course of feeding which has already been begun.

When you sell your old hens just shut chicks out of their temporary department and they will go right in the main house and never have to be taught. When they start to laying, they will keep right at it, and you will thus gain a full month's eggs as changing after they have reached the laying age always stops them.

This lean-to is also very handy for shutting up setting hens and various other purposes.

'To go back to the young chicks again, when your chicks are large enough to think of roosting, and need heat no more you should market the cockerels for squab broilers, if possible, at eight to ten weeks old, and remove your pullets to the laying houses. Your brooders are then ready for another batch of later chicks which can be allowed to grow up in these houses in the same manner as the first batch.

You will find these houses very handy for wintering surplus cockerels and pullets in. It is always nice to have some surplus birds on hand.

I think I have made things plain, and if you will follow my instructions you will have no trouble in raising your chicks, providing your eggs are produced under my method of feeding, from healthy stock.

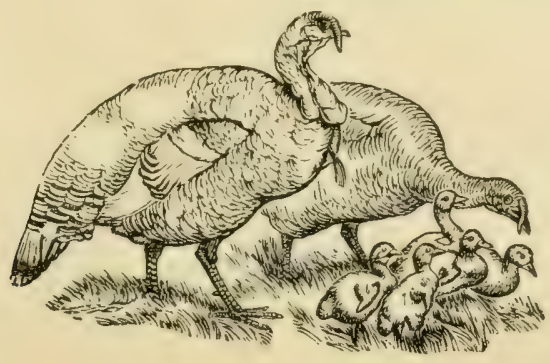




\section{CHAPTER XVII}

\section{A Perfect Brooder}

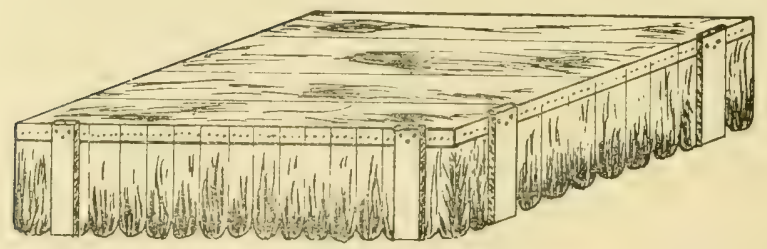

ILLUSTRATION OF BROODER HOVER COMPLETE

I will here describe the most perfect brooder I have ever used-one that is used exclusivaly on my plant. If you are handy with tools you can make these brooders very easily and at a small expense for materials. For the body of these brooders use a board 12 in. wide of hemlock or pine, saw two pieces three feet long and two pieces two feet ten inches long, nail thesc together at ends and you have a box just three feet square. On top of this box nail a sheet of galvanized iron 3 fe.t squa $\epsilon$ ard around the edge on top of the galvanized iron on each side nail flatwise a furring strip I by 2 , and 3 feet long. Now saw two more pieces two feet ten inches long to nail inside of these two pieces. First saw a I-2 inch piece out of each end of these two pieces and nail between your three feet pieces with your I-2 inch cut down, now you are seady for your floor which must be made out of tongued and grooved white pine boards good and dry so it will not shrink. In the center of this floor saw a round hole so a two quart tin basin will just nail over and around it with bottom. Nail around the flanges at the bottom the tin basin. Punch side full of holes with a punch to let fresh air and heat out among the chicks. On top of the basin as inverted, fasten the round block you sawed out of the floor. This must be done before basin is nailed on brooder. This block keeps your chicks from getting killed when the hover is raised or removed and let down again, also keeps the chicks from setting upon the heat drum. In body of brooder you must saw out an opening in center 9 by Io inches. This opening is to put lamps in. Now make a slide for this opening and near the top make 3 holes about two inches apart 3-4 inch in size. Near the bottom also make two three-fourths inch holes. These holes are to provide air for the lamps. The holes must always be kept 
open or the lamps will not burn. You will now make your hover and this must also be made of tongued and grooved white pine and should be inside twenty-four inches square.

\section{Illustration of One-half of Brooder}

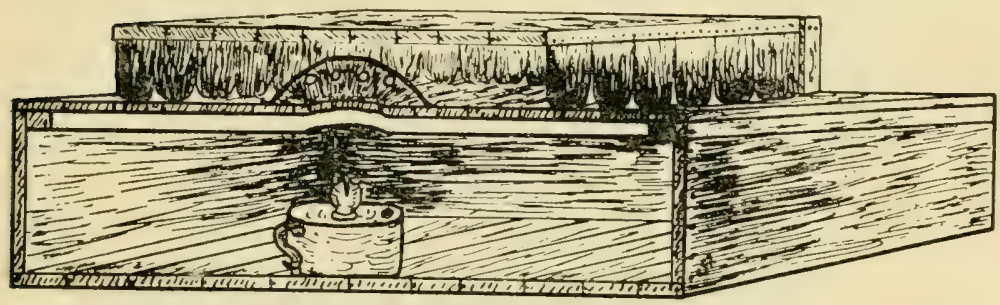

FROM THE CENTER TO THE BACK,

SHOWING MANNER OF CONSTRUCTION, APPLICATION OF HEAT, ETC

Around the edge put a strip of cheap cloth yet substantial, six inches wide; slit this with a pair of shears. This strip of cloth should go twice around. Slit it so chicks can go out and under it at each corner. Put a leg six inches long of onehalf inch stuff three inches wide where you nail to brooder and bring it down to $\mathrm{I}-2$ inch wide where it sets on top of floor cf brooder. This hover sets right over the tin basin. I always set these brooders in the corner of the house described in former chapter. This forms two sides and as the lamp door is always toward you, I first nail a ten inch board along this edge of brooder opposite from the side of the house. This keeps the chicks from falling off; and on the lamp side and in front I put up a ten inch board and set this loose in a pair of cleats at each end so it can be easily removed as this is where the chicks are let out of the brooder down on the ground when five days old. To arrange for the chicks to get from the brooder to the ground, a distance of twelve inches I first put some dirt in front of brooder giving it a nice slope then I cover this over with grass sods. These sods keep the chicks from scratching the dirt away and once fixed in the spring they generally last an entire season.

I consider this brooder far superior to any others I have used as you cannot overheat the chicks and no danger of chilling so long as your lamps are burning. I never use a thermometer in these brooders any time of the year. I put trom 75 to Io chicks in each brooder using two brooders to a colony house and have never lost even five per cent of 
chicks put in and often raise every chick. I find for lamps it is best to let a tinsmith make you a lamp out of galvanized iron that will hold about three quarts of oil. Make these lamps rather low and large around. Use a large sized zenith burner which is a burner needing no chimney. Run a low flame just so you can see it over the cone. Use two lamps under each brooder and fill them only once a week, but trim every day if your oil is poor.

\section{Illustration of Brooder Complete except Hover}

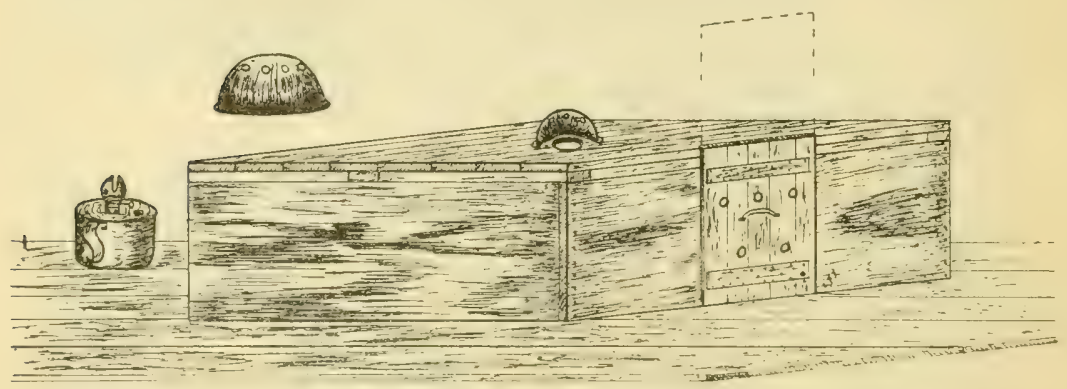

SHOWING POSITION OF VENTILATOR OR FRESH AIR OPENING ON 'THE LEF'T SIDE

A SIMILAR OPENING IS PROVIDED FOR, ALSO ON THE RIGHT SIDE

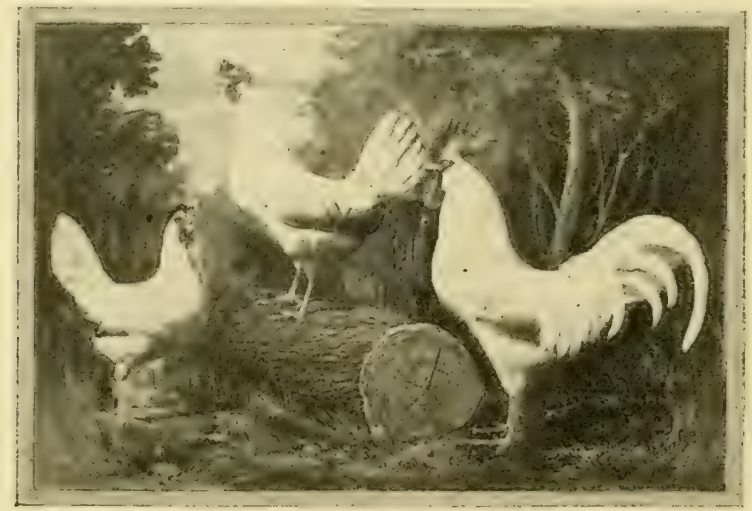

A TRIO OF PRIZE WINNING S. C. WHITE LEGHORNS 


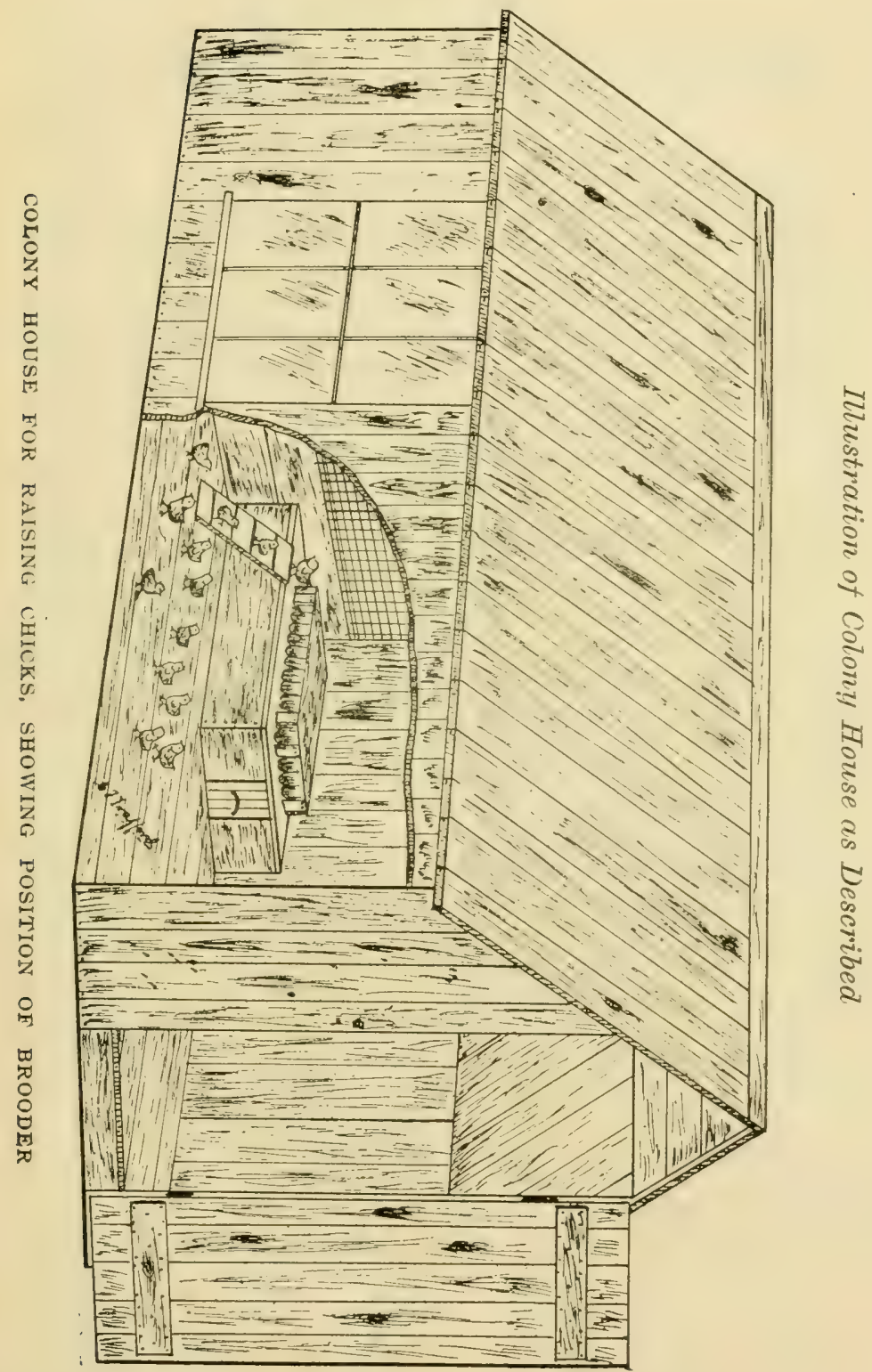




\section{CHAPTER XVIII}

\section{Raising Broilers-Bowel Trouble, Its Cause and Cure}

This chapter is written expressly for broiler men and those who keep their hens mainly on wet mashes.

The failures in this branch led me to experimenting and I have carried on a series of careful experiments for several years until I have now fully satisfied myself that bowel trouble commonly known today as White Diarrhoea is a germ disease and the weaker your chick the quicker it will attack it. Now the next thing was to find something that would kill the germ and at last $I$ have found it in what is known as Crel Oll. I spray my brooders thoroughly with it and cover lightly with wheat bran before putting chicks in, spraying once a week with it until the chicks are five weeks old and feed as follows: From the start put a small box of dry mash before them as described in my Poultry Secrets in the supplement to this book. I also give a light feeding of chick grain three times daily keeping fresh water, grit and charcoal before them and in some case I have raised every chick put out. All chicks intended for broilers hatched after May rst should have sweet milk to drink for three or five weeks, as this will grow them very rapidly and put them right through the critical period with scarcely any loss. I am now speaking more particularly of broiler raising.

If you want healthy, rugged birds, free from disease, never feed them a wet mash.

The cheapest way to feed and have healthy, rugged breeding birds free from disease at all times to raise broilers from is as I have told you, except in place of a light mash at 9 a. m., give your hens a good feeding - of processed oats. If you produce eggs in this way, from yearling hens mated with fully developed cockerels, not less than ten months old, you can raise practically every chick you hatch, even if a piped brooder-house is used providing you can keep tha temperature, anywhere from 80 to 95 degrecs. This is a big variation; but strong, healthy chicks will stand a lot and not get sick. Once they get sick this is the last of them, for they will die about as fast as you can hatch them.

Most breelers, who are in the fancy stock raising, use hens for hatching and brooding them. They get their neighbors to hatch and raise for them, for they cannot hatch them and raise them with incubators and brooders, simply 
because their breeders are fed on wet mashes, so as to get a big price are usually hatched by old hens and raised by them on free-range, which will pull them through if anything will.

Under my system of feeding, eggs laid in January will run 90 per cent fertile, and I have hatched as high as 93 3-4 per cent of fertile eggs.

Yo:1 can see at a glance why so many who have tried the broiler business as a business have failed. I defy any one to find a profitable broiler plant, but I am satisfied this branch can be made to pay under my system of feeding and in no other way.

I want to say to broiler men, who have piped brooder houses, give them one more trial with eggs produced under my system of feeding.

From January until June you can hatch and raise broilers at a splendid profit under this system, for you can grow your later hátches up and make roasters of them at a grand profit. Under my system of feeding your birds will grow very sapidly and develop fully one-third quicker than if fed the old way, stuffed with wet mashes. If fed the old way you will lose a large number with colds and roup, and have but few well chickens to sell.

Just a word about growing roasters. Either good wheat screenings or wheat of some description must be kept before them all the time; also first-class beef scrap, grit, charcoal, and good fresh water and never let them get out of dry mash. They should have one good feeding of processed oats about 9 a. m.- all they will eat. At night give all the cracked corn they will eat and you will grow roasters that will be a credit to you, and sickness among them will scarcely be known, and your profit will correspondingly surprise you.

Howevei, you will find it to your advantage to market chicks as broilers as long as they bring 25 cents a pound and more.

A pan of corn meal, set where the chicks can eat all they want of it, a week or two before marketing them will fatten them nicely. Do not wet it, but let them eat it dry.

Under these conditions only can broilers be made to pay a profit. You can raise them well into the summer on the free-range systam of cultivating the ground. Just as soon as you fail to raise 80 per cent of your hatch you had better stop an 1 sell your eggs. 


\section{CHAPTER XIX}

\section{Colds and Roup}

Of all the diseases that poultrymen have to contend with there is none so prevalent ascolds and roup and they are therefore the most dreaded. Owing to the very sudden changes of weather in nearly all parts of our country colds and roup seem to grow more prevalent each season. The most dangerous form of roup is canker accompanied with swelled eves whicl. fill with a white cheesy substance and means a blind eye in nearly every case. This particular disease is very contagious therefore a chicken that has a sore eye should be re. moved at once from the flock and in many cases it is the wise thing to kill and bury or burn the first case seen of this kind. The treatment should begin at the time they are hatched for this is a germ disease. Spray your brooders with Crel Oll before you put your hatch in and spray once a week there:fter, as long as chicks are in brooder. Their quarters after this should be sprayed twice a month until fully grown and once a month when grown. All chicks hatched in March and April should never get a cold or trace of roup treated this way unless you are breeding from old stock that have had it; or unless your chicks are in very damp quarters or roost in drafts. This Crel Oll also kills all lice and mites. Colds and roup often gets a start from mites during hot weather of summer. Mites multiply very fast in hot weather and they so weaken the chick that in their weakened condition they take cold very easily. If roup gets a good start spray every night with Crel Oll and put I-2 teaspoonful to I gallon of this in their drinking water. This will cure the worst cases in a short time. Many a plant has been put out of business by roup, so let me warn you to watch your birds closely and do not let it get a start. Late hatched chicks are very susceptible to this disesae and, therefore, require close watching.
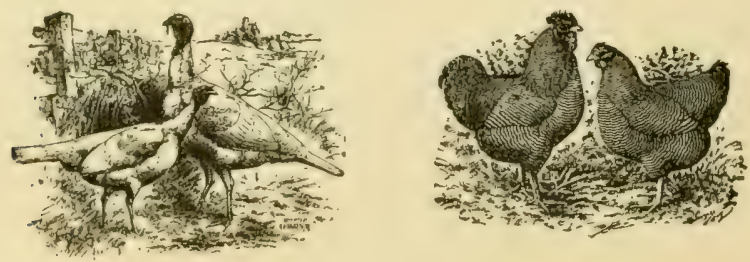


\section{CHAP'IER XX}

\section{Caring for a Plant where Wheat or Screenings Cannot be Bought}

I want to lay down here a system of feeding for those who live in sections of the country where wheat screenings cannot be bought and where wheat is so high it cannot be used at a profit and where oats are so scarce and high in price that they cannot be used. In places of this kind I advise hopper feeding of dry mash entirely. This should be made up of the various ground grains that you can get the cheapest, using I-4 to I-3 wheat bran if it can he had. You will have to use your own judgment as a rule in the making cf this mash. I would not hopper feed any kind of whole grain but feed this rather in the litter mornings. Barley or buckwheat or Kaffir corn whichever is clieapest is good. At night feed corn; also if possilule keep beef scraps before them at all times. You are bound to get a big egg yield under such a system of fecding, especially if you can process some kind of grain, if not oats, try barley or buckwhear w Kaffir corn. If you can get a grain to process, feed this processed grain once a day with a little salt on and if you have a plenty of it feed it twice daily. Remember oats is the best of all grains if you can get it. This system is especially adapted for those who live in some parts of California as well as Florida and other remote Southern points.

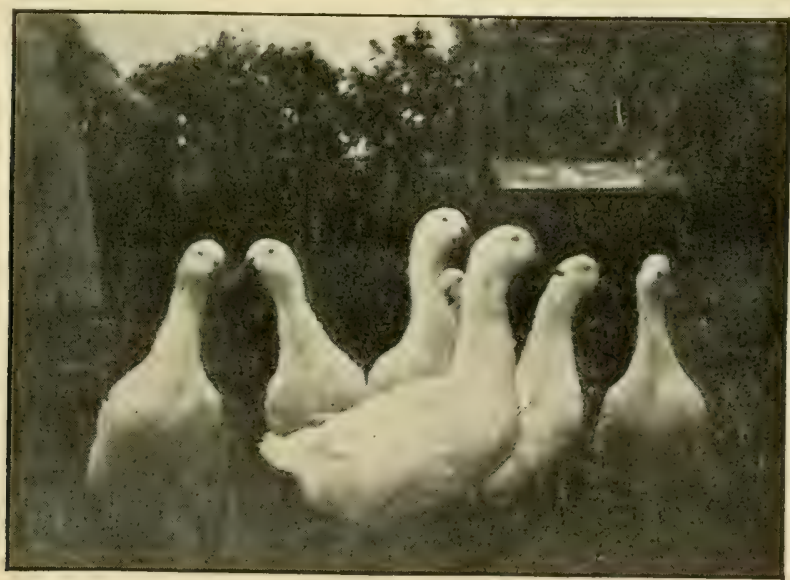

A FLOCK OF HANDSOME PEKIN DÜCKS 


\section{CHAPTER XXI}

\section{When and How to Start in the Poultry Business}

Now comes the important consideration, when to start, and how. In either case you should start in the fall, especially if you wish to start on a large scale, for your buildings should be put up in the fall even if you start by buying eggs and plan to raise your own breeders. This is by far the cheapest way to start if you do not have much capital. Get your incubator house ready in the fall, providing you have not a house cellar, which will answer the purpose temporarily.

You can arrange for your brooders in the spring, but cannot start so early as where you have a brooder-house as out of door brooders will be necessary in this case which cost more. Regular out-door brooders can be used out of doors very early in the spring any time after March Ist, as a rule. Pullets hatched the middle of March should lay in Aug. under my system of feeding, and keep right at it from then on. All the eggs desired can be purchased from reliable parties ot either Single-Comb White Leghorns or White Wyandottes, produced under my system of feeding at $\$ 5$ per one hundred in any quantity on short notice-eggs that will run 90 per cent fertile right in Jantuary. For those who are well fixed, financially, I advise starting in the fall. To such I advise putting up the laying-houses during July and August buying pullets as early as possible during the fall. October and November are usually the two best months as they can be bought cheaper than at any other time of the year.

You should have no trouble to buy all the pullets and yearling hens you want particularly Single-Comb White Leghorns during these two months at \$I. to \$I.50 each. This is a very satisfactory way to start, but not so cheap as buying the eggs and raising your own stock .

Avoid buying eggs of a breeder who feeds mash if you wish to get good hatches and produce chicks that will live, because when an entirely inexperienced man tries to raise them they must be from hardy stock.

You do not have to wait many months for profit when you buy eggs to start with, as you can market your cockerels for broilers at a profit In three months from the time you set your machines you can count on quite an income, so all things considered, with the experience you get, I advise starting in the spring by buying your eggs and raising your own breeders. 
Your chicks can be raised very cheaply under my new system, giving them all the processed oats they will eat twice a day, in connection with a good chick food kept before them all the time, as well as grit, charcoal, and beef scraps.

Your brooders should be cleaned out at least once a week which I find answers every purpose. Also keep your brooder part of the house, where chicks are fed, covered with cut clover, they eat much of this, and it is very beneficial to them.

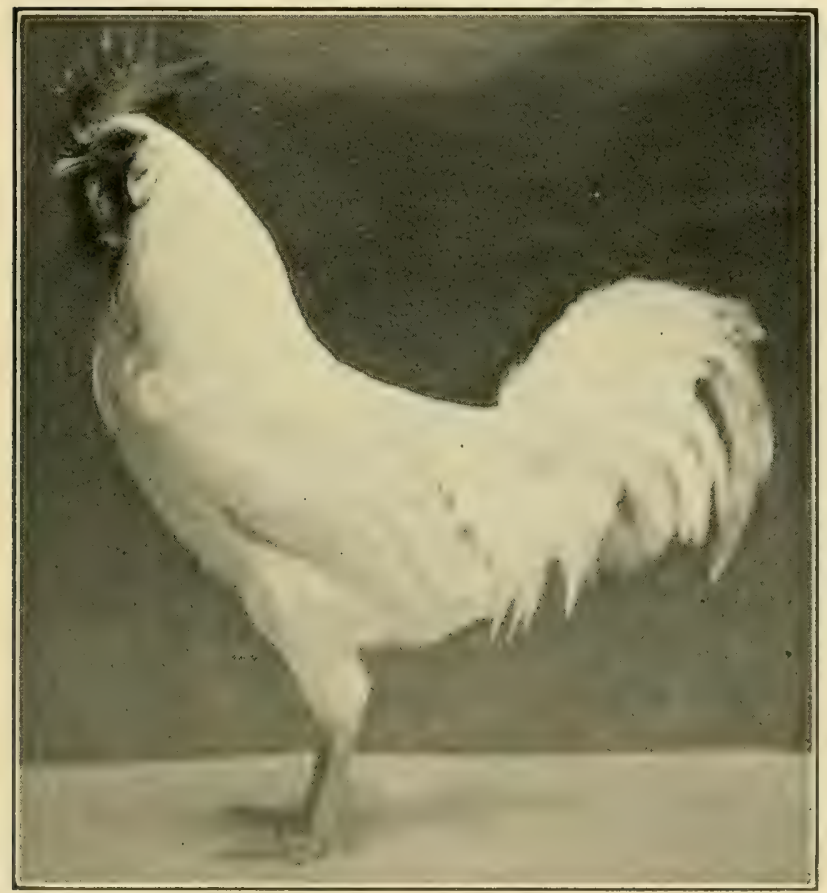

TYPICAL S. C. WHITE LEGHORN COCK 


\section{CHAPTER XXII}

\section{A Leghorn Plant for Profit}

I will tell you here what a Combination Leghorn Plant ran be made to do, and how to run such a plant for the greatest possible profit.

First of all your great aim must be the production of eggs and for at least six months in the year you must feed to produce not only eggs that will hatch but produce eggs that will hatch chickens, that will live. If you feed properly and advertise eggs for hatching, actually producing fertile eggs that wil! hatch strong, healthy chicks, that will live if given half a chance, offering to replace all clear eggs free if returned, express prepaid, I am positive a man with three thousand layers can clear from $\$ 8,000$ to $\$ 10,000$ a year, providing he feeds them on my free range system.

You should sell your eggs during the hatching season for $\$ 6.00$ per IO), or $\$ 50$ per I,0jo. Possibly you could make more money by selling them for $\$ 5$ per IOO in any quantity making no reduction for quantity. $\$ 5$ per 100 is the popular price for good hatching eggs in this country. There is a grand profit in it at this price when you produce them in such làge numbers at so small a cost.

You must not feed a bit of wet mash. I will lay down here the ideal way to feed for fertile eggs at a small cost either a yarded or free-range plant for Leghorns only.

Beginning in December, the first thing in the morning as soon as it is light, give your hens a light feeding of buckwheat or barley in the litter; about I I-2 quarts for 60 or 75 is plenty. Give warm water to drink as early as convenient, and at 9 a. m. give each flock all the processed oats they will eat. At I p. m., give your flock more water, or put in warm water with what they have. Give on this trip a light feeding of green cut bone-a quart to a flock of sixty, if they will eat that much, if not, cut then down to a pint.

About $3 \mathrm{p}$. m. give another feeding of processed oats, all they will eat. Remember, these only cost Io to I $5 \mathrm{c}$ a bushel.

Before dark give not over I to I I-2 quarts of cracked corn to a flock, and gather your eggs. If it is very cold weather, you will also have to gather your eggs on your I o'clock trip.

These hirds must have. 'ways before them grit, oyster shells, and charcoal. Also a hopper of beef scraps and one of wheat screenings or wheat. 
Just a word about mating up your breeders to produce chickens that should be healthy.

Mate all your yearling hens with cockerels, not less than ten months old. Put these birds on a free-range systam, and feed as I have heretofore directed.

Pullets hatched in February and March, mated to good vigorous yearling cocks, will also produce chickens that are very hardy and you should have no trouble in raising 90 to 95 per cent of these chicks.

Under no circumstances use anything but a single-comb White Leghorn for the greatest profit, because they lay the largest egg, and are by far the most popular of the Leghorn family.

To dispose of your breeders to the best advantage during August and September, you should make a great clearance sale at $\$ \mathbf{I}$ each. You will have no trouble in disposing of all surplus stock at this price, and you will find this far preferable to putting them in the market.

Care for your plant during the summer as I have instructed for summer care and feeding in another chapter.

I advise four cocks or cockerels for every sixty to seventy-five layers. These birds should be so mated that there will be no fighting among them, and no "boss," as a rule.

After the breeding season is over, say July, you should remove nearly all your male birds and make one flock of them except a few pens, which it would be well to keep mated the season through, so you can always fill a stray order for hatching eggs.

Your cockerels should also be separated from the pullets anr, placed in one large fock, or several flocks of one hundred or so in a flock. In this way the male birds run together very peaceably and rarely ever fight, and you rarely ever see a "boss" among them.

In mating these up, just take out of the bunch as many as you want for a flock of females, all at once, and let them go. You will then have no fighting, and very seldom even a "boss." This is the only way to mate up your birds for the best possible results.

Never keep a brassy male bird. Have nothing but pure white birds on your place, as you will find your profits can be greatly increased by gradualiy breeding into fancy birds.

Show a few at your fall fairs or local shows. Get a Standard and study it. By careful selection you can soon have a plant of very fine birds. 
Advertise your stock in one or more of the leading poultry journals and keep your advertisement regularly before the public.

Do not try to show at the big shows, such as Madison Square Garden, or Boston at first, for it takes years to win at such shows as these.

If the houses I have given you the plans for in this book are not warm enough for your location, you can build them six feet at the eaves instead of four by using a twelve-foot board sawed in half. Put a loft-floor in at the eaves and fill the top with straw. Do not put on a tight loft-floor; a floor of poles would work all right. You should also line the sides in the same way, and you will have a very warm house, where you could get eggs in any kind of weather.

I want to say right here that Leghorn plants are the only ones up to the present time that have made money in a market way. Eggs for market, at market prices, have made many of them rich.

All who have tried the larger breeds, have failed at it in a market way, so they have all had to go into the fancy, or give it up entirely.

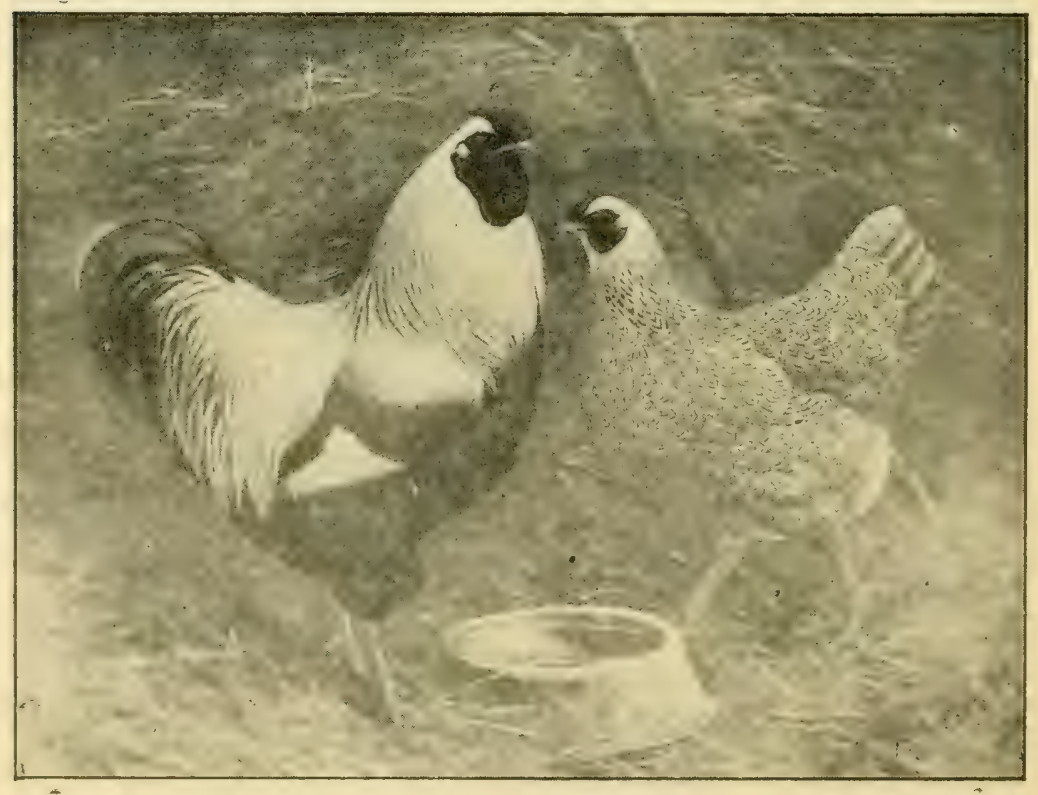

A PAIR OF PRIZE WINNING SILVER LACED WYANDOTTES 


\section{CHAPTER XXIII}

\section{A White Wyandotte Plant for Profit}

I have bred White Wyandottes all my life, that is for the past eighteen years and exhibited them every year. I have seen them lead all the large breeds in popularity, and the demand for them increases yearly. I know of no variety among the large fowls that it is such hard work to get good fertila eggs from that will hatch strong chicks, that are bound to live, as it is from the White Wyandotte that have been bred for exhibition purposes in yarded plants.

In breeding exhibition stock every trace of creaminess or brassiness had to be bred out of them, and their vigor or vitality has gone with it to a large extent. breed.

Inbreeding has done much to injure the vitality of this

My aim here is to tell you how to feed and care for White Wyandottes so you can get them hardy and full of vigor without breeding out their fine qualities-and this can be done by feeding' alone.

I have experimented very carefully along this line and I find all large breeds should be fed quite different from the small breeds.

First of all they should never eat corn in any form-that is, the breeding stock. If any corn it must be very limited quantities.

I find they will stand the hopper feeding and give grand results. In fact, this is the only natural way of feeding any fowl, and the only safe way of feeding.

First of all provide a hopper of beef scrap and wheat screenings; also grit, oyster shells, and cliarcoal. The first thing in the morning give a light feeding of barley or buckwheat in litter to induce all the exercise you can.

At $9 \mathrm{a} . \mathrm{m}$. give all the processed oats they will eat.

At I p. m. a light feeding of green cut bone, a pint to a quart for sixty layers.

At $3 \mathrm{p} . \mathrm{m}$. all the processed oats they will eat again.

At $4 \mathrm{f} . \mathrm{m}$. or later, according to the time of year, another feeding of oats, mprocessed. This should be fed to all large breeds in place of cracked corn.

Always use clipped oats, and feed in the litter, and you will not only get an abundance of eggs, but eggs that will hatch strong healthy chicks that will live. Such eggs will run from 80 to 90 per cent fertile right in the winter months. 
I am not guessing at this, for I am doing it right in February.

Do not be afraid of the processed oats, but give all they will possilly eat for they are very light and it is impossible to over-feed on them. There is nothing I have ever tried that will make hens lay equal to them, and nothing so cheap. It costs only about half to feed this way.

You can always sell any amount of eggs for hatching at $\$ 5$ per one hundred from Wyandottes.

I am positive you could sell all a three thousand laying plant can produce for hatching by a liberal amount of advertising along the same lines as I told you how to advertise Leghorn eggs.

You can sell a large quantity of breeders for good prices, if you start with fairly good stock and exhibit at the small shuws on the start.

One thing you have to contend with on a Wyandotte plant, that you do not have to contend with on a Leghorn plant, and that is setters. This means quite some work, but you will not have nearly the amount of setters on a plant feo as I have directed.

To properly break up a setter, they should not be allowed to remain on the nest the first night, and as a rule three days will break them up. Or, if you want to break a setter up in twenty-four hours, just put her with a bunch of surplus cockerels, where a roost is handy and your hen will not think of setting.

There is no breed at the present time more handsome than the White Wyandotte, when bred for show purposes, and no fowl that makes so fine a broiler and roaster when they are grown up healthy and rugged, that is, nature's way, and this can be done easily on the feeding I have outlined for my free-range system. You can get eggs right in January that will run from 80 to 90 per cent fertile and give you grand hatches of strong, rugged chicks that can be easily raised in the winter-and you will have no trouble at all to dispose of hundreds of laying pullets during Septamber, Octoler and November at $\$ 2$ each. There is a grand profit rasing at this price, when you can raise 90 per cent and more of all the chicks you hatch, and raise them largely on a feed that costs you only IO to I5 cents a bushel. You can easily see what a piofit you can make by running a laige plant of White Wyandottes my way.

Smallness of your feed bills will surprise you,

I am positive $\$ 8,000$ a year can easily be made from a plant of three thousand White Wyandotte layers, and even 
mcre when you work into high-class show birds and get $\$ 3$ to $\$ 5$ a setting for many of your eggs.

Sell high-class birds from $\$$ Io each up to as high as $\$$ Ioo It can be done by pluck and perseverence.

A White Wyandotte plant of three thousand layers will tuir $n$ in a greater profit than the same number of any other breed fed and run my way, which is nature's way, provicling it is handled by a White Wyandotte fancier who thoroughly krows the value of his birds.

The system that has been described above for the care and feeding of White Wyandottes will be found to be correspundingly practicable for other large breeds of fowls, and should be followed with the same accuracy.

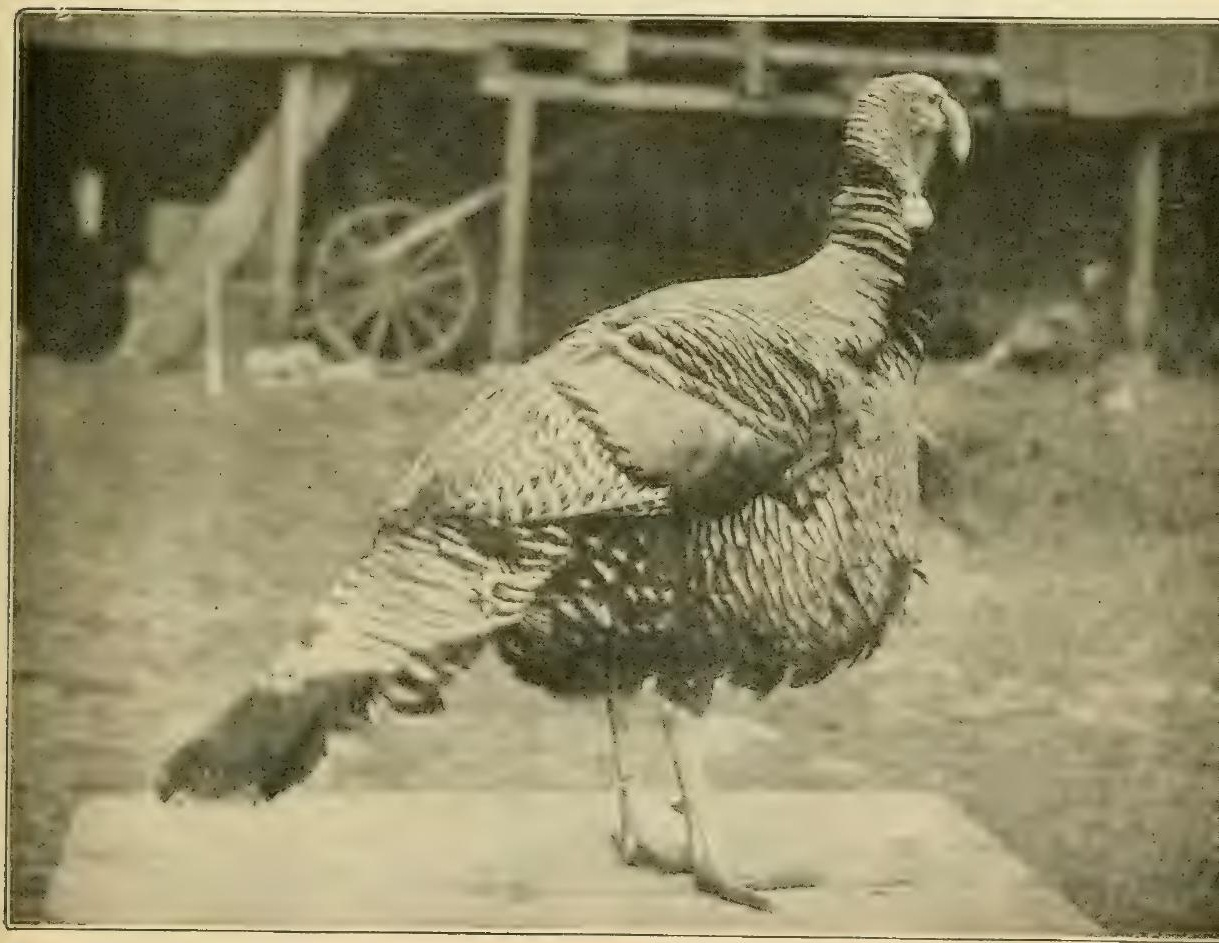

A 'TURKEY PRODUCED AF'TER THE BRIGGS SYSTEM 


\section{CHAPTER XXIV}

\section{Combination. Plant for Profit-Fruit, Poultry and Bees}

I feel that I must write a chapter on a combined plant for the benefit of those who want to go in either on a small or large scale, combining poultry, fruit and bees.

There is no combination that I know of, that is more profitable, and at the same time will give so much pleasure in various ways than this. First of all, every poultry plant should be well set out to fruit. This is one of the very first things you should do to provide your poultry with shade and a peach tree is one of the best fruit trees for poultrymen, as it gives the quickest shade of them and the fruit finds ready sale at good prices. Then the plum and the apple, cherry, pears and grapes come next in value. You are buund to get an immense crop of fruit where you cultivate your ground, and use your poultry manure around your trees. You should plant liberally of all kinds of fruit, and you will find life worth the living.

You want bees to fertilize your blossoms, so you will get laige crops of fruit, and bees for the honey are very profitabic and afford a great amount of pleasure. They often turn in a greater amount of profit, time and capital taken into consideration, than anything I know of. I have cleared as high as $\$ 25$ from a single hive in a season with but little labor. You need to give them 110 attention to speak of from October I to May i. For only two months, May and June, do they need any great amount of attention.

I advise every one who keeps poultry to have a combined plant-poultry, fruit and bees.

There will be years when your profit from fruit alone will not only give you a good living, but will give you a good, fat bank account as well as furnishing the fanily what fruit is needed 'îhink of eating peaches for instance irom the ist of July until November, it makes ones mouth water. This can be done, if you will plant several kinds from the earliest to the latest. Fou can also have all kinds of apples, plums. cherries, and other fruit in the same way, grown at no experse, (m your puultry farm and one should enjoy life under such circumstances. 


\section{CHAPTER XXV}

\section{Loss of Breeders during Heruvy Laying Season}

I want to devote a little time to the discussion under this head of the matter of heary loss of hens during the heavy laying season, during March, April and May principally. This applies largely to Leghorns as they are the phenomenal layers during these three months and the loss of birds from heavy laying is usually very heavy. The Rhode Island Experiment Station lost nearly $34 \%$ of their Leghorns in one year. 'This information will surprise and startle many, but all poultrymen who keep stock in large numbers know the loss is very heavy. This great loss is caused by such heavy laying as to weaken the bird. They droop two or three days and die. I have been making a study of this trouble in order to find out how to avoid the loss and from careful experimenting I am now satisfied beyond a doubt that this trouble primarily is a rerm disease which gets a stronger hold on a hen when she is weakened from heavy laying and as a result she dies in two or three days. I have also found that nearly all the loss of poultry is caused by germ disease, therefore the only cure is to destroy these germs. For this I have found nothing equal to Crel Oll. The roosts and dropping boards if used should be spraved with this every week, sure from January ist on for six months or until the heavy laying season is over. Spray just before hens go to roost. If you follow this up closely you will not only get many more eggs but your loss in hens will be nothing to speak of. You will get $\$$ Ioo in return for every $\$ 25$ spent in Crel Oll. It is also a sure cure for gapes in young chickens. You should always have a supply on hand.

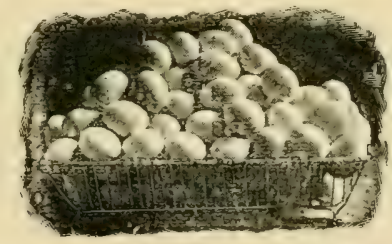




\section{CHAPTER XXVI}

\section{Molting}

Molting is an important consideration especially on a yarded plant, but on a free-range plant I believe in keeping them laying right through the molt. As a rule, when a lien practically lias an entire new coat she will in most cases stop laying and take a rest. A hen must have a rest and time to build up. On a free-range plant, if you continue your harrowingr and sowing oats you can keep your birds laying pretty well all through without reducing their vitality. During Octcher and November, they will drop off and have the rest; then you should have your pullets under full head if you are in the masket egg business. But if you depend on selling eggs for hatching, then I advise you to let your hens have a rest during November and December, and get them under ful. leadway again in January, yo's will then te able to produce eggs that will hatch, and with other things favorable, your eggs should run 90 to 95 percent fertile from Jaruary I on, and hatch equal to eggs laid in March and April, providing your hens are fed under my system.

In caring for a yarded plant, you will find your hens will slack off laying during July and August, and during September, Cctober and Novenber you will get but few eggs from the large breeds, as a rule. All things consiclered, and in order to get your stock in the best possible condition for winter eggs, I advise kreping your hens on nothing but processed oats and beef scraps during this period, for this will put them through the earliest molt of anything. I have ever tried. The oats should contain sprouts one-half inch long. You will also lie surprised at the amount of eggs you will get even during this period.

December Ist put before them their hoppers of wheat screenings or cheap wheat and to every pail of processed oats add one teaspoonful of cayenne pepper and one of salt, which will make your hens very thirsty, and the more water they drink the more eggs they will lay. Your hens will respond to this treatment and surprise you on eggs and should lay as wall during January as any month in the year. Use the cayenne pepper during December, January and February only. 


\section{CHAPTER XXVII}

\section{Feeding and Selection of Large Breeds Important}

Those who have a love for certain large breeds and wish to kecp them, even if their profits are not so large, I desire now to particularly address. Many of those who have read the preceding pages of this book may get the impression there is no profit in any other breeds except the ones I have strongly advised. I do not want any one to think this, for any one with Fush and advertising can boom any breed to a certain extent, but this takes money. I will name some of the most important large breeds for which there is a good demand and money in. Barred and White Plymouth Rocks, Buff Orpingtons; also White and Black Orpingtons; Columbian Wyandottes and the very popular and valuable Rhode Island Reds, the great winter layers, and for broilers their eggs have a great sale. Two of the handsomest of the large breeds, which are now much neglected, are the Buff Wyandottes and Buff Plymouth Rocks. They are great layers, and it remains for some good fancier to again bring them to the front. There is money in any of the breeds I have named, as well as others. Ail iarge breeds need free-range to do their best, as they do not stand confinement nearly as well as the Leghorns, I find. For those favorably located on farms and who can raise crops, the ideal way of feeding all large breeds during winter for the most eggs and for yarded plants the year round is as follows: By introduction, I may say, however, that this same system can be applied to Leghorns with wonderful results. It will produce the most fertile eggs of any system in existence, no matter what anyone tells you. Now, instead of hopper feedins, you must raise a piece of wheat, or barley and oats, and when ripe cut it and bind it in sheaves and put it in your barn. Do not thresh it; but in November begin to give it to your hens in the sheaf and let them thresh it. Give a sheaf the first thing in the morning, and 9 or $10 \mathrm{a}$. m. give a feeding of processed oats, and if they need more grain, depending on the size of your flock, you can give another small sheaf at noon, or give a light feeding of cracked corn in the straw, and at $3: 30$ to $4 \mathrm{p} . \mathrm{m}$. give another feeding of processed oats with some "Egg-maker" mixed in with them according to directions that come with it, and you will never fail to get an abundance of eggs; at the same time your birds will be in the pink of condition and the eggs produced under these conditions will not only give you wonderful hatches of chicks, but chicks that 
will live and grow with half a chance. You will see that in this special case I have cut out beef scraps, for good beef scraps are very high and sometimes hard to get, therefore, I have replaced it with the "Egg-maker," which I have been carefully experimenting with and it has given me excellent results during winter months and kept tha birds in the pink of condition. This can also be mixed with processed oats for little chicks with grand results. Fresh cut bone, three times a week, is excellent where you can conreniently get it during hatching season, but is not absolutely necessary. Always keep dry mash before them made by my formula.

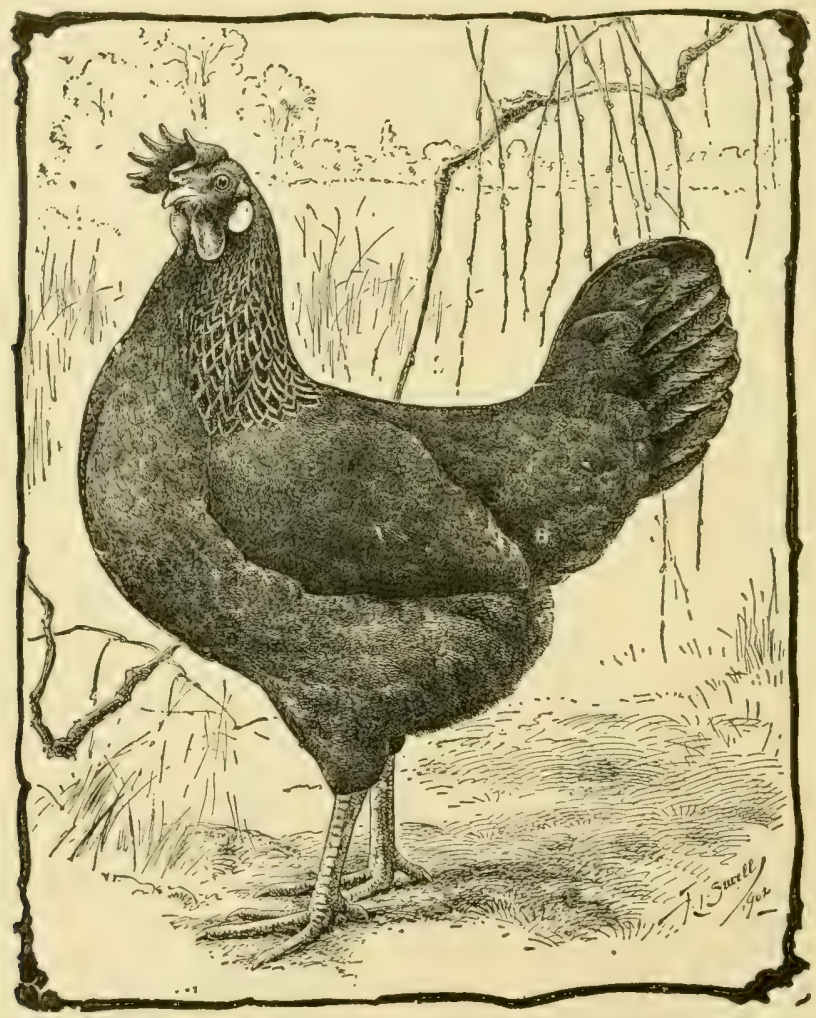

A PRIZE WINNING BLACK MINORCA HEN 


\section{CHAPTER XXVIII}

\section{To Erect a Iarded Plunt}

First you will want a good laying house, and in order to house a large number of birds at the least possible expense and economize in labor, I advise a plain house without an alleyway, one about 80 feet long, for in a house without an alleyway you must open all the doors in passing through. 1 would divide this house into eight pens, Io by I5 feet. The corner dimensions for the house I5 feet wide, so feet long, 7 feet high in front and 5 feet in rear: with one fair sized window in each department about two feet from the ground. Fit your windows loose and slide up to roof. Make holes for letting hens out under the window, fitting wooden slides very loose to slide sideways so you can open and shut them with your foot. Put in wire netting partitions every ten feet and hang your doors one foot from front of house with spring hinges, and have them all swing one way, then you can walk right through the house and your doors will always close themselves behind you. In making the partitions you should always rutı a ten inch board across at bottom and the doors should swing over this. You can also fit a pan on shelf over this board, between partitions, part in one pen and part in the other, and in this way water two flocks at once. The nests can go on one side and the feed hoppers on the other. This house should be filled in with at least six inches of sand and then it will always be dry. Dropping boards can be placed on back side of the house; a platform three feet wide is about right. Place three roosts over it ten inches apart, all on a level, one foot from platform is about right. You can keep thirty Leghorn layers and two male birds to a pen nicely in such a house as this or if larger bi1ds, twenty-four females and two male nirds. These should have yards 50 to I 50 feet long the longer the better and these yards should at once be set out to peach or plum trees for shade, and cultivated about several times during the summer, if possible.

You will need a feed-house handy by for feed. You can use your own judgment in building this; size will depend largely on size of plant. I advise a board floor in this and vou can put bins in and also leave a part tor a picking or dressing room.

A good brooder-house is the next thing needed. The length of this will depend upon the size of the plant you are 
to build or the amount of room you have at your disposal. It is always best to build larger than you need. I advise a house fully I 5 feet wide; and I would raise it one foot from ground on posts and put in a board floor. Would also board this one foot space up with rough boards. I would build this hot:se 7 feet high at the north side, and 4 I-2 feet at the south side, using a single pitch roof. Put along north side a 3 foot alleyway, and cut your house up into 6-foot pens. These will be 6 by 9 about, outside of hover, and each pen will accommodate one hundred chickens. Leave one foot only between hover and alleyway. You will need a window in each department; hang it at bottom so it will open inside. Also put some ventilators along north side of house, every ten feet. Just fit in a board 3 inches wide 3 feet long, put on hinges and let it open inside of house, and you will find these ventilators very fine in hot weather. You will need a slide in every pen in house, so you can move chicks from one end of house to the other. You should use a ten-inch board to divide all your pens from this board up you can use wire net ting a foot of one inch mesh netting first, and from this to roof use two-inch mesh. If you breed Leghorns you will need to have the house wired to the roof. Of course, you must have a gate from alleyway into every pen. A brooder-house like this comes in very handy on a free-range plant for raising chicks during February and March as you can never get out too many early chicks. You will also need several colony houses in yards to grow up your young stock in. A little house, 5 by Io, will accommodate sixty to seventy-five nicely until they are large encugh to move to your laying houses, and the oftener you can plow these yards and sow with oats the faster your chicks will grow. If you have kept them growing without a set back your most forward pullets should be laying at four months of age.

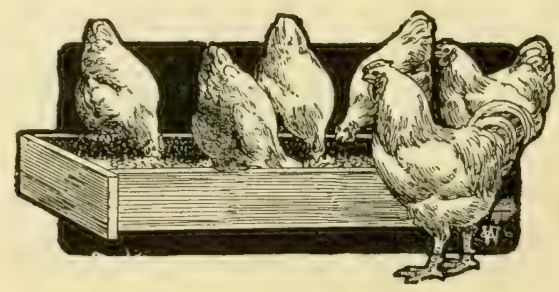




\section{CHAPTER XXIX}

Fireless Brooders, Trick of the Trade, Etc.

Fireless brooders we read so much about, which are reputed to do such wonderful things, are in my opinion an uncertain quantity. I want to say right here that very few, in my opinion, ever meet with success who try them. I sent $\$ 3$ to the manufacturer of these brooders to experiment with and must confess it was a failure with me. The brooder I tell you how to make in another connection at a cost of only $\$ 2.50$ to $\$ 3.00$, cannot be beaten, at any price, and your chicks can remain in them until they can go without heat. You will also see advertised a trick of the trade which among other things helps chicks out of the shell, that is those that cannot hatch out or do not pip. My experience is that if your eggs are produced under natural conditions and you use a good incubator you will have no chicks to pick out of the shell. A chick not able to get out without help is of hut little value. \$I500 from 60 hens in a year is another claim. This can only be done by using fancy stock and at the end of the year you put a fancy value on all stock on hand valueing your birds from $\$ 5$ to $\$ 50$ each, but if you turn these birds into cash you will find yourself several hundred dollars short. My system described in this book is the greatest labor saving system known at the present time, many plants in various parts of the country are now going up or being operated under my system which proves its great superiority over any other system known. My sales from Iooo layers during I909 will exceed $\$ 5,000$ and these sales were eggs sent to market, eggs for hatching at $\$ 5$ per Ioo, baby chicks at $\$$ Io - per IOO, cockerels as broilers and hens for breeders at \$I each which were replaced by me with pullets for my own use. No stock at fancy prices is figured in this calculation. And all the labor on my plant including the raising of 2,000 youngsters was performed by myself and one helper and in addition the crops on 60 acre farm were cared for beside including 5 acres of oats, 3 acres of wheat and 2 acres of potatoes, gathering of the hay crop, caring for the garden, lawn, etc. So you can see the amount of work that can be done with little relp under my system. 


\section{CHAPTER XXX}

\section{Duck Culture}

Believing that this book may fall in the hands of many who raise a few duclis, and possibly in the hands of some who raise thousands annually, and as I have raised from five to ten thousand yearly for many years very successfully, and am able to raise nearly every duck hatched that has strength cnough to eat and drink, I will tell how I do it. The breeding stock is the foundation of success in the duck business. Your breeders in every case must be young ducks.

Never keep an old duck over the second year, for they will not lay before February, as a rule, while young ducks start in December, if properly fed and housed. I prefer brceders hatched in April to any other month, as they get fully matured early in the fall and are hatched from our strongest eggs.

All breeders should be hatched from April $\mathrm{r}_{5}$ to May I5. Such ducks should begin to lay in December.

Your breeding ducks can be kept on very little feed during September and October, but do not let them get too poor, for if you do you may loose some.

If you are on a farm give them range and but little feed. A mash of wheat bran and gluten meal, equal parts, makes a very cheap feed to summer them on.

About November I you must begin to feed them heavier and house them, if you wish to get early eggs. This is where the profit comes in. Give a mash, morning and night from November I on as follows: One part bran, on part middlings, one part corn meal, one part clover, 5 per cent leef scraps, 2 per cent grit and oyster shells. Give all they will eat of this night and morning, and keep water by them if they do not have a pond. Also give them water in their houses at night. A butter tub, sawed down, makes a handy thing for this purpose.

About December I, increase your beef scrap gradually from 5 per cent to 10 per cent and lift your ducks occasionally by the neck and see how they are in flesh. Do not let them get too fat to begin to lay in December and in January. If they do not gain much, and are thin in flesh, gradually increase your corn-meal and add some whole corn and whole wheat. The more they gain on eggs the heavier feed they must have to keep them in good flesh. A good Pekin duck 
should lay from seventy-five to one hundred eggs without stopping. Give plenty of oyster shells and grit. It requires great judgment in feeding a flock of ducks to get the most eggs and to have them run good and fertile. I have seen flocks of breeders knocked out for the whole season by getting them too fat before they got to laying good. Tour breeders for best results should be mated up at the ratio of one drake to five ducks. The eggs from such a mating should run fully 90 per cent fertile from March 20 on, if they do not, as a rule you will find your breeders are too fat.

If you keep ducks for the greatest possible profit you will find none to equal the Pekins as layers, and quick growers. They stand close confinement, and head the list of market ducks.

In hatching duck eggs I find a temperature of IO2 I-2 plenty high for good results, and you will get much better hatches in warm weather by airing your eggs both morning and night.

When they hatch put them in your brooder and give warm water to drink. Watch them closely for two days and teach them to go where the heat is, and after that you wili have no further trouble. Give them warm water to drink for first two weeks, sure, for cold water will give them cramps, which quickly kills them, and if they do not die it will so stunt them that they will never get over it.

I have at last found a perfect feed for young ducks when first hatched and that is a well known patent chick feed. I pour hot water on it, which increases the bulk about one-half; when cool, feed and you will find every duck that can be raised, or better every duck that has strength to eat, will live on this feed, and they grow very rapidly on it too. In fact, they could be raised to market size on it, but it would not pay as the feed is too high priced; but it pays well to start them on it, for they eat but little the first two weeks. I would not be without it in raising ducks.

After the ducklings are two weeks old you can gradually change them onto a mash made as follows: One part of wheat bran, one part middlings, two parts corn meal, io per cent. beef scraps, a little grit. They grow very rapidly on this. Twenty per cent of green feed can be added with grand results. After the serenth week double up your corn-meal and increase your beef scraps to $\mathrm{r} 5$ per cent and if you have the large kind of Pekins they should be ready for market on this feed at nine weeks of age, and fully 80 per cent of your flock should average five pounds each, dressed weight, many will go over this weight. 
'This chick feed will cost you $\$ 6$ per hunded, and even at this price it is the cheapest thing I know of for starting young ducks, for every one lives on it that is fit to leave the incubator. It is the natural duck feed, although not generally known.

In dressing ducks for market hang them in pairs on a line, and stick in roof of mouth with a sharp knife, and at the same time hit them a solid blow on top of the head, and pull cut their main tail feathers and wing feathers, except flight feathers or plainer feathers on last or outside joint of wing. Soon as dead take them down, wash out mouth, and take them by the head, two at a time, and dip them in a kettle of boiling water until feathers come off easy. You will quickly learn this with little practice. Have a pail of cold water ready to wet your fingers, and take the feathers from the breast first, and then turn over and remove the rest, taking all large feathers off. They are then laid on a shelf for a "finisher," who generally gets 3 cents each. The finisher cleans them up. Then they go into tubs of cold water and later into a barrel of ice water, from which they are packea in barrels and heavily iced and shipped to market.

As soon as your breeders are done laying, about July I, they should be sent to market alive. You will never get more profit out of them as a rule.

You can also make a fine profit selling duck eggs for hatching at $\$ 8$ per hundred. A duck plant surely can make a fine profit if handled right, as sickness and lice are not known in the dluck business. Duck eggs do not hatch nearly as well as hen eggs in incubators as a rule, but you have no loss after they are hatched if handled right.

I have carefully experimented with processed oats for ducks during 1907, and find this a wonderful feed for young ducks. After they are two weeks old give all they will eat twice daily, say Io a. m., also 3 p. m., and you will find them the greatest growing feed ever fed to a duck, also greatly reduces the feed bill, and your young will be ready for market fully one week sooner They are also a fine feed for old ducks, and will greatly increase the egg yield. Give the old breeders all they will possibly take noons. And if they do not run on grass, give them all the processed oats they will eat twice a day, about I I a. $\mathrm{m}$. and $3 \mathrm{p}$. m., it will not only produce a larger number of eggs, but more fertile. Always select your largest, finest ducks for breeders.

In case your young ducks are in very small yards and do not get sufficient exercise, and begin to go back or have bowel trouble on the chick feed, then you can mix 
bran with it, also stale bread, soaked in water, say equal parts of each, and feed every other feeding on this until you cliange their feed, after two weeks of age, and you should have no further trouble. You must remember one thing that in going in the duck business it means lots of hard work and is no business for a lazy man. But if you live near a goodsized city and can work up a good, private trade for your young ducks among private families, markets, and hotels, and not have to depend on the commission man, you will find a fine profit in ducks.
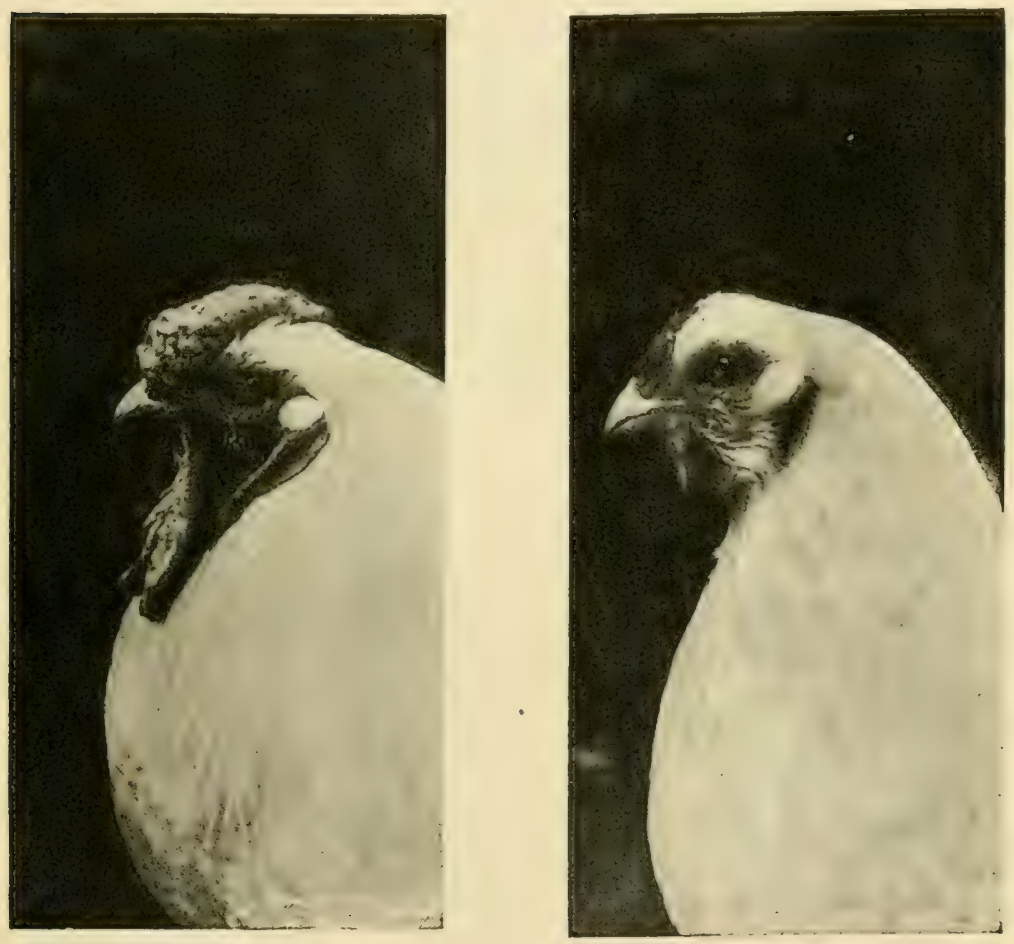

TYPICAL HEADS OF MALE AND FEMAIE WHITE WYANDOTTES 


\section{CHAPTER XXXI}

\section{Summary.}

All oats will not grow satisfactorily, and if you get some that will not nearly all grow, try another lot of another dealer, for when they grow satisfactory you will have a complete mass of roots and sprouts, which should be I to I I-2 inches long.

Have several larg: lots of oats growing for a large plant and do not get out of them, for this is your main feed for producing eggs and growing chicks. There is nothing like it. Give them all ther will eat twice each day, as they will live and grow on this as they will on nothing else. It forms fully 60 per cent of their rations after they are a week old.

If you fail to make the success you expect under this system, write me, enclosing stamp, and I will straighten you out, for you cannot go wrong if you follow my instructions to the letter.

If your little chicks are on board floors you should clean their pens out every four days sure, and put the leavings in runs of your old hens. They will clean up all the seeds and oats not eaten by chicks. Cover your floor lightly with clover. There is nothing as good.

Your Leghorn pullets should lay at five months of age, if you have fed and cared for them as laid down in this book. If they do not, you have failed to carry out some important part, or your stock is not the laying kind.

A poor memory is a bad thing for a poultry man, and will put you out of business. By all means put your memory in your business. Nothing can be neglected or forgotten if you wish certain success.

Trap and poison all rats during the fall and early winter, for you cannot raise rats and chicks on the same plant. 
Hopper feed only wheat, such as a good grade of screening or a cheap grade of wheat. Do not hopper feed grain of any other kind and then wonder why you are not getting results.

Remember you cannot get a hen laying in a day or two. It takes from two to five weeks, depending on the condition of the hen and the time of the year. So, for big results, do not neglect your hen and let her stop laying.

Do not neglect your houses and let them get full of mites and lice. Go over your roosts at least once a month during summer with crude oil and carbolic acid, half and half-or a good lice exterminator. Also clean droppings from board floors once a week sure at all times of the year, for lice multiply very rapidly in droppings in the summer time on board floors. On the ground it is different.

In order to get the greatest egg-yield always add some salt to your processed oats daily the year around, not less than a teaspoonful to a ten-quart pailful of feed, for the greater amount of water a hen drinks the more eggs she will lay.

In hot weather keep your oats well wet down with cold water so they will not spoil; wet them thoroughly twice daily if necessary. Never wet them before faeding. Any common feading oats will grow just as fast as high priced and if you want them at any time for green feed only, let sprouts get I I-2 to 2 inches long. But remember they have more feeding value and are the greatest $\epsilon$ gg-producers when sprouts are I to I I-2 inches long. Give your young chicks all they will eat twice a day sure. Also remember they are a sreat feed for young ducks and will grow them very rapidly and increase their size. Do not be afraid to give them all they will eat twice daily.

While I find a good grade of wheat screenings far ahead of any other feed for hopper feeding, I also find it very hard to obtain ard at times I am compelled to feed wheat. If you cannot get good screenings by all means use a cheap grade of wheat. Red wheat is better than white wheat. 
I want to impress on you the importance of a free-range plant, for you cannot fail if you build one of my free-range systems and handle it accordingly. I know of no business that will make you money faster, all things considered, than the poultry business if handled properly. And I know of no business where money can be lost faster all things considered than in the poultry business. I have taken plants that have had to go out of business and started them in again under my freerange system with Leghorns, and they have made money very rapidly on same plant, where under the old system they lost everything. So you can see it is the proper feed and care that makes success certain.

If many of your little chicks die during first two weeks you will find your trouble is with your breeders almost every time. To all who follow my free-range system success is certain. If your chicks are closely confined in small yards and begin to die and dwindle away at three to four weeks of age, you must begin to feed them green cut bone when three weeks old sure. Give a liberal feeding every noon.

Spade yards up and sow with oats as often as you can until you get them on more range. I am always ready to give advice and help all I can, time permitting.

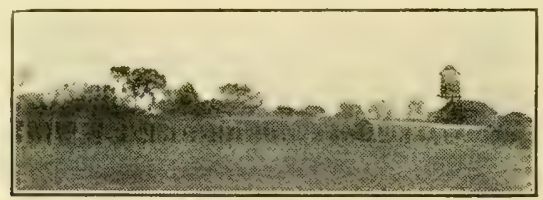




\title{
THE BRIGGS'
}

\section{SECRETS IN POULTRY CULTURE}

बृत्या

\author{
SUPPLEMENT TO \\ FOURTH EDITION \\ "PROFITS IN POULTRY \\ KEEPING SOLVED”
}

\section{BY WAY OF INTRODUCTION.}

I am giving on the few pages following some valuable poultry secrets as discovered in my 20 years of careful experimenting in the poultry world, secrets of value that have never been published before. Poultry Secrets without a system to know when and where and how to use them is like owning a steam engine and not knowing how to run it. By using these secrets in connection with the methods set forth in the preceding pages of this book, you cannot fail to succeed.

EDWARD BRIGGS. 


\section{Secret of Success Is Handling Early Chicks.}

Under this heading I want to say that the great secret of success is hatching chicks in March and April. If every one in this country would hatch out all their chicks about April Ist, we would not read of so many failures, for at this time chicks are easily raised and if given half a chance, one can raise nearly every chick hatched.

There are many advantages in hatching chicks all out at nearly one time. The amount of labor saved during the season is a wonderful item for when the chicks get to one and and and a half pounds they can be watered in open vessels, hopper fed and are all at roost, saving the labor of caring for brooders, all this labor is gone through and over at one time.

Also the labor of caring for incubators is out of the way and you can arrange things so you can go away for a day or two and the chicks can take care of themselves. So I want to emphasize here for sure success and a saving of labor during the season, hatch all chicks out early and all as nearly at one time as possible.

The pullets will be laying September and will pay a profit right through the Winter and will make the very best of breeders for the following season. Failures are not known where the chicks are all hatched early, for the cockerels are marketed as two pound broilers at a good price, generally for enough to mature the pullets on, so one is not out for feed and a profit is practically secured from the start.

\section{Secret of Raising Late Hatched Chickens.}

As a rule the raising of late chickens is what puts many poultry plants out of business.

Chicks hatched in May, June, and July have not the vitality to start with that the March and April chicks have and with the hot weather coming on to waken them, at two or three weeks old they begin to droop and die very rapidly as bowel trouble takes hold of them at this time, (known as white diarrhoea) and the result is they often die just as fast as you can hatch them, and the few that pull through grow so slow and are so puny that they never amount to much and are worthless as breeders.

I will give a feeding formula that will raise nearly every chick hatched in May, June and July, and carry them right through the critical age of from two to five weeks cld, and keep them growing. 


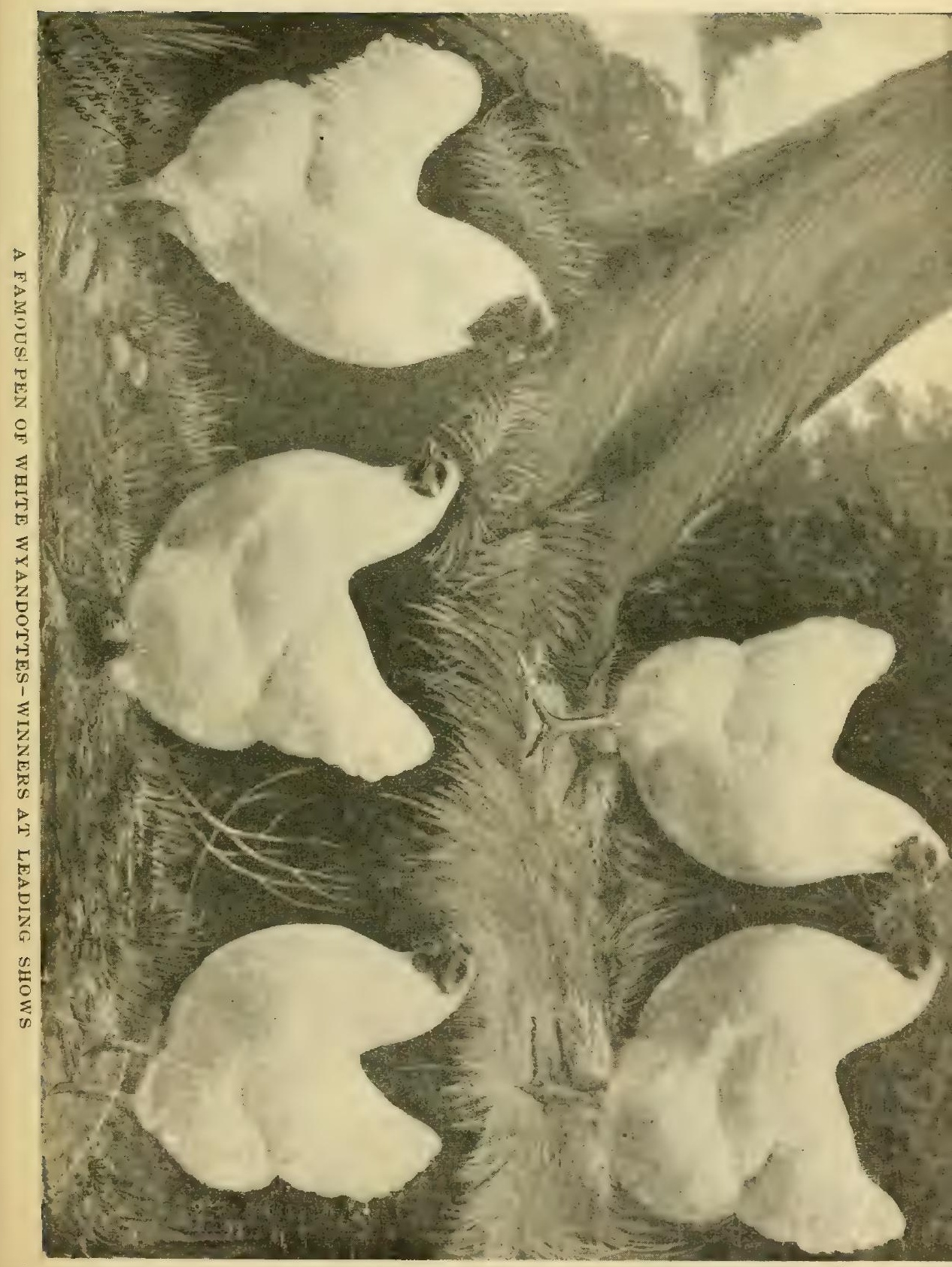


First, spray brooder thoroughly with Crel Oll, sold at nearly all feed stores at \$I.OO per quart. After spraying cover bottom of brooder with half inch of wheat bran, put on hover and put your chicks in. Set a small box of my dry mash in near them I use a cigar box for this purpose for first two weeks, then use a larger one and nail a lath around edge so they cannot scratch the feed out. Keep this dry mash before them at all times. Secret of formula for making found in this book. Also feed three times a day a light feeding of Patent Chick Feed, or some other of good quality, the less cracked corn in it the better. The best chick grain contains no cracked corn, also give grit, and good clean water. And every morning give a quart of sweet milk right from the cow to every Ioo chicks, if you keep a cow; if not, it will pay you to buy the milk, as this is most important as on this one thing hangs the secret of success. Give them milk just as long as you can and you will fairly see them grow, and you will be able to mature them fully two months sooner than in any other way. Give all the processed oats they will take every noon, and if you can give them free range so much the better; put them under my cultivated svstem and the raising of late chicks will become both a pleasure and very profitable.

I have spent many years and hundreds of dollars in experimenting with late hatched chicks to find a way to raise them successfully and at a profit and now I am rewarded. The secret alone is worth the price of my book many times over.

\section{Secret of a Large Egg Yield.}

The secret of a profitable egg yield is keeping your hens laying the year round, or getting a large egg yield during the summer months of June, July, August and September, and this can only be done under my free-range cultivated system of harrowing the ground every other day sure, with a spring tooth harrow and sow liberally with oats. As the season advances in August and September add some corn, say threequarters oats and one-quarter corn, and if you can give sour milk to drink, they will pay you a grand profit the entire season in eggs.

Old hens will not lay many eggs in October, November and December, no matter what you feed, so it is best to give them a rest at this time, and not try to force them. Do not neglect the processed oats at any time of the year. They should have one good feed daily all summer even on free range with ground harrowed every other day or daily. The ground should be plowed once a month sure. 


\section{Secret of Feeding Unthrashed Grain in Winter.}

I believe, as far as I know, I am the first and only one who has advocated this and parties who have followed my methods have received an exceptional egg yield during the Winter and the fertility of the eggs has run exceptionally high and given wonderful hatches. To flocks of 60 to 75 birds, I give in the morning a good sized sheaf of oats; at noon a good-sized sheaf of wheat, and at night a feeding of

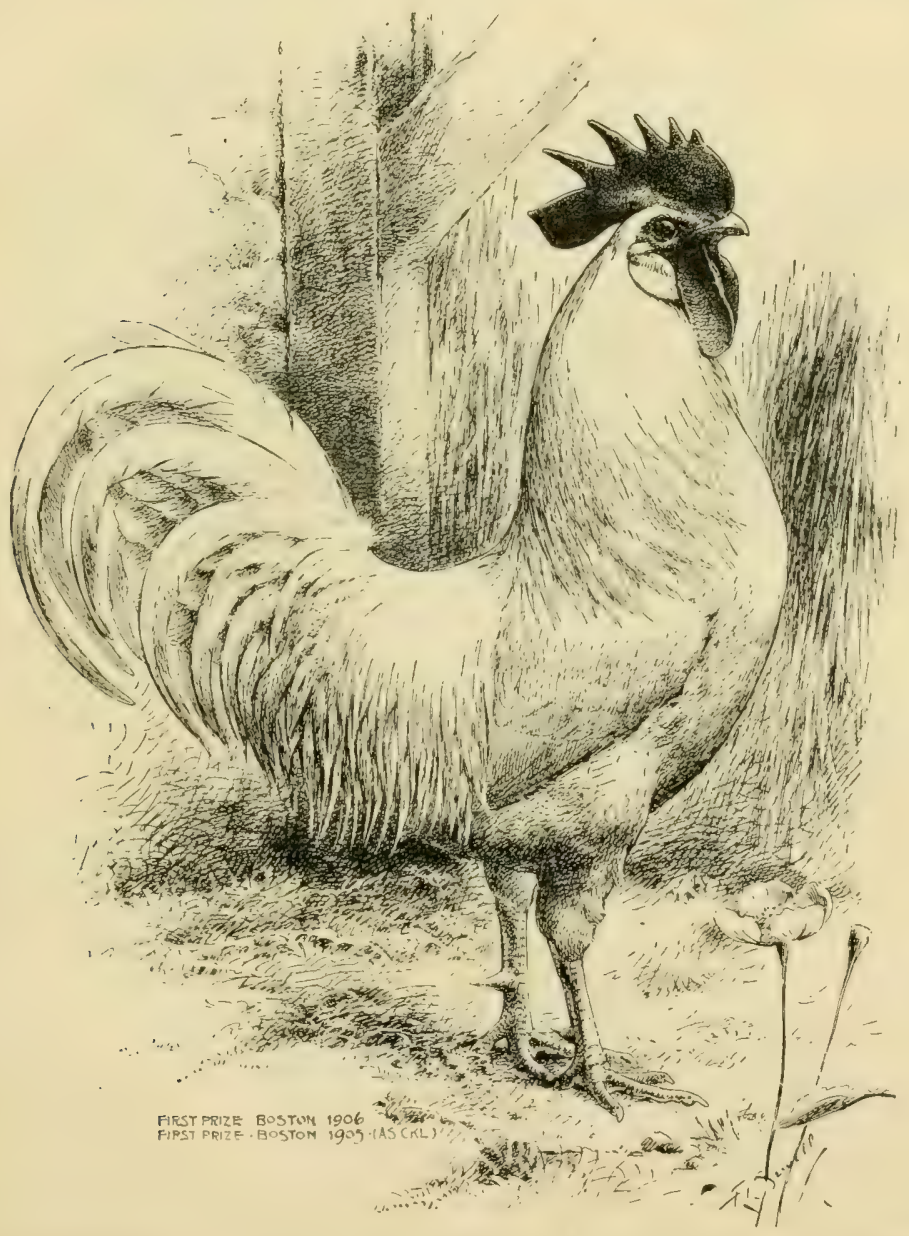

A HIGH CLASS S. C. WHITE LEGHORN COCK THAT IVON AT SEVERAL OF THE LARGEST SHOWS 
corn, which may be fed on the ear, giving it to them in the afternoons. Nornings I give a good feeding of processed oats, all they will eat with special Egg Maker fed according to directions. I keep before them all the time my dry mash for producing eggs, as found in this book, I also keep before them grit, charcoal and oyster shells, also beef scraps, in case you do not use a special Egg Maker. This method is only available on larms, but it is the cheapest method known and the greatest egg producer, nearest to nature of any system in the world.

\section{Secret of Getting Eggs Every Month in the Year.}

It no time in the whole year are eggs so scarce as during October, November and December, and for profit in market eggs you will never find a time when fresh eggs are sought after more than at this time. Buyers are always ready to give a premium on fresh eggs at this time of year.

Now, the great question is how to get a large egg yield these three months. I want to say right hare, a large egg yield at this time is hard to get, for all old hens are in moltand can be depended on for but a few eggs. A hen can be kept laying until she drops nearly all her feathers, and then when she gets her new coat nearly all on she is used up and is bound to take a two month's rest. So the only way to keep the egg yield up at this time is with February and March pullets grown to full maturity before they are allowed to lay, for if they lay too young their eggs are very small and unmarketable. When your pullets are fully matured and ready to lay, or better just started, then move them to their laying houses which may stop their laying for a short tıme; if so it will be much better for when they start again their eggs will be much larger and can then be maketed for regular size eggs.

Now you may wonder why pullets will not lay as well at this time as in Spirng. I will tell you why. A chicken is like a tree, they require the Spring sun to do their best. A tree drops its leaves from October on, whether we have any frost or not and lies dormant until the sun begins to travel North again and puts life in it. A hen in her natural state is just the same and if we expect eggs in abundance during these three months it requires the very best of care and feed and gnod judgment. Sour or lopper milk is a great help at this time. Cultivate your ground all good days and sow plenty of grain and on bad days give grain in the sheaf; do everything possible to keep them busy, and your egg yield will repay you for your trouble. 


\section{Secret of Curing White Diarrhoea.}

Of all the diseases that ever struck little chicks, White Diarrhoea is the worst and has probably killer more little chicks than all the other diseases put together. It will take whole bronds off in a few days, and the further the season advances the more fatal it gets. I have known plants that had none of it in their early hatches, and in their late hatches whole broods would go with it. After years of careful experimenting, I am satisfiad it is a germ disease and the treatment

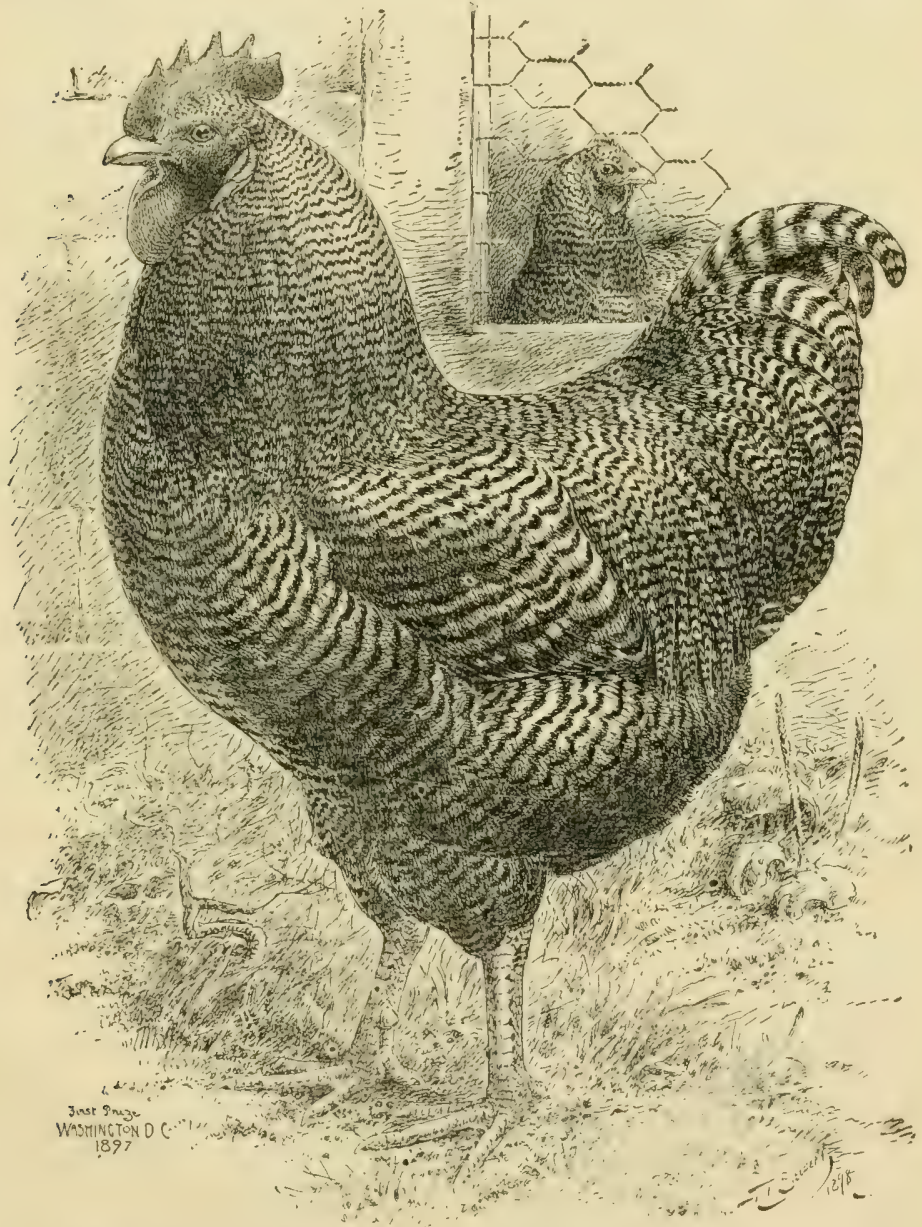

A BARRED PLYMOUTH ROCK MALE SHOWING FINE SHAPE A ND BARRING 
should be started with the old stock. I find chicks bred from old breeders on free cultivated range, as my book describes, rarely ever have anyof this bowel trouble. Now as a positive preventative, spray your houses once every two weeks with Crel Oll. Spray your brooders before you put your chicks in and after you spray it cover bottom with quarter inch of wheat bran and put your chicks right in and feed as I laid down in the Secret of Feeding Late Hatched Chicks, by wiving sweet milk to drink, and I am sure you will see no trace of this trouble. In case you see any cases spray your brooder once a week with Crell Oll and put one-third of a teaspoonful of Humphrey's Specific J. K. to a quart of water; this J. K. can be bought at any drug store at $50 \mathrm{c}$ a bottle. Follow these directions closely and I am sure you will have 110 further trouble with this disease. Spray your roosts once a month sure all summer with this for both old and young stock.

\section{Secret of Curing Gapes.}

Capes carries away thousands of chicks every year, specially among the farmers and to catch each chick and take the worms out is a tedious undertaking and then you injure many chicks isesides the large number you kill and the large number you let die through neglect in taking them in time. If you will spray your coops with Crel Oll before putting your chicks in and when a week old, if they show any trace of it, spray coops again at night just before they go to roost; this will prevent it, but if any show gapes after this just take them all and put then in a box that has just had the bottom sprayed with it, cover with an old bag and all the worms in windpipe will quickly be killed. Every one that has followed my directions has cured their chicks and not lost one.

\section{Secret Formula for Making the Cheapest and Best Lice Powder Known.}

The lice powder I am going to tell you how to make may be made at 8 to 9 cents a pound, and is far superior to the powders sold on the market at 25 cents per pound, and will not only kill all the lice it comes in contact with, but will remain on the hen for two or three days. Buy at your drug store one pound Persian Insect Powder and from your feed store three pounds Red Dog Flour, usually one and one-half cents a pound, or the best white middlings; mix this thoroughly and you have four pounds of the best insect powder known. The Persian Insect Powder usually costs thirty cents a pound. 
Secret of Making the Best Liquid Lice Killer.

This lice killer I consider far superior to any now sold on the market at any price and can be bought at almost any drug store, at a cost of about 50 cents per gallon. Take a gallon can to your druggist and have him put in it half crude carbolic acid and half crude oil; shake this up well and you have one of the best lice paints that can be made. Just spray your houses once a month with this and you will never be troubled with lice.

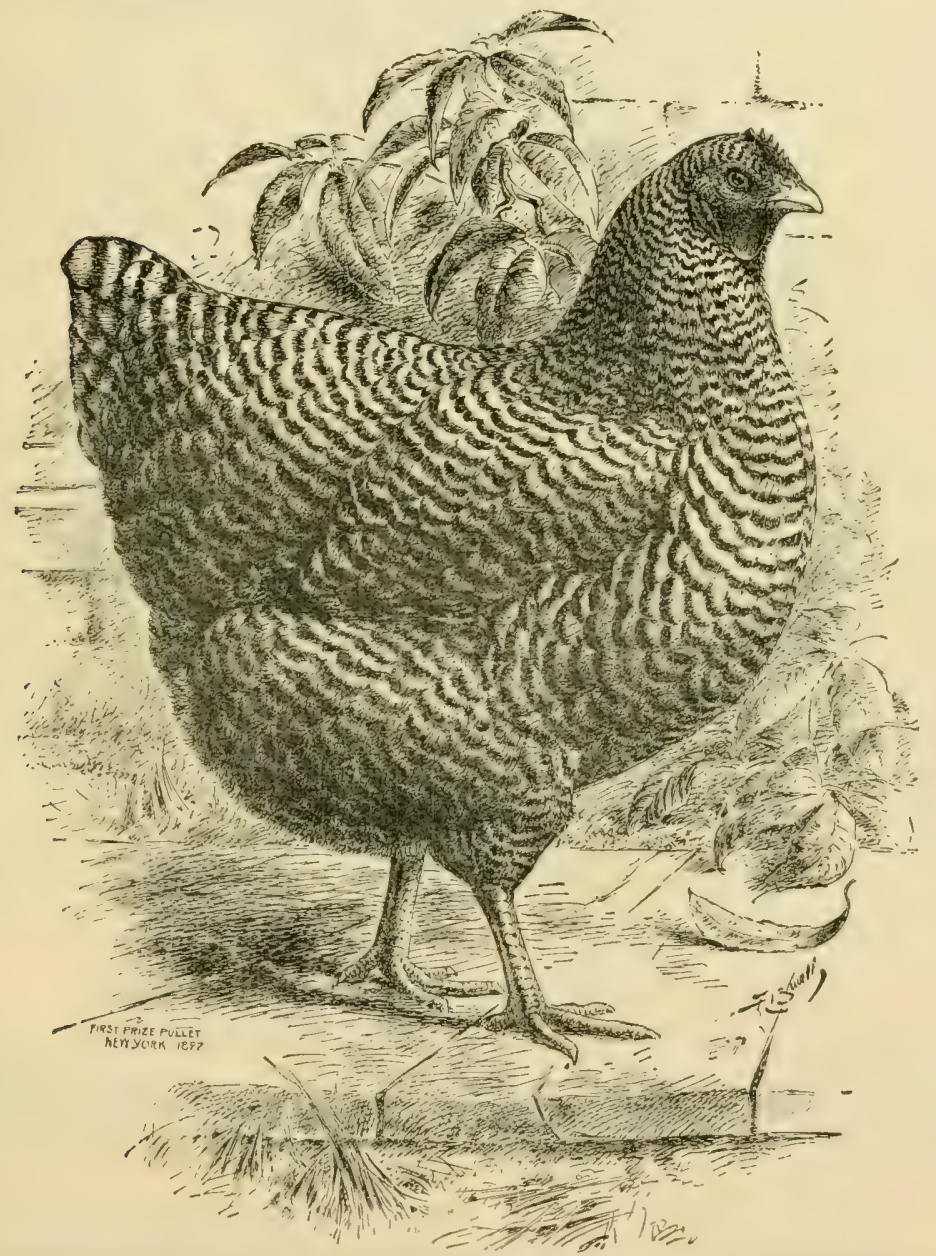

$\triangle$ BARRED PLYMOUTH ROCK HEN REPRESENTING A FINE TYPE OH THIS POPULAR BREED 


\section{Secret of Raising Turkeys.}

This secret will be more than valuable to those who try to raise a large number of turkeys yearly, and have met with severe losses, for it is now generally conceded that turkeys are the hardest to raise of any of the feathered tribe. They may look fine today and be dead tomorrow. I have been carefully experimenting to perfect a system with which I could raise nearly evely turkey hatched and I have yet to lose the first one that was perfectly hatched. When I take the young ones from the nest I first put them in a small box that has been sprayed with Crel O1l. I then put a loose bag over them and leave them 5 minutes so they will breathe this thoroughly to kill all germs. This should be done once a week for 5 weeks as I find the greatest loss comes from a germ disease and when you kill the germ you can raise turkeys and in no other way. Turkeys two years old make the best breeders as their young are much stronger. I shut the old turkey in a coop of good size for first two weeks with chicks and feed them principally on a special Patent Chick grain and cracked corn cooked A curd made from loppered milk is also very good. I give hem sweet milk to drink right from the cow. A fountain of milk and one of water. They have this every morning and are fed lightly three times daily. After two weeks old I put three drops of Spirits of Camphor to a quart of water and if at ary time I sae any of them droop I increase the camphor to five drops to a quart of water. This braces them right up and carries them safely through the critical period. It is a pleasure to see them grow. The sweet milk just pushes them right through. After five weeks of age they can be put on good wheat screenings and cracked corn dry and will thrive fine if given plenty of range. A cow pasture makes an ideal range for turkeys. In the early fall put them on whole corn and good wheat. You will find more profit in a flock of turkeys than anything you raise on your farm. Just try this method and I am sure you will have no further trouble in raising turkeys.

\section{Briggs' Secret Dry Mash for Baby Chicks.}

The dry mash I am going to tell you how to make, has proven for me to be the greatest dry mash for growing chicks from shell to maturity of any mixture I have ever been able to secure and I consider it the nearest perfect of any mash ever compounded.

Take by weight 100 lbs, wheat bran. Ioo lbs. middlings, roo lbs. corn meal, roo lbs. gluten meal, mix thoroughly and 
keep before them at all times. Also keep before them grit and beef scraps.

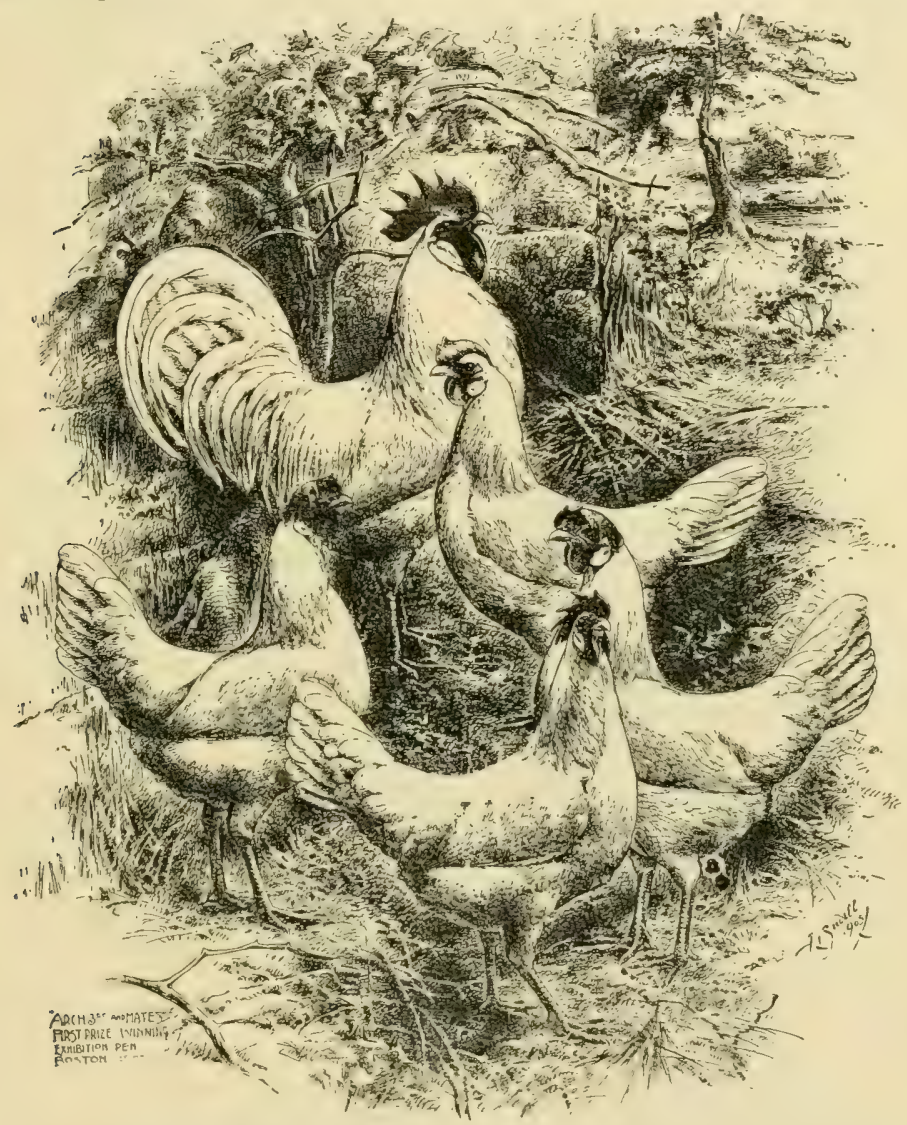

A FAMOUS PEN OF PRIZE WINNING S. C. WHITE LEGHORNS

\section{Briggs' Secret Dry Mash for Laying Fowls.}

Take equal parts by weight of wheat bran, white middlings, corn meal, gluten meal and ground oats; mix thoroughly and keep before them in hoppers. Feed some grain by hand and the results will surprise you.

\section{Secret Egg Preserving Formula.}

Purcháse from your druggist as much Silicate of Soda as you may wish. Mix in with cold water in the proportion of six parts of water to one of Silicate of Soda. Use newly laid 
cggs not more than one week old. Dip each egg separately in the solution, and place it in a vessel large part down; then pour over the eggs enough of the solution to entirely immerse them. Do not fail to dip each egg separately before placing in the vessel, and hold the egg in your hand for two or three seconds after you have dipped it, that the coating may set, and place in the vessel as directed. Cover the ressel up and the next day or the next week, as the case may be, when you wish to add more eggs, repeat the operation of dipping, set the eggs in on top of those already in the vessel as directed. Cover the vessel up and for the next day or the next week, as the case may be, when you wish to add more eggs, repeat the operation of dipping, set the eggs in on top of those already in the vessel and cover again with the solution. You will find the air has been entirely excluded from the shell, and the eggs have been hermetically sealed and will stay fresh indefinitely if you have properly handled them.

\section{Secret of Breeding for Layers.}

After two years careful experimenting on my new plant and from careful obeservation from other plants, I have come to the conclusion that it does not pay to trap nest to produce a strain of prolific layers, in fact, every large plant that has tricd it as a rule has given it up or has been compelled to sell out in 2 or 3 years. Exceptions to this rule are very scarce. The amount of labor that it requires to run a plant with trap nests will quickly put it out of business. The greatest success today comes from the system where but little labor is required and my system stands alone in this respect. You may not know that the Maine Experiment Station made a careful test for ten years with trap nests using all the different nests know11, for money was no object and after breeding from their greatest layers for ten years by the use of the trap nest their average per hen was over 30 eggs less per hen than when they started. This I am sure is a great surprise to the poultry world and proves beyond a doubt that it does not pay to trap nest birds. To breed up a strain of heavy layers without extra labor, take each year about half of your pullets, those that mature the quickest and start to lay ahead of the rest, and flock them by themselves and band them so they will be known from others, for they are bound to make your best layers. Mate these with your earliest maturing cockerels and continue to do this year after year, using the selected pullets two years for breeds. In this way you not only get a phenominal flock of layers but your birds will increase in size and vigor and sickness will rarely be known 
among them. Slow maturing birds are much more subject to disease, and never prove great layers while the quick maturing kind do. You will find this system of picking out the layers far ahead of any system now in use and the only system in my estimation that will ever prove a success.

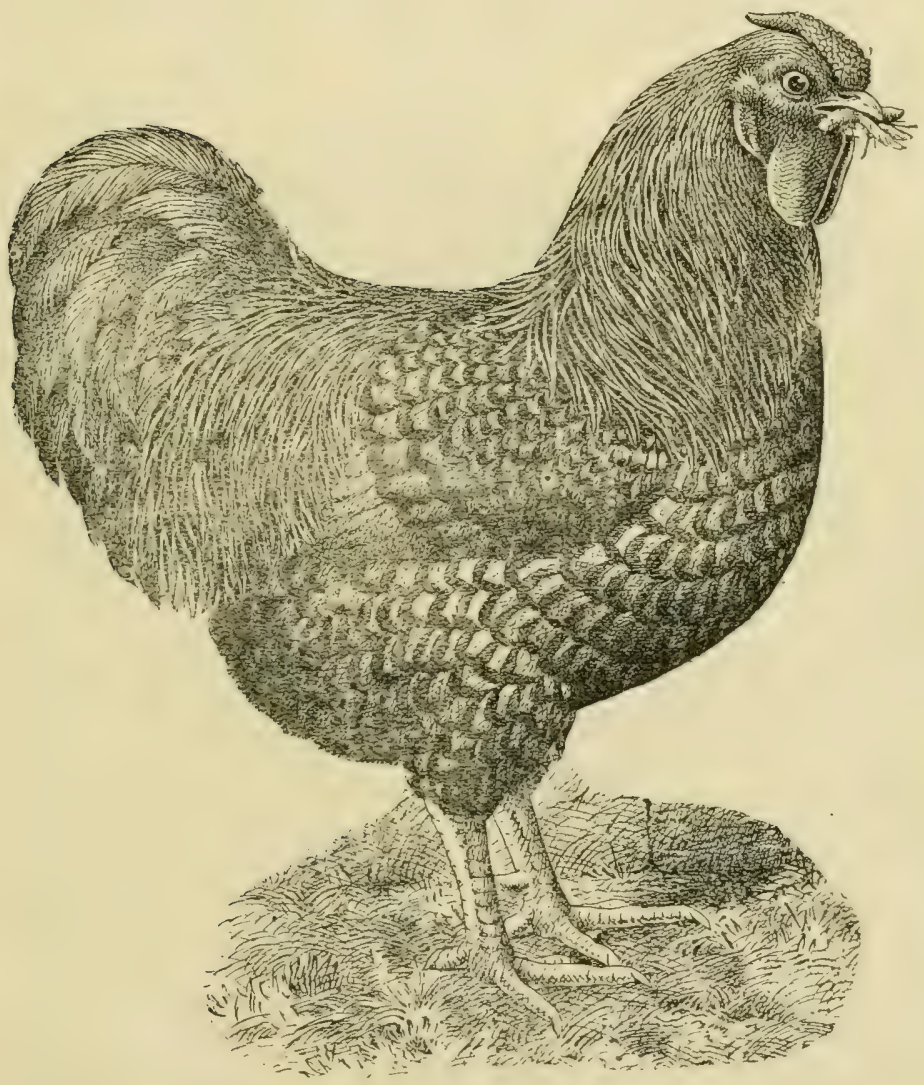

A POPULAR MEMBER OF THE WYANDOTTE FAMILY 


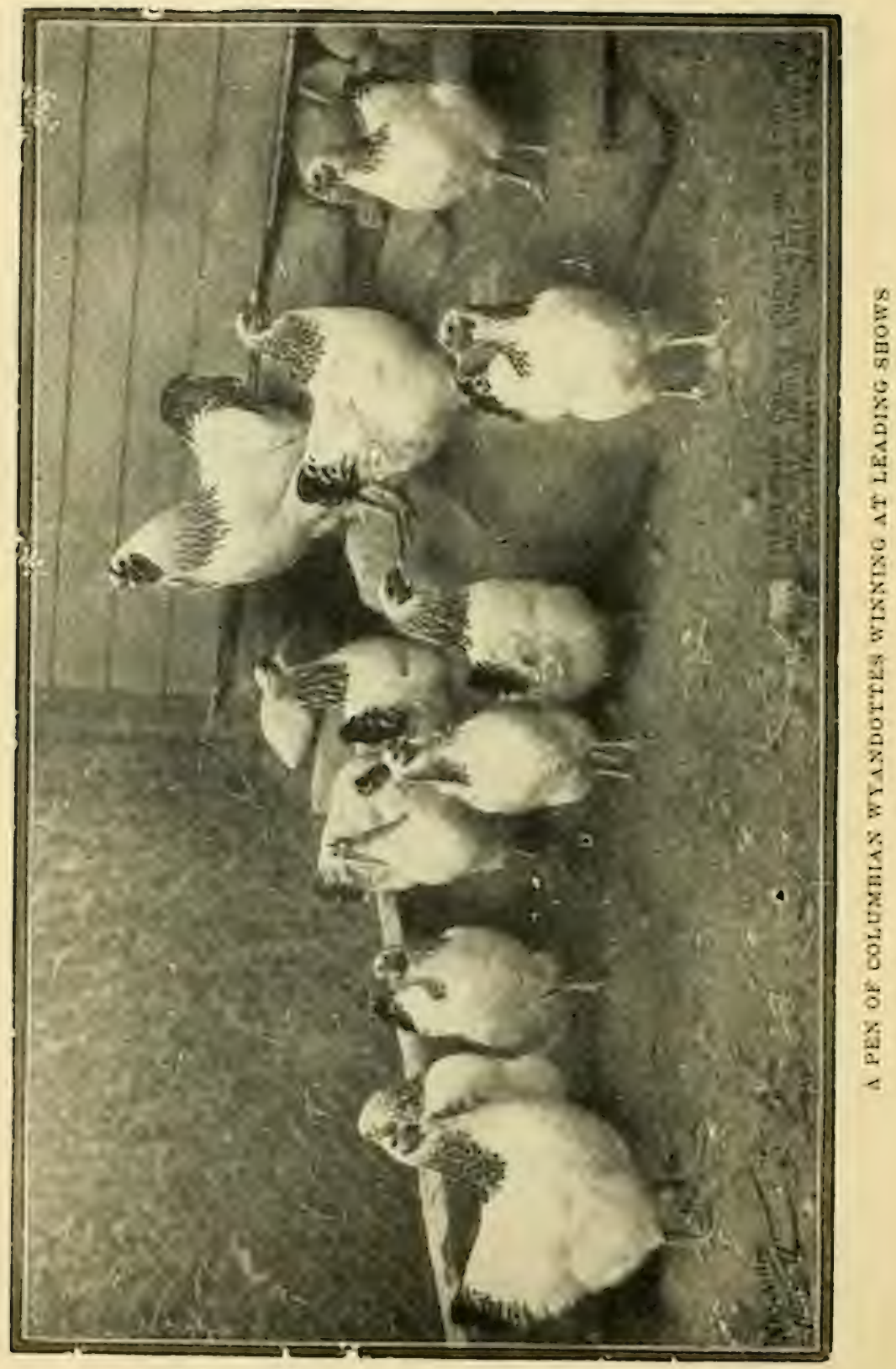




\section{Secret of Telling the Laying Hen.}

This secret is often valuable during the early fall when hens are slacking off fast on egg yield, and you might wish to market a part of the flock that are through laying or might want to kill a pair for dinner and certainly would not want to kill the layers. You may always know that as a rule a hen with a bright red comb is a laying hen so do not kill these kind. Rather kill the lazy looking hens, those with pale combs. After catching them up notice if you can lay three fingers between the pelvic bones which are just below the vent. In old hens you can lay 3 fingers between these bones if they are laying. Leghorns often lay when only two fingers can be laid between the bones. The egg passes between these bones in being deposited. If the bones are close together and stiff you may safely conclude that the hen is not laying and will not lay for several weeks as a rule. I understand this is the same system as is used by several others although I have never seen their system.

\section{Secret of Fattening Poultry.}

If for broilers take chicks that are about I I-2 lbs. each in weight, and put them in flocks of about fifty. If they have had free range so much the better. If they have a good large house they will need no yard. One of my 10 by $2 n$ houses is just right for 50 to 75 chicks. I advise feeding them two weeks before killing. Mix up dry six parts corn meal, two parts middlings, one part gluten meal, one part linseed meal, an 1 one and one-half parts beef scraps and add 5 per cent grit; mix thoroughly dry and before feeding mix with milk either sweet or sour or with water and give them all they will eat twice daily. Keep before them all the time, six parts corn meal and two parts beef scraps mixed dry, keep this in a box so they can have free access to it at all times and in two weeks they should be as fat as squabs and weigh two lbs. and over each.

\section{Secret of Breaking Up Broody Hens Quickly}

The great secret of breaking up broody hens quickly is to shut up a number together, a dozen or more. Put them in a coop right on the ground with a wire netting front and they will not think of setting, where one hen is alone in such a coop a persistent setter will scratch a nest at one end and go to setting. If you take every setter off the nest the very night they start to set you can as a rule break them up in three days. Always keep water before them but give but little feed while they are shut up. In case you shut up your broody hens only once a week and want to break them up 
ly every case and have a rest. Nothing will molt them so fast as processed oats and beef scraps. "To have them mol: in June and July just take away all grain and give all processed oats keeping beef scraps before them all the time and they will surprise you in the short time they will be in getting a new coat of feathers. Try this for birds you wish to exhibit at Fall shows. A bird in new plumage always does the winning.

\section{Secret of Preparing White Birds for Exhibition.}

To prepare white birds for exhibition and have them white as snow with that glossy finish, is an art that few possess. In our large shows where judges have gone color crazy it is no longer an easy matter to win a prize. In washing white birds I use four tubs of water. In first tub of warm water I shave half a cake of Ivory soap and make a good suds, then I use half a cake of soap, a good hand brush and I soak the-bird thoroughly and rub plenty of soap into the feathers and give her a thorough scrubbing; then put her in next tub of clean warm water and wash her thoroughly, getting all soap out of the feathers, then I put her in the third tub of warm water. In this tub of water I put a small amount of blueing and wash all traces of soap out of her; she then goes in a fourth tub of cold water nicely blued but not enough to color the feathers, rinsing her thoroughly and then I put her in a clean cage to dry where the temperature is about so degrees, using plenty of clean straw in botton, the cage being provided with wire netting bottom. Wash the feet and legs thoroughly and pick off all old scales. In washing white birds you should remove all colored feathers as they show plainly when wet. After your birds are dry and do not come out chalk white nave on hand some peroxide of hydrogen and take a sponge and go over them with this bing careful to get none on legs. This will put them in pink of condition. Ifter this put some vaseline on their leg's rubbing them well with it. If you have done your work thoroughly your lird will be in fit condition co go into any show and win the blue ribbon if it has the natural quality. Icu sheuld tame your birds so they will be very gentle and pose nicely for the judge. A bird must be trained to show its shape if you expect to win in strong competition.

\section{The Secret of Feeding Salt.}

It is not generally known to the poultry world that salt is the greatest conditioner and the greatest egg producer 


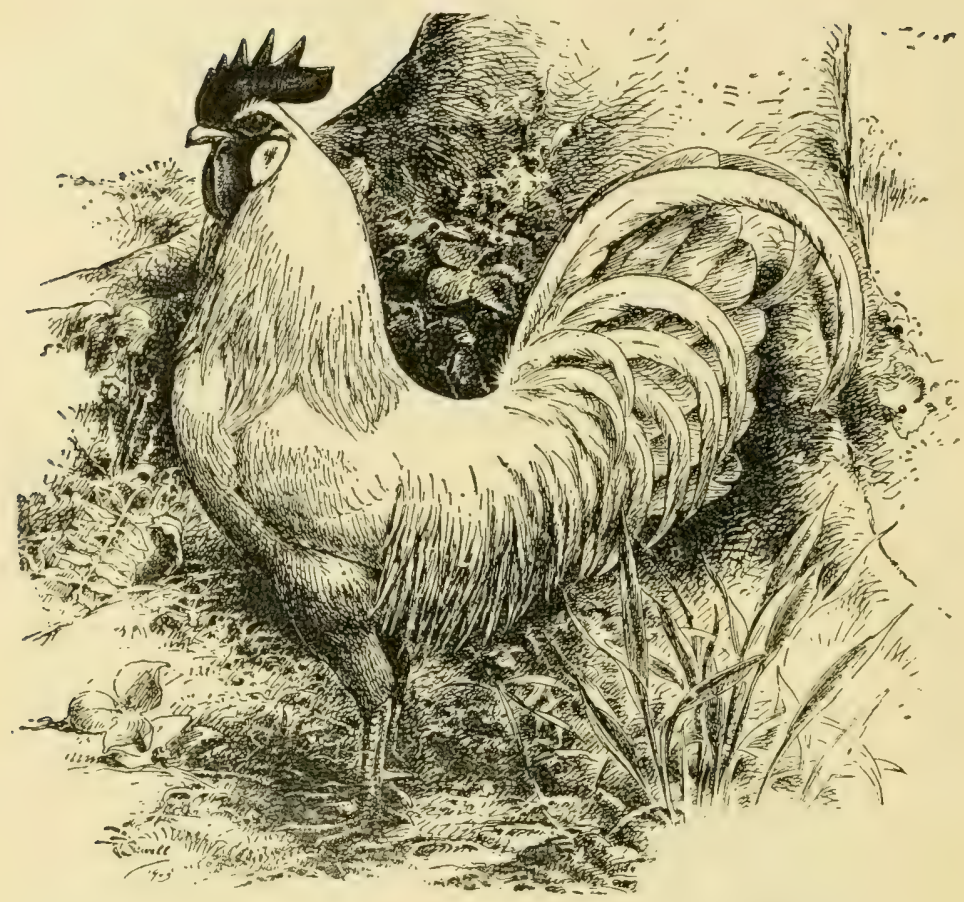

A WELL BRED S. C, WHI'TE LEGHORN COCK

known to the poultry world. Poultry will be in much better condition and lay fully 25 per cent more eggs per year per hen if fed a reasonable amount of salt the year around and the whole flock will be in much finer condition for it.

I am satisfied after a series of careful experimenting that the only perfect way to feed it is by mixing it with processed oats or barley whichever you process. An ounce to Ioo hens is about right or a small handful to a large pail of feed. Fowls are just crazy all the time for the processed oats which have been salted as directed. I discontinued salt on one lot of layers during July and started it again in August and doubled the egg yield in I5 days from the time I started using it again. Young chicks will grow much faster and keep much more healthy if fed processed oats salted same as for laying hens. The loss should be nothing to speak of and birds will mature and lay fully a month sooner. If you want to obtain the greatest profit from your poultry plant do not fail to use salt the year around as directed. 


\section{RESULTS :}

Among the thousands who have bought my book I find there are a few who want results of my plant in figures. On account of selling part of my breeders every season beginning in August, for this reason it is impossible to give results on my plant for one year, but to show you what can be done with IOOO layers in seven months, starting January I, I have carefully gone over my books and am giving you results in sales of eggs and baby chicks only for seven months for tine reason that Poultry Success has been advertising $\$ 3500$ in seven months from 1000 layers. When I gave them these fi! ures I had no idea my sales were about $\$ 4,000$, had I taken sales of stock and broilers in my estimate which I did not. First I will give you sales of eggs for each month for se:en months beginning January $\mathrm{I}$, and will give you a separate account of baby chicks sold monthly. This will give you some idea what can be done by anyone who will follow my System and do a liberal amount of advertising for you cannot sell hundreds and thousands of dollars' worth of eggs for hatching and baby chicks if you do not advertise and advertise liberally. In giving the sales of eggs and baby chicks for seven months I want to say Ioo Leghorn hens were sold May roth for \$135.00. So from May Ioth on I had only 900 layers in $\mathrm{my}$ estimate. I will first give you my sale of eggs by months: January, \$123.50; February, \$271.84; March, \$385.18; April. $\$ 740.82$; May, \$406.96; June \$182.64; July \$201.36; or a total of $\$ 2312.30$ worth of eggs in seven months from Iooo layers. Now remember this is independent of the eggs used for hatching 2,000 young chicks for my own plant. The baby chicks sold as follows: March, \$186.40; April, \$34.3; May, $\$ 459.93$; June, \$197.50; July, $\$ 79$, or a total of $\$ 1.265 .83$ for baby chicks for first seven months and all Leghorn baby chicks were sold at $\$ 10.00$ per 100 and the average hatches were 300 to 330 chicks from 400 eggs set, which proves that my eggs run as fertile as I claim and give phenomenal hatches of chicks that are so large and strong that they are easily raised with but little care. In closing I want to say what I have done I believe can easily be done by anyone who will put up one of my free-range plants and follow my System as laid down in this book and do a liberal amount of advertising, I want to say that the total sales from I,O0o layers at end of year will exceed $\$ 5,000$. So you must know that there is a fair amount of profit left such as but few other kinds of business can return. 


\section{INDEX OF SUBJECTS}

A.

A combination plant..... 60

A Leghorn plant for profit

$54,55,56$

An egg plant for proft. .25, 26

A perfect brooder ...44, 45, 46

A system for large breeds

$\ldots \ldots \ldots \ldots \ldots 9,63,64$

A White Wyandotte plant for profit......57,58,59

A yarded plant, how to erect .......6.65, 66

B.

Bees ..............6 60

Bowel trouble, cause and cure .............. 48

Breeders, loss of ....... 61

Breeding for Layers ... 86,87

Brigg's dry mash for baby chicks ........... 84

Brigg's dry mash for laying fowls .......... 85

Brigg's poultry plant ....7, r

Broilers, how to raise. 48,49

Brooder, a perfect ..44, 4546

Brooder, fireless ....... 67

Broody hens, how to break ............89, 90

C.

Care of laying hens on free

Caring for a yarded plant

Changing breeding stock $\ldots \ldots \ldots \ldots 33,34,43$

Chicks, helping out of shell 67

Chicks, how to feed....41, 42

Chicks raised Nature's way $\ldots \ldots \ldots \ldots 40,41,42,43$

Colds and roup........ 50

Colony, size of . . . . . 1\%

Construction of model lay-

ing house .....15, 16, 17

11.

Desirable size of plant..... 11

Dry mash for baby chicks

............84, 85

Dry mash for laying fowls. . 85

Duck culture...68 $69,70,71$

W.

Early chicks
Eggs every month in the year .............. so Egg preserving formula. 85,86

F.

Fattening poultry, how to do it............ 89

Feed for young ducks.... 69

Feed hoppers ......... 21

Feed processed ...28, 29, 30

Feeding and selection of large breeds......663, 64

Feeding chicks.......41, 42

Feeding.salt ......991, 92

Feeding system when wheat and oats can not be used. 57

Feeding unthrashed grain

............. 79, 80

Fences ............ 11

Fireless brooder ....... 67

Free range plant with least labor ........33, 34, 74 Fruit, poultry and bees... 60

\section{G.}

Gapes, secret of curing and how to prevent ...... 82

H.

Hatch, when to....... 76

Helping chicks out of shell. 67

Hen in wild or natural state

................ 10

Hoppers for feed........ 21

House, incubator ...... 37

House, model laying house plan ............ 13

House, construction of model laying .....15, 16, 17

How to colonize or flock hens ............ 12

How to keep green feed all summer in a yarded plant 35

How to make best lice powder ........... 8 -

How to make best liquid lice killer ......... 83

How to start in the poultry business ........52,53

How to tell the laying hen. 89

I.

Incubator house, how to build ........... 37 Incubator, how to run..3s, 39 
I.

Late hatched chicks....76, 78

Laying nens, care of on range ............ 22

Laying hens, how to tell .. 89 Laying house....13, 15, 16, 17 Laying out a plant....... 12

Leghorn plant for profit $\ldots \ldots \ldots \ldots 54,55,56$

Lice powder, how to make. 82

Liquid lice killer ,how to make ........... 83

Location of plant ........ 11

Loss of breeders ........6 61

\section{M.}

Mating breeders ........ 55

Molting .......662, 90, 91

Molting fowls early, how to

do it ..........90,91

N.

Nets ............ 17

o.

Jats, sprouted....2s, 29, 30

Oats, sowing for flock.... 31

P.

Plan of model laying house. 1:

Preparing white fowls for exhibition

Processed oats, feeding.... $\ldots \ldots 22,25,26,31,32$

Processed oats, how to make $\ldots \ldots \ldots \ldots .28,29,30$

R.

Raising broilers......48, 49 Raising chicks Nature's way $.40,41,42,43$

Raising late hatched chicks ..............76, 78

Roasters ............ 49

Roup .............. 5t

Results, financial ...... 93

S.

Salt, feeding .......91, 92

Secret of breeding for layers ............86,87

Secret of breaking up broody hens quickly..89, 90

Secret of curing gapes... 82
Secret of curing white diarrhoea ..........\&1, \&?

Secret of fattening poultry 89

Secret of feeding salt. .91, 92

Secret of feeding unthrashed grain ..........79, so

Secret of getting eggs every month in the year..... 80

Secret of large egg yield....78

secret of making best and cheapest lice powder.... $\$ 2$

Secret of making best liquid lice killer ........... 83

Secret of molting forwls early ............90,91

Secret of preparing white fowls for exhibition..... 91

secret of preserving eggi $\ldots \ldots \ldots . . .85,86$

Secret of raising turkeys.. 84

Secret of raising late hatched chicks ........76,78

Secret of success ....... 76

Secret of telling the laying hen ............. 89

Selection and feeding of large breeds ......63,64

Size of colony or flock.... 12 slope of land .......... 11

sंoil .................. 11

Specifications of model laying house .......... 13

Sprouted oats ....2\&, 29, 30

Starting in the poultry business, when and how. .52, 53

Summer care of flocks...31, 32

T.

Turkeys, secret of raising. $\$ 4$

IV.

IVater supply by streams or springs ........... 11

Watering in winter ...25, 26

White diarrhoea ....48,81, 82

White fowls, how to prepare for exhibition ........ 91

White Wyandotte plant for profit .......57,58,59

IVinter care of layers...25, 26

$\mathbf{Y}$.

Yarded plant, caring for. 35,36

Yarded plant, how to erect 65,66 


\section{Worth Looking Into}

THE "Briggs' System" is a good 1 thing and the publishers want many more agents to handle this book and also

\section{POULTRY SUCCESS}

The Twentieth Century Poultry Magazine

Very attractive terms are offered and every agent can build up a nice trade.

Other works to follow will make it well worth while to get an agency in your locality and work faithfully.

\section{Profits Are Large and Orders Bome Easy.}

WRITE AT ONCE

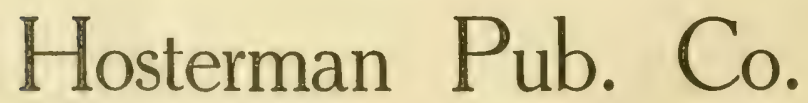

Springfield, Ohio. 





21 st year; monthly, 64 to 164 pages; handsome illustrations; best writers; tells just what you want to know. Shows how to get eggs; how to hatch, raise and care for chicks; best methods for broilers and roasters, how to use incubators and brooders; how to mate to produce prize winners; gives building plans, etc. and shows how to build and equip your plant. Full of good things, just the paper you want. Gives full details and all necessary information for the successful care and management of poultry for both Faicier and the Beginner.

The monthly visits of the POULTRY SUCCESS will enable you to make more money out of your poultry; give you the up-to-date methods of successful poultrymen and the secrets that contribute to the best success in the business.

\section{HENRY TRAFFORD, Editor Eastern and Editorial Office Binghamton, N. Y.}

We want local representatives in each community and have an attractive proposition to offer you. Write for particulars of our special club offers.

Advertising rates on application. Lowest rates in proportion to circulation of any of the leading poultry journals.

Cotrespondence solicited.

\section{SUBSCRIPTION PRICE-50c PER YEAR} SAMPLE COPY FREE

\section{Our Fine Book "POULTRY KEEPING IN A NUTSHELL"}

FREE TO NEW YEARLY SUBSCRIBERS

If you ask for it when you send your order and no other premium is taken in connection.

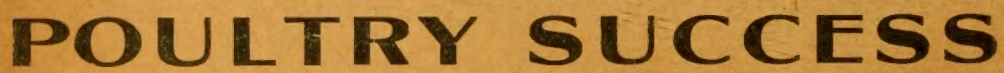

A. D. HOSTERMAN, Publisher 